\title{
HIV/aids: gênero e fatores prognósticos para a sua incidência e mortalidade em um Centro de Referência da Cidade de São Paulo
}

\section{Patrícia Emília Braga}

Tese apresentada ao Programa de PósGraduação em Saúde Pública da Faculdade de Saúde Pública da Universidade de São Paulo para obtenção do título de Doutor em Saúde Pública.

Área de concentração: Epidemiologia Orientadora: Profa. Dra. Maria Regina Alves Cardoso

São Paulo

2005

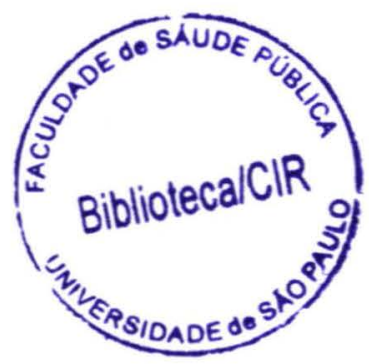


Autorizo, exclusivamente para fins acadêmicos e científicos, a reprodução total ou parcial desta tese, por processos fotocopiadores.

Assinatura:

Data:

$$
46970 / 2006 \text { doc }
$$


Dedico este trabalho:

ao Aluísio, mentor da idéia, incentivador, companheiro sempre presente e, literalmente, meu co-orientador. 


\section{Agradecimentos}

Ao CNPq, pelo apoio financeiro concedido.

À minha orientadora, Professora Doutora Maria Regina Alves Cardoso, pelas oportunidades e por todo apoio concedidos ao longo desses três anos.

Aos professores titulares Guilherme Rodrigues da Silva e José Eluf Neto, aos professores associados Sabina Léa Davidson Gotlieb e Paulo Rossi Menezes, ao professor doutor Eliseu Alves Waldman e à doutora Ana Marli Christovam Sartori pela valiosa contribuição na finalização deste estudo.

Ao Dr. Mauro Taniguchi (PRO-AIM), à Ângela Tayra e à Berenice Ferreira (CRT-Aids), à Margarete Jordani (SEADE) e à Dra. Maria de Fátima Marinho de Souza (SVS/MS) pelo auxilio na coleta das informações complementares do estudo.

À bibliotecária Sra. Maria Lúcia Ferraz, pela prestimosa gentileza e contribuição na revisão das referências bibliográficas.

Às secretárias da Pós-Graduação da Faculdade de Saúde Pública da USP Ângela Silva, Marilene Pereira, Renilda Schimono, Márcia Garcia, Maria Aparecida Mendes, Rosana Testa de Souza e Elisabete Regina dos Santos pelas orientações administrativas.

Ao Washington Araújo e à assistente social Mildred Pitman de Castro pela inestimável ajuda na Casa da Aids.

À minha amada amiga Fernanda Chauí Petroni pela paciência e companheirismo nas horas mais dificeis. 


\section{RESUMO}

A infecção por HIV/aids pode ser considerada uma das mais devastadoras epidemias já vistas pela humanidade. Desde seu início, tem apresentado perfis epidemiológicos heterogêneos nas diversas regiões do mundo e em subgrupos populacionais específicos. Apesar de se observar significativa melhora no prognóstico da infecção, resultante dos avanços terapêuticos recentes, o impacto das intervenções em termos de incidência e de mortalidade parece ter sido menos evidente entre as mulheres. Com o propósito de comparar o perfil clínico evolutivo e a sobrevida de mulheres e homens vivendo com HIV/aids acompanhados em serviço de referência de São Paulo, foi estudada amostra aleatória de pacientes atendidos na Casa da Aids, do Hospital das Clínicas da Faculdade de Medicina da USP, no período de janeiro de 1998 a dezembro de 2002.

Definiram-se dois eventos de interesse (desenvolvimento de aids e óbito por aids), tomando como variáveis dependentes o tempo de sobrevivência livre de aids e o tempo para a ocorrência do óbito por aids. Para avaliação do primeiro desfecho foram considerados apenas os indivíduos que não apresentavam diagnóstico de aids à admissão ao serviço. A data inicial de cada indivíduo na coorte foi a da realização do teste sorológico confirmatório de infecção por HIV, tendo sido os pacientes avaliados em seu seguimento no serviço até 30/03/2003.

As características sócio-demográficas e clínicas dos pacientes, bem como os resultados de exames laboratoriais foram obtidos dos prontuários médicos. Os dados de mortalidade foram oriundos de bancos de informações de óbitos.

$\mathrm{Na}$ análise dos resultados, foram comparadas proporções por meio da estatística Qui-quadrado, enquanto o teste $t$ de Student e o teste não-paramétrico de Mann-Whitney foram utilizados na avaliação de médias e medianas, respectivamente. Compararam-se as taxas de incidência e de mortalidade pela distribuição binomial. As probabilidades acumuladas de sobrevida foram calculadas utilizando o estimador produto limite de Kaplan-Meier e o modelo de riscos proporcionais de Cox na estimativa das razões de risco.

A coorte analisada no estudo de mortalidade por aids compreendeu 1072 pacientes $(71 \%$ homens e $47 \%$ com diagnóstico de infecção por HIV+ anterior a 1997). À admissão ao serviço, $55 \%$ dos homens e $38 \%$ das mulheres apresentavam aids. Dentre os 534 indivíduos admitidos no serviço sem aids, foram

identificados 156 casos incidentes da doença, em 2.455 pessoas-ano de 
seguimento, dos quais 52 (33\%) receberam o diagnóstico de aids, por terem desenvolvido afecções oportunistas definidoras. Verificou-se, após ajuste para a variável sexo, que a progressão para a aids foi associada, de forma independente, com a determinação mais elevada da carga viral de HIV superior a 100.000 cópias/mL durante o seguimento na Casa da Aids $(p<0,001)$ e com o tipo de tratamento anti-retroviral recebido $(p<0,001)$.

Ocorreram 91 óbitos relacionados à aids em seguimento total de 6.004 pessoas-ano. Mostraram-se preditores de óbito por aids, após ajuste pelo tipo de tratamento anti-retroviral recebido: o sexo feminino $(p=0,02)$, a idade ao diagnóstico de infecção por HIV $(p=0,005)$, a menor determinação de células CD4+ inferior a $200 / \mathrm{mm}^{3}(p<0,001)$ e a maior carga viral de HIV superando 100 mil cópias $/ \mathrm{mL}$ $(p=0,007)$ durante o seguimento na Casa da Aids e a ocorrência de afecção oportunista prévia à admissão $(p<0,001)$ ou durante o seguimento no serviço $(p<0,001)$.

Este estudo observou que as mulheres, quando comparadas aos homens, parecem ter-se beneficiado em menor intensidade do cuidado recebido em um serviço universitário de referência do Município de São Paulo. O reconhecimento dos fatores associados a maior vulnerabilidade no cuidado por parte da população feminina pode contribuir para o planejamento de novas iniciativas, visando aprimorar a assistência prestada, em tempos de terapia anti-retroviral de alta potência (HAART), às pessoas vivendo com HIV/aids de um modo geral e às mulheres, em particular. 


\section{SUMMARY}

HIV/aids may be regarded as one of the most devastating epidemics seen by mankind. From the start, distinct epidemiological profiles have been described in different geographical areas and population groups. Despite the significant improvement in prognosis due to recent progress in HIV chemotherapy, the impact of these interventions in terms of incidence and mortality seems to have been less remarkable among women. In order to compare the clinical course and survival of men and women living with HIV/AIDS followed by a reference center in São Paulo, we studied a random sample of patients who were assisted at the AIDS Clinic, affiliated to the University of São Paulo Medical School Hospital from January 1998 to December 2002.

We defined two outcomes (incidence of AIDS and AIDS-related death), taking survival time free from AIDS and time to AIDS-related death as the dependent variables. For evaluation of the first outcome, we selected individuals who did not fulfill AIDS diagnostic criteria at admission. Patients were included in the cohort on date of diagnosis of HIV infection and followed up until $30^{\text {th }}$ March 2003.

Medical charts were reviewed in search of socio-demographic and clinical data, as well as laboratory outcomes. Mortality data were obtained from official databases. For analysis, proportions were compared by $\chi^{2}$, whereas means and medians were evaluated by $t$-Student or Mann-Whitney tests. Incidence and mortality rates were compared by binomial distribution. Overall cumulative survival probability was estimated by the Kaplan-Meier method and hazard ratios calculated by the Cox proportional hazards model.

The survival cohort comprised 1,072 patients $(71 \%$ men and $47 \%$ diagnosed as HIV-positive before 1997). At admission to the clinic, $55 \%$ of men and $38 \%$ of women had AIDS. Among 534 patients admitted to the clinic without AIDS, 156 incident cases were identified, in a total of 2,455 person-years of follow-up (PYFU), $52(33 \%)$ received a diagnosis of AIDS for having presented AIDS-defining opportunistic illnesses. Predictors of progression to AIDS, after adjustment by sex, included the highest HIV viral load assessment during follow-up $>100,000$ copies $/ \mathrm{mL}$ $(p<0.001)$ and the prescribed antiretroviral regimen $(p<0.001)$.

Ninety-one AIDS-related deaths occurred in a total of 6,004 PYFU. Predictors of AIDS-related death, after adjustment for prescribed antiretroviral regimen, included: female sex $(p=0.02)$, age at HIV diagnosis $(p=0.005)$, lowest CD4 
count $<200$ cells $/ \mathrm{mm}^{3}(p<0.001)$ and highest viral load assessment during followup $>100,000$ copies $/ \mathrm{mL}(p=0.007)$, as well as having an HIV-defining illness diagnosed at admission ( $p<0.001)$ or during follow-up ( $p<0.001)$.

This study showed that women seem to have benefited less than men from care provided at a university reference center in São Paulo city. Recognizing factors that might be associated to a higher vulnerability in care among women may contribute to the establishment of new strategies to enhance care in times of HAART for people living with HIVIAIDS as a whole and to women in particular. 


\section{ÍNDICE}

\section{RESUMO}

SUMMARY

LISTA DE TABELAS

LISTA DE FIGURAS

1. INTRODUÇÃO...........................................................................

1.1 A epidemia de aids no Brasil $\quad 8$

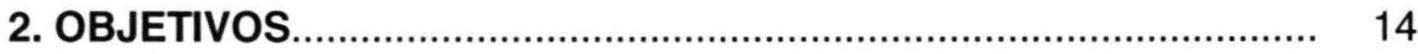

3. PACIENTES e MÉTODO 16

3.1 População de estudo......................................................... 16

3.1.1 Tamanho da Amostra............................................... 18

3.2 Delineamento de estudo........................................................ 19

3.2.1 Estudo de sobrevida................................................. 20

3.3 Variáveis de estudo.......................................................... 22

3.4 Etapas do estudo............................................................. 24

3.4.1 Submissão às Comissões de Ética pertinentes 24

3.4.2 Estudo Piloto........................................................ 24

3.4.3 Coleta de dados............................................................ 24

3.5 Fontes de dados............................................................. 25

3.6 Análise dos dados............................................................ 25

3.6.1 Organização do banco de dados....................................... 25

3.6.2 Análise descritiva..................................................... 26

3.6.3 Análise bivariada...................................................... 26 
3.6.4 Análise multivariável....................................................... 27

3.6.5 Softwares utilizados................................................... 29

4. RESULTADOS........................................................................... 30

4.1 Análise descritiva................................................................. 30

4.2 Afecções oportunistas....................................................... 34

4.3 Comorbidades................................................................. 38

4.4 Marcadores laboratoriais....................................................... 40

4.5 Tratamento anti-retroviral.................................................... 46

4.6 Internações.......................................................................... 49

4.7 Progressão para aids....................................................... 52

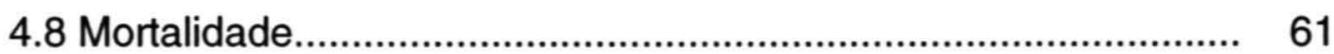

4.9 Avaliação da sobrevida da população estudada de portadores 63

4.9.1 Avaliação da sobrevida em análise bivariada................... 64

4.9.2 Avaliação da sobrevida em análise multivariável.............. 78

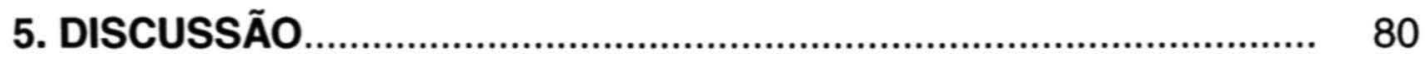

6. CONCLUSÕES........................................................................... 97

7. REFERÊNCIAS...................................................................... 99

\section{ANEXOS}




\section{LISTA DE TABELAS}

Tabela 1:

Prevalências (\%) estimadas da infecção por HIV em jovens de 15 a 24 anos de idade de diferentes regiões do mundo no ano de 2001 segundo sexo

Tabela 2:

Taxa de sobrevida (\%) estimada para pacientes HIV/aids segundo sexo e tempo desde o diagnóstico.

Tabela 3:

Distribuição dos pacientes com HIV/aids atendidos na Casa da Aids segundo sexo, idade ao diagnóstico de infecção por HIV, características sócio-demográficas, ano do diagnóstico de infecção por HIV e categoria de exposição ao HIV. São Paulo, 1998 a 2002.

Tabela 4:

Distribuição dos pacientes com HIV/aids atendidos na Casa da Aids segundo sexo e motivo para realização do teste anti-HIV. São Paulo, 1998 a 2002.

Tabela 5:

Distribuição dos pacientes atendidos na Casa da Aids segundo sexo e estadio clínico. São Paulo, 1998 a 2003.

Tabela 6:

Número de casos e prevalência (\%) de afecções oportunistas em pacientes com HIV/aids no momento da matrícula na Casa da Aids. São Paulo, 1998 a 2002.

Tabela 7:

Número de casos e prevalência de afecções oportunistas em pacientes com HIV/aids durante seguimento na Casa da Aids. São Paulo, 1998 a 2003.

Tabela 8:

Distribuição dos pacientes com HIV/aids segundo sexo e resultado da determinação quantitativa de linfócitos CD4+ no sangue periférico/ $/ \mathrm{mm}^{3}$ à matrícula na Casa da Aids. São Paulo, 1998 a 2002.

Tabela 9:

Médias (DP), medianas, valores mínimos e máximos dos resultados da menor e da última determinação quantitativa de linfócitos CD4+ no sangue periférico/ $\mathrm{mm}^{3}$ dos pacientes com HIV/aids durante o seguimento na Casa da Aids segundo sexo. São Paulo, 1998 a 2003. 
Tabela 10:

Médias (DP), medianas, valores mínimos e máximos dos e resultado da menor, maior e última determinação do log da carga viral plasmática de HIV dos pacientes com HIV/aids durante o seguimento na Casa da Aids segundo sexo. São Paulo, 1998 a 2003.

Tabela 11:

Número e porcentagem de pacientes HIV/aids com marcadores sorológicos de infecções de transmissão sangüínea e/ou sexual atendidos na Casa da Aids segundo sexo. São Paulo, 1998 a 2003.

Tabela 12:

Número e prevalência (\%) de pacientes usuários de drogas injetáveis com HIV/aids atendidos na Casa da Aids segundo presença de marcadores sorológicos de infecção pelos vírus das hepatites $\mathrm{B}$ e $\mathrm{C}$. São Paulo, 1998 a 2003.

Tabela 13:

Distribuição dos pacientes com HIV/aids segundo sexo, estadio clínico e tratamento anti-retroviral recebido à matrícula e ao final do seguimento na Casa da Aids. São Paulo, 1998 a 2003.

Tabela 14:

Distribuição do número e porcentagem de pacientes com HIV/aids atendidos na Casa da Aids segundo sexo e número de internações.

Tabela 15:

Distribuição dos 432 pacientes internados segundo sexo e ano de ocorrência.

Tabela 16:

Distribuição dos 696 episódios de internação de pacientes acompanhados na Casa da Aids segundo ano de ocorrência e morbidade.

Tabela 17:

Número de pacientes com infecção por HIV e número de casos novos de aids durante o seguimento na Casa da Aids, segundo características sócio-demográficas, categoria de exposição ao HIV, maior carga viral plasmática de HIV observados, presença de marcador sorológico de infecção pelo vírus da hepatite $\mathrm{C}$ e tratamento anti-retroviral ao final do seguimento. Casa da Aids, São Paulo, 1998 a 2003.

Tabela 18:

Análise bivariada, pelo modelo de Cox de fatores potencialmente associados à evolução para aids na população estudada de 534 pacientes com infecção por HIV. Casa da Aids, São Paulo, 1998 a 2002. 
Tabela 19:

Análise multivariável pelo modelo de riscos proporcionais de Cox segundo fatores preditivos do desenvolvimento de aids na população estudada de 534 portadores do HIV. São Paulo, 1998 a 2002.

Tabela 20:

Distribuição dos 91 óbitos por aids segundo CID-10. Casa da Aids, São Paulo, 1998 a 2003.

Tabela 21:.

Proporção de sobreviventes entre pacientes HIV atendidos na Casa da Aids segundo tempo de acompanhamento. São Paulo, 1998 a 2003.

Tabela 22:

Número de óbitos por aids segundo variáveis sócio-demográficas e principal categoria de exposição ao HIV. São Paulo, 1998 a 2003.

Tabela 23:

Análise bivariada, pelo modelo de Cox, de fatores potencialmente associados à evolução para óbito por aids. Casa da Aids, São Paulo, 1998 a 2003.

Tabela 24:.

Número de pacientes com infecção por HIV, número de óbitos por aids segundo marcadores clínicos e laboratoriais. Casa da Aids, São Paulo, 1998 a 2003.

Tabela 25:.

Análise bivariada, pelo modelo de Cox, da associação entre marcadores clínicos e laboratoriais e a evolução para óbito por aids. Casa da Aids, São Paulo, 1998 a 2003.

Tabela 26:

Análise multivariável pelo modelo de riscos proporcionais de Cox, segundo fatores preditivos de evolução para o óbito por aids. Casa da Aids, São Paulo, 1998 a 2003.

Tabela 27:

Razão entre homens e mulheres vivendo com HIV/aids segundo região. 


\section{LISTA DE FIGURAS}

Figura 1:

Mapas do Brasil segundo estados, do Estado de São Paulo segundo municípios, do Município de São Paulo segundo distritos administrativos de residência e do Distrito Administrativo da Sé.

Figura 2:

Distribuição do número de casos segundo as afecções oportunistas observadas à matrícula na Casa da Aids e durante seguimento no serviço. São Paulo, 1998 a 2003.

Figura 3:

Distribuição do número de casos segundo as comorbidades de maior ocorrência em pacientes com HIV/aids antes e após a matrícula na Casa da Aids. São Paulo, 1998 a 2003.

Figura 4:

Distribuição dos pacientes com HIV/aids segundo sexo e resultados da menor e da última determinação quantitativa de linfócitos CD4+ no sangue periférico/ $\mathrm{mm}^{3}$ durante acompanhamento na Casa da Aids segundo sexo. São Paulo, 1998 a 2003.

Figura 5:

Boxplots dos valores detectáveis (menor, maior e último) do log da carga viral plasmática de HIV durante o seguimento na Casa da Aids segundo sexo. São Paulo, 1998 a 2003.

Figura 6:

Média e IC $95 \%$ para log do maior valor de carga viral plasmática de HIV registrado durante seguimento na Casa da Aids segundo sexo. São Paulo, 1998 a 2003

\section{Figura 7:}

Distribuição de pacientes HIV/aids atendidos na Casa da Aids segundo sexo e tipo de tratamento anti-retroviral recebido antes da matrícula no serviço. São Paulo, 1998 a 2002.

Figura 8:

Distribuição de pacientes HIV/aids atendidos na Casa da Aids segundo sexo e tipo de tratamento anti-retroviral recebido ao final do seguimento no serviço. São Paulo, 1998 a 2003.

Figura 9:.

Probabilidade geral acumulada de desenvolver aids segundo tempo transcorrido desde o diagnóstico de HIV. Casa da Aids, São Paulo, 1998 a 2003.

Figura 10:

Probabilidade acumulada de desenvolver aids segundo tempo transcorrido desde o diagnóstico de infecção por HIV e sexo. Casa da Aids, São Paulo, 
1998 a 2003.

Figura 11:

Probabilidade acumulada de desenvolver aids segundo tempo transcorrido desde o diagnóstico de infecção por HIV e idade a este diagnóstico. Casa da Aids, São Paulo, 1998 a 2003.

Figura 12:

Probabilidade acumulada de desenvolver aids segundo tempo transcorrido desde o diagnóstico de infecção por HIV e estado civil. Casa da Aids, São Paulo, 1998 a 2003.

Figura 13:

Probabilidade acumulada de desenvolver aids segundo tempo transcorrido desde o diagnóstico de infecção por HIV e escolaridade. Casa da Aids, São Paulo, 1998 a 2003.

Figura 14:

Probabilidade acumulada de desenvolver aids segundo tempo transcorrido desde o diagnóstico de infecção por HIV e categoria de exposição ao HIV. Casa da Aids, São Paulo, 1998 a 2003.

Figura 15:

Probabilidade acumulada de desenvolver aids segundo tempo transcorido desde o diagnóstico de infecção por HIV e valor da maior carga viral de HIV durante seguimento no serviço. Casa da Aids, São Paulo, 1998 a 2003.

Figura 16:

Probabilidade acumulada de desenvolver aids segundo tempo transcorrido desde o diagnóstico de infecção por HIV e soropositividade para infecção pelo vínus da hepatite C. Casa da Aids, São Paulo, 1998 a 2003.

Figura 17:

Probabilidade acumulada de desenvolver aids segundo tempo transcorrido desde o diagnóstico de infecção por HIV e tratamento anti-retroviral ao final do seguimento. Casa da Aids, São Paulo, 1998 a 2003.

Figura 18:

Distribuição percentual dos pacientes com HIV/aids atendidos na Casa da Aids segundo desfecho à avaliação de mortalidade e sexo. São Paulo, 1998 a 2003.

Figura 19:

Probabilidade acumulada de sobrevivência em pacientes HIV. Casa da Aids, São Paulo, 1998 a 2003.

Figura 20:

Probabilidade acumulada de sobrevida para pacientes com infecção por HIV, segundo sexo. Casa da Aids, São Paulo, 1998 a 2003. 
Figura 21:.

Probabilidade acumulada de sobrevida para pacientes com infecção por HIV, segundo idade ao diagnóstico de infecção por HIV (anos). Casa da Aids, São Paulo, 1998 a 2003.

Figura 22:.

Probabilidade acumulada de sobrevida para pacientes com infecção por HIV, segundo estado civil à matrícula na Casa da Aids. São Paulo, 1998 a 2003.

Figura 23:.

Probabilidade acumulada de sobrevida para pacientes com infecção por HIV, segundo escolaridade (anos) à matrícula na Casa da Aids. São Paulo, 1998 a 2003.

Figura 24:

Probabilidade acumulada de sobrevida para pacientes com infecção por HIV, segundo categoria de exposição a essa retrovirose. Casa da Aids, São Paulo, 1998 a 2003.

Figura 25:

Probabilidade acumulada de sobrevida para pacientes com infecção por HIV, segundo tratamento anti-retroviral ao final do seguimento. Casa da Aids, São Paulo, 1998 a 2003.

Figura 26:

Probabilidade acumulada de sobrevida para pacientes com infecção por HIV, segundo número de linfócitos CD4+ periféricos à matrícula na Casa da Aids. São Paulo, 1998 a 2003.

Figura 27:

Probabilidade acumulada de sobrevida para pacientes com infecção por HIV, segundo diagnóstico de afecção oportunista $(\mathrm{AO})$ prévio à admissão na Casa da Aids. São Paulo, 1998 a 2003.

Figura 28:

Probabilidade acumulada de sobrevida para pacientes com infecção por HIV, segundo menor número de linfócitos CD4+ periféricos durante seguimento na Casa da Aids. São Paulo, 1998 a 2003.

Figura 29:.

Probabilidade acumulada de sobrevida para pacientes com infecção por HIV, segundo valor do log da maior carga viral de HIV observada na Casa da Aids. São Paulo, 1998 a 2003.

Figura 30:.

Probabilidade acumulada de sobrevida para pacientes com infecção por HIV, segundo diagnóstico de afecção oportunista $(A O)$ durante seguimento na Casa da Aids. São Paulo, 1998 a 2003. 
Figura 31:...

Probabilidade acumulada de sobrevida para pacientes com infecção por HIV, segundo soropositividade para infecção pelo vírus da hepatite C. Casa da Aids, São Paulo, 1998 a 2003.

Figura 32:..

Probabilidade acumulada de sobrevida para pacientes com infecção por HIV, segundo presença de anticomos anti-HBc. Casa da Aids, São Paulo, 1998 a 2003.

Figura 33:

Probabilidade acumulada de sobrevida para pacientes com infecção por HIV, segundo presença de anticorpos anti-Treponema. Casa da Aids, São Paulo, 1998 a 2003. 


\section{INTRODUÇÃO}

A infecção por HIV/aids pode ser considerada uma das mais devastadoras epidemias já vistas pela humanidade. Desde o seu surgimento, no início da década de 80 , até os dias de hoje, a infecção por HIV já causou aproximadamente 25 milhões de óbitos e estima-se que haja, no mundo, 40,3 milhões de pessoas vivendo com HIV ou aids, sendo que aproximadamente $64 \%$ destas habitam a região africana localizada ao sul do Saara (UNAIDS 2005).

Sabe-se que, desde o início, a epidemia da aids tem apresentado perfis epidemiológicos heterogêneos nas diversas regiões do mundo.

Nos países asiáticos e na Europa Oriental, os primeiros casos foram diagnosticados somente dez anos após o aparecimento da doença em países da América do Norte, da América Latina, do continente africano ao sul do Saara, da Oceania e da Europa Ocidental (ONUSIDA 2004).

Diferenças marcantes são encontradas quando se comparam os modos de aquisição da infecção nos diversos países. A transmissão através do uso de drogas intravenosas destaca-se de forma preponderante na Ásia Central e na Europa Oriental e, associadamente à categoria heterossexual, no Oriente Médio, Ásia, América do Norte, América Latina, Caribe e África (com exceção apenas dos países africanos ao sul do Saara, onde o grupo de usuários de drogas injetáveis (UDI) não é tão prevalente). Já os homens que fazem sexo com homens (HSH) aparecem como principal categoria de exposição na Austrália e Nova Zelândia, na Europa Ocidental (juntamente com os UDI) e na América do Norte (DUNNE e cols. 1997, UNAIDS 2004a, TSANTES e cols. 2005). Essas diferenças têm sido observadas dentro de um mesmo país. Na Colômbia, por exemplo, em algumas áreas destaca-se o grupo HSH e, em outras, os heterossexuais.

O impacto da epidemia também é variável segundo a região geográfica. Em 2003, enquanto a prevalência de infecção por HIV era de 
0,1\% em países do oriente asiático, do Pacífico, da Austrália e da Nova Zelândia, atingiu 3,0\% nas Bahamas, 5,6\% no Haiti e índices bem superiores a esses no continente africano ao sul do Saara (UNAIDS 2004a). Sendo essa a área mais afetada pela doença, em Botsuana, por exemplo, aproximadamente $37 \%$ da população adulta encontra-se infectada pelo HIV. Essas diferenças são ainda mais marcantes quando subgrupos populacionais específicos são analisados. Por exemplo, na China entre trabalhadores do sexo, registrava-se no ano 2000 uma prevalência de infecção por HIV inferior a 1\%; enquanto, em Bangladesh, verificou-se uma prevalência de $20 \%$. Prevalências altas também têm sido encontradas entre os usuários de drogas injetáveis (UDI): $50 \%$ em Jacarta, Indonésia, no ano de 2003 e superior a 60\% em chineses em 2002 (ONUSIDA 2004, UNAIDS 2004a).

É importante, contudo, destacar que em uma mesma localidade encontram-se discrepâncias relevantes quando se consideram as prevalências segundo o sexo. Entre jovens de 15 a 24 anos, por exemplo, notam-se diferenças marcantes nas taxas de prevalência da infecção por HIV em várias regiões do mundo (Tabela 1).

Atualmente as mulheres representam quase metade das 40 milhões de pessoas vivendo com HIV ou aids (ONUSIDA 2004). Acredita-se que devido à complexa interação de fatores biológicos, socioeconômicos e culturais a epidemia da aids vem-se difundindo com maior velocidade entre as mulheres (PAHO 2000). Nos Estados Unidos, por exemplo, entre 1999 e 2003 , o número estimado de casos de aids aumentou $15 \%$ entre as mulheres, enquanto que na população masculina houve um acréscimo de somente $1 \%$ (CDC 2004).

Essa tendência aparece de modo mais destacado nos países em que a transmissão heterossexual é predominante. Nessas regiões, a vulnerabilidade feminina à infecção pelo HIV aparece na maioria das vezes associada às práticas de risco de seus companheiros (PAHO 2000, UNAIDS 2004a). 
Tabela 1: Prevalências (\%) mínimas e máximas estimadas da infecção por HIV em jovens de 15 a 24 anos de idade de diferentes regiões do mundo no ano de 2001 segundo sexo.

\begin{tabular}{|c|c|c|}
\hline \multirow{2}{*}{ Localidades } & \multicolumn{2}{|c|}{ sexo } \\
\hline & feminino & masculino \\
\hline $\begin{array}{l}\text { ÁFRICA } \\
\text { SUBSAARIANA }\end{array}$ & 6,41 a 11,39 & 3,13 a 5,56 \\
\hline $\begin{array}{l}\text { ÁFRICA DO NORTE } \\
\text { E ORIENTE MÉDIO }\end{array}$ & 0,23 a 0,41 & 0,08 a 0,15 \\
\hline $\begin{array}{l}\text { AMÉRICA DO } \\
\text { NORTE }\end{array}$ & 0,16 a 0,29 & 0,33 a 0,58 \\
\hline AMÉRICA LATINA & 0,26 a 0,46 & 0,39 a 0,69 \\
\hline ÁSIA (sul e sudeste) & 0,36 a 0,64 & 0,22 a 0,38 \\
\hline $\begin{array}{l}\text { ÁSIA ORIENTAL E } \\
\text { PACÍFICO }\end{array}$ & 0,06 a 0,10 & 0,12 a 0,22 \\
\hline $\begin{array}{l}\text { AUSTRÁLIA E } \\
\text { NOVA ZELÂNDIA }\end{array}$ & 0,00 a 0,01 & 0,01 a 0,02 \\
\hline CARIBE & 1,78 a 3,17 & 1,42 a 2,43 \\
\hline $\begin{array}{l}\text { EUROPA } \\
\text { ORIENTAL E ÁSIA } \\
\text { CENTRAL }\end{array}$ & 0,19 a 0,34 & 0,75 a 1,33 \\
\hline $\begin{array}{l}\text { EUROPA } \\
\text { OCIDENTAL } \\
\end{array}$ & 0,10 a 0,17 & 0,15 a 0,27 \\
\hline TOTAL & 1,00 a 1,78 & 0,59 a 1,05 \\
\hline
\end{tabular}

Fonte: UNAIDS, 2002.

O impacto da aids na população feminina é muito grande, visto que as mulheres são mais susceptíveis à infecção pelo HIV que os homens. Em uma relação sexual, o risco de um homem transmitir o vírus para uma mulher é $100 \%$ maior quando comparado ao risco de um homem contrair o vírus de uma mulher. Esse risco é ainda maior entre as mulheres mais 
jovens, não somente por sua maior exposição, mas também pelo fato de não possuírem o colo uterino totalmente formado, conseqüentemente apresentando maior risco de contrair uma infecção durante o coito vaginal (HADER e cols. 2001, QUINN e OVERBAUGH 2005).

$\mathrm{Na}$ África subsaariana, por exemplo, as mulheres chegam a representar $60 \%$ das pessoas infectadas pelo vírus e $75 \%$ dos jovens infectados com idade entre 15 e 24 anos (UNAIDS 2004a).

Percebe-se assim que, muitas vezes, as intervenções programáticas voltadas à prevenção da aids podem não se mostrar eficazes se não atentarem para particularidades dos grupos populacionais identificados como mais vulneráveis.

A progressão na história natural da infecção pelo HIV tem sido associada a fatores de diferentes naturezas. No que se refere a características do vírus, são mencionados 0 inóculo e as variantes virais (LEVY 1998), que poderiam_intensificar o potencial patogênico do HIV. Do ponto de vista do hospedeiro tem sido aventados a idade à infecção (PORTER e cols. 2003), o sexo, a categoria de exposição ao HIV (VELLA e cols. 1995), a condição socioeconômica (SCHECHTER e cols. 1994), determinantes genéticos (DEAN e cols. 1996, PRICE e cols. 2004, FRAHM e cols. 2005), a presença de co-infecção com o vírus da hepatite $C$ (HCV) (GREUB e cols. 2000) e o tempo de infecção (PORTER e cols. 2003).

No que tange à mortalidade, em alguns países da África, a aids foi responsável por redução de 10 anos na expectativa de vida (que se tornou inferior a 40 anos em Botsuana, Maláui, Moçambique e Suazilândia) e incremento de $100 \%$ nos coeficientes de mortalidade infantil (UNAIDS 2002). Além disso, a aids representava, em 2001, a principal causa de morte na África e no Caribe entre adultos de 15 a 44 anos, segunda região mais afetada pela epidemia, e a quarta causa no restante do mundo (CDC 2001). Em 2003, em todo o mundo, 3,1 milhões de pessoas morreram devido à aids (ONUSIDA 2004). O impacto do HIV na mortalidade tem sido maior nos 
países em desenvolvimento, em indivíduos com idade entre 20 e 40 anos e, proporcionalmente, na população feminina (PORTER e ZABA 2004).

No tocante aos fatores associados à mortalidade por aids, diferentes autores têm apontado a importância da idade à soroconversão (CHEQUER e cols. 1992, PORTER e cols. 2003), do período de diagnóstico (LUNDGREN e cols. 1994, MOCROFT e cols. 1997, MARINS e cols. 2003), da co-infecção com HCV (MONGA e cols. 2001), da quimioprofilaxia antipneumocistose (SAAH e cols. 1994) e do uso de terapia antiretroviral (EGGER e cols. 1997, PALELLA e cols. 1998, MARINS e cols. 2003).

Ao lado do tratamento anti-retroviral, particularmente na forma de combinação de medicamentos de alta potência (PEREZ-HOYOS e cols. 2003, PORTER e cols. 2003), destacam-se como fatores prognósticos de maior relevância os marcadores laboratoriais indicativos do status imunológico do hospedeiro (número de células CD4+ no sangue periférico) e da intensidade de replicação viral (carga viral plasmática de HIV) (MELLORS e cols. 1997, EGGER e cols. 2002).

É importante destacar que os avanços recentes na terapêutica determinaram uma significativa melhora no prognóstico da infecção pelo HIV. Em 1995, menos de uma década após a introdução da zidovudina, primeiro anti-retroviral utilizado no tratamento da infecção, tomaram-se disponíveis para uso clínico os medicamentos inibidores da enzima protease viral (IP), os quais, um ano depois, passaram a ser empregados como padrão de tratamento, em combinação com as drogas inibidoras da transcriptase reversa análogas de nucleosídeo (ITRN). Mais recentemente verificou-se que a terapia anti-retroviral tríplice pode também ser conduzida com associações que incluem compostos não nucleosídicos inibidores da transcriptase reversa com eficácia terapêutica semelhante à dos esquemas contendo IP. A utilização de esquemas terapêuticos que combinam diferentes drogas anti-retrovirais tem apresentado resultados bastante positivos, elevando a sobrevida e a qualidade de vida dos pacientes com 
HIV/aids e reduzindo significativamente a incidência de doenças oportunistas.

$\mathrm{Na}$ Itália, por exemplo, observou-se um aumento na taxa de sobrevida dos pacientes vivendo com HIV/aids após 18 meses do diagnóstico de 41\% (1993-1995) para 65\% (1996-1997) (RAPITI e cols. 2000). Já nos Estados Unidos o coeficiente de mortalidade por aids passou de 35,1/100 pessoas-ano em 1994 para 8,8/100 pessoas-ano em 1997 (PALELLA e cols. 1998). Nesse país, o tempo mediano de sobrevida para pacientes com aids passou de 11 meses, em 1984, para 46 meses em 1995 e a taxa de sobrevida após 24 meses do diagnóstico da doença de $60 \%$ (1993) para 87\% (1997) (LEE e cols. 2001). No que diz respeito às doenças oportunistas, com a introdução dos anti-retrovirais na terapêutica dos pacientes houve decréscimo na incidência das três infecções mais comuns (pneumonia por Pneumocystis carinii, infecção por bactérias do complexo Mycobacterium avium-intracelulare e coriorretinite pelo citomegalovírus): de 21,9/100 pessoas-ano em 1994 para 3,7/100 pessoas-ano em 1997 (PALELLA e cols. 1998).

Entretanto, o alto custo do tratamento e a escassez de políticas públicas relacionadas à implantação de infra-estrutura necessária para o fornecimento dos medicamentos anti-retrovirais têm acarretado desigualdades no acesso à terapêutica e aos serviços de saúde. Tal situação justifica o aumento progressivo nas discrepâncias entre taxas de sobrevida de indivíduos de diferentes níveis socioeconômicos ou mesmo entre populações residentes em regiões distintas. Em Roma (Itália), por exemplo, um paciente vivendo com aids e com baixa escolaridade apresentava, em 1996, risco de morrer dobrado quando comparado a outro com escolaridade mais alta (LEE e cols. 2001). Nos Estados Unidos constatou-se que pacientes atendidos em serviços privados recebem mais prescrições de IP que aqueles atendidos nos públicos, levando a diferenças nos coeficientes de mortalidade observadas nessas instituições (PALELLA e cols. 1998). Em 2003, estimava-se que, em todo o mundo, apenas cerca de 
$8 \%$ das pessoas vivendo com HIV/aids com indicação de terapêutica antiretroviral tinham acesso a esse tratamento (UNAIDS 2004a).

Uma questão certamente relevante no contexto da epidemia é a avaliação de possíveis diferenças na evolução clínica da infecção por HIV/aids e da mortalidade a ela associada quando se comparam homens e mulheres. Assim, MELNICK e cols. (1994) procurando justificar a menor sobrevida observada em mulheres, quando comparadas aos homens nos Estados Unidos em 1994, apontam para possível papel da desigualdade no acesso aos serviços de saúde ou mesmo ao tratamento, uma vez que não verificaram diferença na progressão da doença em relação a gênero. Analogamente, outros pesquisadores têm enfatizado que o comportamento biológico da infecção pelo HIV parece não diferir entre os sexos, dado que eventuais desigualdades nas taxas de sobrevida desaparecem após controle por variáveis indicativas de prognóstico, particularmente o número de células CD4+ circulantes (CHAISON e cols. 1995, HADER e cols. 2001, LEE e cols. 2001, SIGHEM e cols. 2003, NICASTRI e cols. 2005). 


\subsection{A epidemia de aids no Brasil}

No Brasil a epidemia da aids já tem mais de vinte anos e a notificação de casos novos da doença passou a ser compulsória em todo o território nacional em 1986. Desde então até junho de 2004 foram notificados 362.364 casos (BOLETIM EPIDEMIOLÓGICO-AIDS e DST 2005) e estima-se haver cerca de 660.000 pessoas vivendo com HIV no país (UNAIDS 2004a).

No início os casos praticamente restringiam-se às capitais do Rio de Janeiro e de São Paulo e tinham como categorias de exposição preponderantes: HSH (homossexuais e bissexuais), hemofílicos e pessoas que receberam sangue e hemoderivados. Entretanto, nessas duas décadas de epidemia, o perfil dos pacientes com HIV/aids apresentou várias mudanças no aspecto sócio-demográfico.

Hoje observa-se uma disseminação da epidemia para todas as regiões geográficas, atingindo mais da metade dos quase seis mil municípios brasileiros (SZWARCWALD 2000). Nota-se, também, impacto crescente nos coeficientes de incidência da doença em municípios de pequeno porte (com menos de 50.000 habitantes), caracterizando assim o fenômeno denominado interiorização da epidemia, com envolvimento de municípios que apresentam desvantagens socioeconômicas e menor acesso às informações e serviços, quando comparados aos de maior população.

Além disso a epidemia acabou se propagando mais intensamente entre pessoas de menor renda e escolaridade, tornando-as mais vulneráveis ao desenvolvimento da doença (a chamada pauperização da epidemia). Dentre os casos com 19 anos de idade ou mais, diagnosticados no Brasil no ano 2003 , observou-se que aproximadamente $60,5 \%$ tinham escolaridade igual ou inferior ao $1^{\circ}$ grau (BOLETIM EPIDEMIOLÓGICO-AIDS E DST 2005). Em estudo realizado com todos os casos de aids notificados no país de 20 a 69 anos de idade, verificou-se que a incidência da doença no estrato social de menor escolaridade (até $1^{\circ} \mathrm{grau}$ ), passou de $10,1 / 100.000$ homens 
nessa faixa etária, em 1989, para 33,4/100.000, em 1996; já no sexo feminino, de 3,1/100.000 mulheres de 20 a 69 anos para 13,3/100.000 (FONSECA 2000). Em recente análise da participação dos pacientes com aids notificados ao Ministério da Saúde entre 1987 e 1998 no mercado de trabalho, FONSECA e colaboradores (2003) puderam reforçar a evidência de pauperização da epidemia em nosso país, sugerida pelos dados de escolaridade. Em sua análise os autores avaliaram a participação proporcional das ocupações profissionais de acordo com a inserção da atividade nos setores produtivos e na distinção entre trabalho manual e mental, concluindo que havia maior envolvimento dos indivíduos classificados em posições desvantajosas em relação ao mercado de trabalho.

Tais tendências talvez possam ser, em parte, explicadas por modificações observadas no modo de transmissão da doença no decorrer da epidemia. Os HSH que perfaziam $46,5 \%$ dos casos na década de 80 passaram a $11,9 \%$ em 2003. Decréscimo também foi observado na categoria de exposição sangüínea, de 23,5\% para 12,7\%. Porém, nesse grupo devem-se destacar os UDI que, no início da década de 90, chegaram a somar $25 \%$ dos casos de aids, ocupando posição de destaque (99\%) entre os casos secundários à transmissão sanguínea. $\mathrm{Na}$ análise socioeconômica segundo categorias de exposição, constata-se que os $\mathrm{HSH}$ apresentam maior status socioeconômico, ao passo que os UDI, o menor (FONSECA e cols. 2003).

Em anos recentes observa-se ainda a heterossexualização da doença. A transmissão heterossexual já é predominante tanto para o sexo masculino (40\% dos casos) quanto para o feminino (90\%) (BOLETIM EPIDEMIOLÓGICO-AIDS E DST 2005). Essa tendência epidemiológica tem levado a modificações na razão de sexos dos casos notificados de aids que passou de 18:1 (18 casos de homens para cada caso de mulher) em 1983 para 1,8:1 a partir do ano 2000 (BOLETIM EPIDEMIOLÓGICO-AIDS 2004). Segundo PARKER e GALVÃO (1996) em nenhum outro país a feminização 
da doença foi tão rápida e tão profunda quanto no Brasil. Para SANTOS (1996), a disseminação da doença entre as mulheres menos diferenciadas (baixa escolaridade e com ocupação não qualificada) está associada com o uso de drogas intravenosas, quer se tratem de usuárias ou de parceiras sexuais de usuários; já entre aquelas socioeconomicamente mais diferenciadas, a transmissão sexual é o fator mais importante.

Essas modificações refletem-se nos coeficientes de incidência da doença no período de 1999 a 2003, que embora tenham permanecido constantes entre os homens $(22,8 / 100.000)$, apresentaram crescimento na população feminina, passando de $12,0 / 100.000$ para $14,1 / 100.000$ (BOLETIM EPIDEMIOLÓGICO-AIDS E DST 2005). Enquanto tem-se tendência à estabilização da incidência da doença entre os homens, as mulheres apresentaram crescimento da mesma. E a maior expansão do número de casos ocorre nas mulheres com idade entre 20 e 40 anos, pobres, com escolaridade inferior a 7 anos e residentes nas periferias urbanas e cidades do interior com menos de 100 mil habitantes (MS-CNDST/AIDS 2004).

O crescimento da epidemia de HIV/aids entre as mulheres brasileiras vem influenciando a transmissão matemo-infantil do HIV no país, responsável entre os anos de 1983 e 2003 por 89,5\% do total de casos de aids entre menores de 13 anos (VERMELHO e cols. 1999, BOLETIM EPIDEMIOLÓGICO-AIDS E DST 2005). Porém, vale a pena destacar que, devido ao aumento da cobertura do rastreamento de gestantes para a infecção pelo HIV e seu tratamento, tem-se observado significativo declínio nos casos de transmissão vertical (BOLETIM EPIDEMIOLÓGICO-AIDS 2004). Sabe-se que com a correta profilaxia medicamentosa e cuidados na assistência ao parto, os riscos de transmissão para o recém-nascido decrescem de $20 \%$ para menos de $2 \%$ (MINISTÉRIO DA SAÚDE 2004a).

Desde o início da epidemia, em 1980, até o final de 2003 a aids já provocou 160.834 óbitos no Brasil. Na era que precedeu o uso da terapia anti-retroviral de alta potência (HAART) observou-se tendência crescente na 
mortalidade por aids no país atingindo os coeficientes máximos de mortalidade nos estados de São Paulo e Rio de Janeiro, em ambos os sexos, entre 1994 e 1995. A partir de então pôde-se constatar discreta redução na mortalidade masculina relacionada à doença, tendência essa não observada entre as mulheres (LOWNDES e cols. 2000).

A letalidade pela doença, que em 1983 chegou a atingir 97,4\% dos casos, atualmente encontra-se abaixo de $20 \%$ (BOLETIM EPIDEMIOLÓGICO-AIDS 2001, BOLETIM EPIDEMIOLÓGICO-AIDS E DST 2005). Esse declínio, inicialmente decorrente do uso de profilaxia medicamentosa contra as afecções oportunistas definidoras de aids, atualmente mostra-se relacionado principalmente ao avanço das terapias anti-retrovirais combinadas de alta potência que têm sido oferecidas universal e gratuitamente na rede pública do país desde 1996, ano em que a aids foi responsável por uma perda de 0,77 anos na esperança de vida ao nascer no Brasil (GOTLIEB e cols. 2000). Atualmente o programa nacional de anti-retrovirais distribui medicamentos para mais de 170 mil pacientes (MINISTÉRIO DA SAÚDE 2005).

Com base em dados nacionais de notificação de casos de aids, MARINS e colaboradores (2003) encontraram significativa alteração no tempo mediano de sobrevida em adultos, passando de 5 meses, entre os casos diagnosticados nos anos 80 , para 18 e 58 meses, respectivamente, naqueles diagnosticados em 1995 e 1996. Dados regionais confirmam esses achados, como, por exemplo, os do Município de Ribeirão Preto (SP), onde a utilização em larga escala das drogas anti-retrovirais elevou o tempo mediano de sobrevida de 12 meses, entre os pacientes diagnosticados com aids de 1986 a 1990, para 29,5 meses, naqueles com diagnóstico entre 1996 e 1997 (MENESIA e cols. 2001). Paralelamente em Sorocaba (SP), observou-se que a probabilidade de sobrevida de dois anos passou de 11,5\% para indivíduos com diagnóstico entre 1985 e 1990 para 66,5\% para aqueles com diagnóstico em 1997 (ANJOS 2000). 
Entretanto o impacto da terapêutica anti-retroviral parece ter sido menos evidente entre as mulheres do que entre os homens. No Município de São Paulo, entre 1996 e 1999, houve uma redução de mortalidade por aids de $60 \%$ para os homens de 25 a 49 anos de idade e de $53 \%$ para as mulheres da mesma idade. (FARIAS 2002). A tendência de queda no coeficiente de mortalidade para os homens é observada em todas as regiões brasileiras e é duas vezes maior que a feminina. Porém, entre as mulheres essa tendência não se reflete em todo o território nacional, pois nas regiões Sul, Norte e Nordeste a mortalidade por aids continua aumentando (ALVES e cols. 2003, MS-CN-DST/AIDS 2004).

Com base nos dados de mortalidade do Sistema de Informação sobre Mortalidade (SIM), observa-se que o coeficiente de mortalidade por aids no Brasil, entre 1995 e 2003, passou de 15,1 para 8,8 (por 100.000) no sexo masculino e de 4,5 para 4,0 (por 100.000) no feminino (BOLETIM EPIDEMIOLÓGICO-AIDS E DST 2005).

Além do aumento nas taxas de sobrevida, observou-se, também, dentre todos os casos de aids notificados no Brasil entre 1980 e maio de 1999, redução na incidência das oito principais condições oportunistas clinicamente associadas (candidíase, tuberculose, pneumonia por Pneumocystis carinii (PCP), neurotoxoplasmose, infecções herpéticas, sarcoma de Kaposi e criptococose). Com exceção da neurotoxoplasmose entre as mulheres, todas essas morbidades apresentaram declínio com significância estatística para ambos os sexos (GUIMARÃES 2000).

No momento atual em que há evidências significativas do impacto das intervenções terapêuticas e profiláticas na história natural da infecção pelo HIV/aids e que seus reflexos sobre a morbidade e a mortalidade da doença vêm também sendo observados no Brasil, justifica-se comparar a extensão desses benefícios em diferentes segmentos da população acometida.

Conhecer de que forma homens e mulheres puderam se beneficiar das estratégias de intervenções propostas pelo Programa Nacional de 
DST/aids do Ministério da Saúde poderá contribuir para definir perfis diferenciados de vulnerabilidade ao cuidado. Uma melhor compreensão desses perfis poderá subsidiar e permitir readequações nas estratégias de intervenção de seguimento de pessoas vivendo com HIV/aids de modo a otimizar o sucesso de tais medidas.

Com esse propósito idealizou-se este trabalho com o intuito de comparar o perfil clínico evolutivo e a sobrevida de homens e mulheres vivendo com HIV/aids, assistidos em uma unidade ambulatorial de referência do Município de São Paulo.

Sabe-se que o Estado de São Paulo é responsável por $42 \%$ das notificações de aids ao Ministério da Saúde e o Município de São Paulo por 16\% (BOLETIM EPIDEMIOLÓGICO-AIDS E DST 2005 e BOLETIM EPIDEMIOLÓGICO DE AIDS DO MUNICÍPIO DE SÃO PAULO 2004), concentrando assim nessa cidade diversos serviços especializados no atendimento a pessoas vivendo com HIV/aids. Dentre esses destaca-se o Serviço de Extensão ao Atendimento de Pacientes com HIV/aids (Casa da Aids), da Divisão de Clínica de Moléstias Infecciosas e Parasitárias do Hospital das Clínicas da Faculdade de Medicina da USP.

A Casa da Aids atende preferencialmente a população de todo o centro expandido da cidade e oferece atendimento multidisciplinar em nível ambulatorial e de Hospital-dia. Inaugurado em 1994, a partir da extensão do ambulatório do Hospital das Clínicas, o serviço dispõe, desde 1998, de arquivo próprio, que centraliza os prontuários dos pacientes ali atendidos pela equipe de infectologia, outras especialidades médicas, bem como pelos setores de odontologia, psicologia, serviço social e nutrição. Por ocasião da realização deste estudo 3662 pessoas vivendo com HIV/aids encontravamse em acompanhamento regular no serviço. 


\section{OBJETIVOS}




\section{OBJETIVOS}

\subsection{Objetivo geral}

Descrever e analisar o perfil clínico e epidemiológico de homens e mulheres com infecção por HIV/aids acompanhados na Casa da Aids no período de janeiro de 1998 a dezembro de 2002.

\subsection{Objetivos específicos}

$\checkmark$ descrever e comparar as características sociodemográficas de homens e mulheres com HIV/aids do serviço e as razões que os motivaram a realizar o teste anti-HIV, quando do diagnóstico inicial da infecção;

descrever e comparar o estadio clínico da infecção por HIV/aids de homens e mulheres no momento de admissão ao serviço;

$\checkmark$ descrever e comparar as prevalências das principais afecções oportunistas definidoras de aids e as distribuições das co-morbidades e dos marcadores laboratoriais evolutivos da infecção por HIV/aids (número de células $\mathrm{CD}_{4}+/ \mathrm{mm}^{3}$ e carga viral plasmática de HIV) de homens e mulheres no momento de admissão e durante o seguimento no serviço;

$\checkmark$ descrever e comparar a utilização de drogas anti-retrovirais por homens e mulheres no momento de admissão e ao final do seguimento no serviço;

descrever e comparar a ocorrência de admissões hospitalares durante o acompanhamento no serviço, bem como as doenças que motivaram tais internações para ambos os sexos; 
$\checkmark$ estimar e comparar os coeficientes de incidência de aids e de mortalidade por aids entre os homens e mulheres acompanhados no serviço;

$\checkmark$ estimar o tempo de sobrevida e investigar os fatores associados aos desfechos :

(a) desenvolvimento de aids;

(b) óbito decorrente de aids. 
PACIENTES e MÉTODO 


\section{PACIENTES e MÉTODO}

\subsection{População de estudo}

O presente estudo avaliou pacientes acompanhados no Serviço de Extensão ao Atendimento de Pacientes com HIV/aids (Casa da Aids), da Divisão de Clínica de Moléstias Infecciosas e Parasitárias do Hospital das Clínicas da Faculdade de Medicina da USP.

A Casa da Aids é um serviço universitário público, especializado no cuidado de adultos portadores do HIV, em todas as fases evolutivas da infecção pelo vírus. Trata-se de um serviço de referência do Município de São Paulo que dispõe de equipe multiprofissional composta por médicos infectologistas, ginecologista e psiquiatra, enfermeiros, assistentes sociais, dentista e psicólogos. Atende, em regime ambulatorial e de hospital-dia, preferencialmente a população do centro expandido da cidade.

O Município de São Paulo (MSP) é a maior cidade paulista, possui 10.434.252 habitantes e está oficialmente dividido em 31 subprefeituras. $\mathrm{O}$ centro da cidade, onde se localiza a Casa da Aids, está sob administração da subprefeitura da Sé.

Entre os anos de 1980 e 2004 (até setembro), a Coordenadoria de Saúde da Sé, que engloba os Distritos Administrativos da Bela Vista, Bom Retiro, Cambuci, Consolação, Liberdade, República, Santa Cecília e Sé (Figura 1), registrou $13,5 \%$ dos 58.624 casos de aids do MSP (BOLETIM EPIDEMIOLÓGICO DE AIDS DO MUNICÍPIO DE SÃO PAULO 2004).

Neste estudo foram avaliados os prontuários médicos evolutivos dos pacientes com idade igual ou superior a 16 anos atendidos na Casa da Aids entre janeiro de 1998 e dezembro de 2002. 


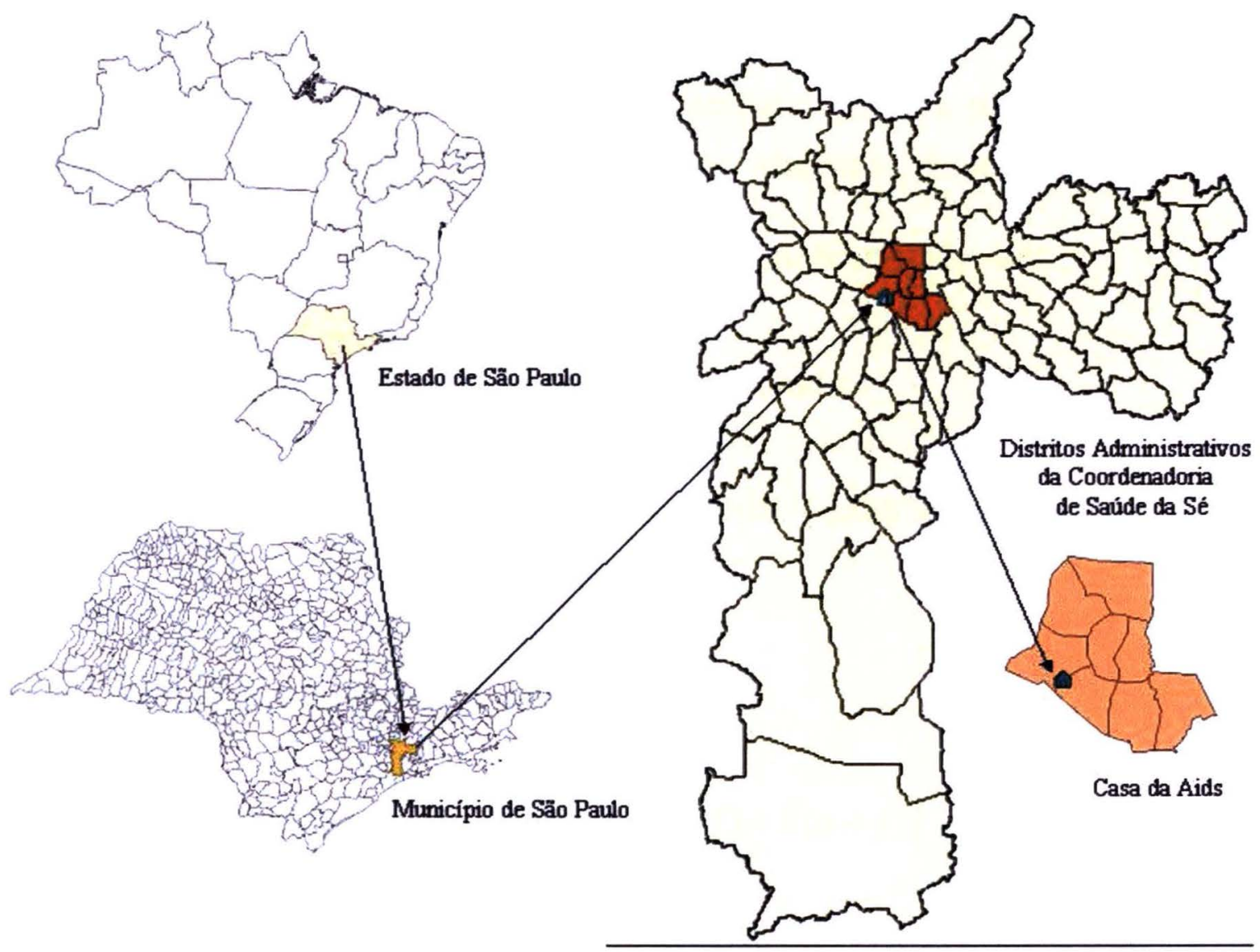

Figura 1: Mapas do Brasil segundo estados, do Estado de São Paulo segundo municípios, do Município de São Paulo segundo distritos administrativos de residência e do Distrito Administrativo da Sé.

Para todos os pacientes analisados, o diagnóstico de infecção por HIV foi baseado na pesquisa de anticorpos anti-HIV pela técnica de ensaio imunoenzimático (ELISA), com posterior confirmação do resultado por meio do teste de Western Blot.

Estabeleceu-se como critério adicional de inclusão para o estudo ter sido acompanhado na Casa da Aids por um periodo igual ou superior a 30 dias, intervalo habitual entre a consulta de admissão e o primeiro retorno ambulatorial para verificação dos resultados de exames laboratoriais iniciais. Com isso visou-se eliminar da investigação os pacientes que não retornaram ao serviço ou cuja admissão tenha ocorrido em data próxima ou coincidente à do óbito. 


\subsubsection{Tamanho da Amostra}

Segundo Collett (1994) o tamanho da amostra (n) para estudos de comparação de sobrevida de dois grupos distintos é dado por: $n=\frac{d}{P(\text { óbito })}$; ou seja, para a população e período analisados têm-se:

d o número necessário de óbitos que deve ser observado:

$d=\frac{4\left(z_{\alpha / 2}+z_{\beta}\right)}{\theta_{R}^{2}}$; sendo $\theta_{\mathrm{R}} \circ$ In do hazard ratio (razão de riscos) de mortalidade e

$\mathbf{P}($ óbito) a probabilidade de ocorrência de óbito:

$$
P(\text { óbito })=1-\frac{1}{6}\{\bar{S}(f)+4 \bar{S}(0,5 a+f)+\bar{S}(a+f)\}
$$

com a: "accrual period"

(tempo de recrutamento, ou seja, de 01/01/1998 a 31/12/2002);

f: "follow-up period"

(período compreendido entre o término do recrutamento (31/12/2002) e o final do seguimento (30/03/2003).

$\bar{S}(t)$ : média das taxas de sobrevida dos dois grupos no instante $t$

\section{Cálculo de d:}

Tomando os achados de MARINS e cols. (2003), estimou-se o hazard ratio de óbitos por aids entre homens e mulheres como sendo igual a 1,25. Partindo então de uma taxa de sobrevida aos 24 meses para os homens de $60 \%$, obteve-se sobrevida para as mulheres de $68 \%$.

Para cálculo do número de óbitos necessários para este estudo temse:

$$
\theta_{R}=\ln \left(\frac{\log S_{\text {mulheres }}}{\log S_{\text {homens }}}\right)=\ln \left(\frac{\log 0,68}{\log 0,60}\right)
$$


Assim, para $\alpha=5 \%$ e $\beta=20 \%: d=\frac{4(7,85)}{\ln \left(\frac{\log 0,68}{\log 0,60}\right)^{2}}=397$, ou seja, são necessários 397 óbitos para se detectar com $80 \%$ de chance tal diferença de sobrevida entre os sexos, com nível de significância de $5 \%$.

\section{Cálculo de P(óbito):}

Considerando-se a população de estudo, o tempo de recrutamento (a) foi de 60 meses e sabendo-se que os pacientes foram acompanhados até $30 / 3 / 2003$, o período entre o término do recrutamento e o final do seguimento $(f)$ foi de 3 meses. A partir desses dados obtém-se: $a=60$ e $f=3$. Pôde-se assim, calcular:

$$
P(\text { óbito })=1-\frac{1}{6}\{\bar{S}(3)+4 \bar{S}(33)+\bar{S}(63)\}
$$

A partir de resultados obtidos por MARINS e cols. (2003), estimaramse os dados necessários para essa fórmula (Tabela 2).

Tabela 2 - Taxa de sobrevida (\%) estimada para pacientes HIV/aids segundo sexo e tempo desde o diagnóstico.

\begin{tabular}{cccc}
\hline \multirow{2}{*}{$\begin{array}{c}\text { Tempo desde o diagnóstico } \\
\text { (meses) }\end{array}$} & \multicolumn{2}{c}{ sexo } & \multirow{2}{*}{ média } \\
\cline { 2 - 3 } & feminino & masculino & \\
\hline 3 & 98,0 & 98,0 & 98,0 \\
33 & 60,0 & 56,0 & 58,0 \\
63 & 50,0 & 45,0 & 47,5 \\
\hline
\end{tabular}

Portanto,

$P($ óbito $)=1-\frac{1}{6}\{\bar{S}(3)+4 \bar{S}(33)+\bar{S}(63)\}=1-\frac{1}{6}\{0,98+4.0,58+0,475\}=0,37083$

Finalmente, tem-se: $n=\frac{397}{0,3708}=1071$ 
Sabendo-se que havia pacientes cadastrados no serviço que apresentavam sorologia negativa para HIV e outros cujo acompanhamento ambulatorial foi inferior a trinta dias, decidiu-se sortear $12 \%$ a mais de prontuários para a amostra, chegando a um total de 1200 indivíduos.

Para a seleção dos prontuários que fazem parte da amostra, todos os indivíduos da população foram classificados por sexo e número de matrícula no serviço. Com o sistema de referência assim ordenado, foi realizado o sorteio por amostragem sistemática (KISH 1965, KALTON 1983).

\subsection{Delineamento de estudo}

\subsubsection{Estudo de sobrevida}

Esse trabalho foi realizado como um estudo de coorte retrospectiva com o objetivo de calcular o tempo de sobrevida de pacientes vivendo com HIV da população estudada para: evolução para aids (período de incubação) e óbito relacionado a essa doença, bem como de identificar fatores associados a esses desfechos.

\section{Desfecho: aids}

Para essa etapa do estudo foram considerados apenas os indivíduos sem diagnóstico de aids no início do seguimento. Considerou-se como aids a ocorrência de qualquer afecção oportunista, de acordo com os critérios estabelecidos pelos Centros de Controle de Doenças dos Estados Unidos (CDC 1992), ou determinação de linfócitos CD4+ periféricos inferior a 200 células $/ \mathrm{mm}^{3}$.

A data inicial de cada indivíduo na coorte foi a da realização do teste sorológico confirmatório de infecção por HIV e, nos oito casos para os quais essa informação não era disponível, a data de matrícula no serviço. A data final foi a da ocorrência da falha, ou seja, a data do diagnóstico de aids. Os pacientes que não desenvolveram a doença até 30/3/2003 e os que 
abandonaram o seguimento do estudo (perdas) foram considerados censuras. A data da censura para os primeiros foi 30/3/2003 e para as perdas, a da última consulta no serviço.

Dessa forma obteve-se o tempo de sobrevida livre de aids pela diferença entre a data do diagnóstico da doença ou da censura e a data inicial.

\section{Desfecho: óbito}

Nessa segunda etapa do estudo foram avaliados todos os pacientes da amostra sorteada.

A data inicial de cada indivíduo na coorte, como na etapa anterior, foi a da realização do teste sorológico confirmatório de infecção por HIV, e nos 11 casos para os quais essa informação não era disponível, a data de matrícula no serviço. A data final do seguimento foi a do registro de óbito, tendo como causa básica aids, qualquer afecção oportunista definidora de aids (CDC 1992) ou afecção não definidora de aids, porém reconhecidamente relacionada à infecção pelo HIV (ALBRECHT 1997).

A identificação desse desfecho foi consensual entre os investigadores, dois médicos infectologistas da Casa da Aids e um profissional vinculado ao Programa de Aprimoramento das Informações de Mortalidade no Município de São Paulo (PRO-AIM).

Foram censurados, os pacientes que se encontravam vivos em $30 / 3 / 2003$, os que foram a óbito até essa data, porém por causa não relacionada à aids, e, finalmente, aqueles que abandonaram o seguimento no serviço. As datas de censura para esses indivíduos foram: 30/3/2003, a data do óbito e a data da última consulta no serviço, respectivamente.

Assim, o tempo de sobrevida foi dado pela diferença entre a data do óbito relacionado à aids ou da censura e a data inicial, conforme explicitado anteriormente. 


\subsection{Variáveis de estudo}

Como neste trabalho há dois eventos de interesse (desenvolvimento de aids e óbito relacionado à aids) têm-se duas variáveis dependentes: o tempo de sobrevida livre de aids e o tempo para a ocorrência do óbito relacionado à aids.

As variáveis independentes utilizadas para a construção dos modelos explicativos para os desfechos analisados neste estudo foram:

a) Variáveis sócio-demográficas:

- sexo;

- idade ao diagnóstico sorológico de infecção por HIV;

- idade à matrícula na Casa da Aids;

- escolaridade à matrícula na Casa da Aids;

- estado civil à matrícula na Casa da Aids.

b) Variáveis relacionadas à exposição ao HIV:

- data do diagnóstico de infecção por HIV;

- principal categoria de exposição a HIV;

- motivo para realização do teste anti-HIV.

c) Variáveis clínicas:

à matrícula na Casa da Aids:

- estadio clínico da infecção pelo HIV;

- comorbidade(s) diagnosticada(s) previamente;

- última determinação quantitativa de linfócitos CD4+ periféricos e último valor do logaritmo decimal da carga viral plasmática de HIV antes do início do seguimento;

- tratamento anti-retroviral (tipo e tempo de uso) recebido antes do ingresso na Casa da Aids;

- marcadores sorológicos de infecção pelo vírus da hepatite B (HBV); 
- marcador sorológico de infecção pelo vírus da hepatite C (HCV);

- marcador sorológico de infecção pelos vírus linfotrópicos de células T humanas (HTLV);

- marcador sorológico treponêmico e não treponêmico para sífilis;

- marcadores sorológicos para Doença de Chagas;

- resultado de teste tuberculínico.

\section{durante o seguimento no serviço:}

- menor, maior e última determinação quantitativa de linfócitos CD4+ periféricos;

- menor e último valor do logaritmo decimal da carga viral plasmática de HIV;

- ocorrência de afecção oportunista;

- comorbidade(s);

- hospitalização (morbidades e número de episódios);

- gestação(ões) para as mulheres;

- tratamento anti-retroviral (tipo e tempo de uso).

Considerou-se como terapia anti-retroviral de alta potência (HAART) o tratamento com pelo menos um medicamento inibidor da protease viral (IP) ou inibidor não nucleosídico da transcriptase reversa (ITRNN), em combinação com no mínimo dois medicamentos inibidores nucleosídicos da transcriptase reversa (ITRN). Calculou-se o tempo proporcional de uso da HAART em relação ao tempo total de tratamento anti-retroviral até a ocorrência do desfecho analisado (desenvolvimento de aids ou óbito relacionado à aids). 


\subsection{Etapas do estudo}

\subsubsection{Submissão aos Comitês de Ética pertinentes}

A pesquisa teve início após a aprovação do protocolo pela Comissão de Ética para Análise de Projetos de Pesquisa do Hospital das Clínicas da Faculdade de Medicina da Universidade de São Paulo (CAPPesq) e pelo Comitê de Ética da Faculdade de Saúde Pública da USP (Anexos 1 e 2).

Por se tratar de estudo baseado em revisão de prontuários médicos do serviço, com preservação do sigilo e do anonimato dos sujeitos, foi dispensada a utilização de Termo de Consentimento Livre e Esclarecido. Entretanto, as pesquisadoras responsáveis pelo estudo, em Termo de Compromisso (Anexo 3) esclareceram as garantias de anonimato dos pacientes, bem como a forma de utilização dos dados coletados dos prontuários, restringindo-a aos objetivos desta pesquisa.

\subsubsection{Estudo Piloto}

As fichas e os procedimentos para a coleta dos dados dos prontuários foram testados por meio de um estudo piloto com 38 pacientes. Dessa maneira pôde-se verificar a adequação do instrumento e dos métodos envolvidos na coleta de dados, procedendo-se às alterações que se fizeram necessárias.

\subsubsection{Coleta de dados}

A transcrição do prontuário médico para as fichas padronizadas (Anexo 4) iniciou-se em abril de 2003, com término em agosto de 2004. A maioria das fichas foi preenchida por um único médico infectologista da Casa da Aids, tendo as demais sido revisadas por esse mesmo clínico. Os prontuários foram obtidos diretamente do Arquivo da Casa da Aids ou mediante solicitação à Divisão de Arquivo Médico do Hospital das Clínicas da FMUSP, quando necessário. 
Eventuais perdas de seguimento foram objeto de reavaliação por busca ativa, por meio de contatos telefônicos com familiares dos pacientes (efetuado pelo médico infectologista que se responsabilizou pela coleta de dados, com auxílio de uma assistente social do serviço) ou mediante consulta a bancos de dados de outros serviços de referência para assistência a pessoas com HIV/aids do MSP (Centro de Referência e Treinamento em DST-Aids da Secretaria de Estado da Saúde - CRT-Aids e Instituto de Infectologia Emílio Ribas) ou mesmo a bancos de dados de mortalidade disponíveis. Persistindo a falta de informação relativa aos desfechos estudados, os pacientes foram considerados como censuras na data da última visita ao serviço.

\subsection{Fontes de dados}

As características sócio-demográficas e clínicas e os resultados de exames laboratoriais dos pacientes foram obtidos dos prontuários médicos da Casa da Aids.

Os dados de mortalidade (a causa básica e a data de óbito) dos pacientes foram oriundos dos bancos de informações de óbitos da Secretaria de Saúde do Município de São Paulo (PRO-AIM) e do Estado de São Paulo (Fundação Sistema Estadual de Análise de Dados-SEADE), do CRT-Aids e do Ministério da Saúde (Sistema de Informação em MortalidadeSIM).

\subsection{Análise dos dados}

\subsubsection{Organização do banco de dados}

As fichas padronizadas foram transcritas para um banco de dados informatizado. Em seguida, realizaram-se as checagens de consistência, com as correções pertinentes. 


\subsubsection{Análise descritiva}

Inicialmente efetuou-se a análise descritiva das variáveis do estudo, para homens e mulheres acompanhados na Casa da Aids. Os resultados foram apresentados em tabelas de freqüências para as variáveis qualitativas. No que tange às variáveis quantitativas, foram feitas estimativas das medidas de tendência central e de dispersão, e, para aquelas que não apresentavam distribuição normal à avaliação pelo teste não-paramétrico de Kolmogorov-Smirnov, utilizou-se a mediana acompanhada dos valores mínimo e máximo.

Para comparar proporções apresentadas nas tabelas de associação, empregou-se a estatística Qui-quadrado, enquanto que o teste $t$ de Student (considerando desigualdade entre as variâncias, quando necessário) (SHOTT 1990, TRIOLA 1999) e o teste não-paramétrico de Mann-Whitney (teste da soma de postos de Wilcoxon) foram utilizados na comparação de médias e medianas, respectivamente (SIEGEL 1975).

Os coeficientes de incidência de aids na população estudada foram calculados tomando-se no numerador o número de casos novos identificados da doença e no denominador o total de pessoas-tempo em risco para o evento. Para o cálculo dos coeficientes de mortalidade tem-se o total de desfechos de interesse dividido por pessoas-tempo em seguimento (FLETCHER e cols. 1989, LAURENTI e cols. 2005).

Os coeficientes de incidência e de mortalidade foram comparados, segundo sexo, pela distribuição binomial.

\subsubsection{Análise bivariada}

Após o estudo descritivo, prosseguiu-se à análise de sobrevida que inicialmente foi realizada pelo estimador produto-limite de Kaplan-Meier (KAPLAN e MEIER 1958), com elaboração dos respectivos gráficos. As possíveis diferenças entre as curvas de sobrevida foram testadas por meio do teste de logaritmo de escores (log-rank) (MANTEL 1966), adotando-se 
como nível de significância $\alpha=5 \%$. Quando a variável apresentava mais de duas categorias que permitiam ordenação foi calculado o teste log rank para tendência (PETO e cols. 1977). Essa análise foi realizada para cada um dos desfechos do estudo (desenvolvimento de aids e óbito relacionado à aids) e a partir dos seus resultados pôde-se avaliar quais variáveis poderiam ser consideradas como prováveis fatores preditivos para cada situação.

Finalmente, foram realizadas análises pelo método dos riscos proporcionais das funções de Cox (COX 1972) para investigação dos fatores prognósticos, com determinação da razão de riscos (hazard ratios) para cada um dos eventos de interesse do estudo com o intuito de estimar a função de sobrevivência $(S(t))$.

Com o objetivo de constatar se os riscos para uma variável independente foram constantemente proporcionais no decorrer do tempo, foram construídos gráficos tendo $\ln (-\ln (S(t)))$ nas ordenadas e a variável tempo nas abscissas (KLEINBAUM 1996).

\subsubsection{Análise multivariável}

As variáveis que apresentaram valor de $p<0,25$ no teste log-rank à análise bivariada foram utilizadas para a construção do modelo final para cada um dos desfechos avaliados.

No modelo de regressão múltipla de Cox, para variáveis tempoindependentes, a função de risco $h(t)$ é descrita como função de $p$ variáveis independentes:

$$
h(t, X)=h_{o}(t) \cdot e^{\sum_{i=1}^{p} \beta_{i} \cdot X_{i}} \quad \text { onde: } \mathrm{X}=(\underbrace{\mathrm{X}_{1}, \mathrm{X}_{2}, \mathrm{X}_{3}, \ldots, \mathrm{X}_{\mathrm{p}}}_{\substack{\text { varíaveis tempo-independentes } \\ \text { preditoras ou explanatorias }}})
$$

Os coeficientes de regressão $\left(\beta_{\mathrm{i}}\right)$ são estimados pelo método da verossimilhança parcial. 
A partir dessa fórmula pode-se estimar a razão das funções de riscos (hazard ratio: $\mathrm{HR}$ ) para cada uma das variáveis independentes $\mathrm{X}_{\mathbf{i}}$, supondo todas as demais variáveis do modelo como constantes.

Com essa razão podem ser comparadas as funções de riscos de duas categorias de uma variável. O modelo de Cox para uma variável independente dicotômica $\left(x_{k}=0\right.$ ou $\left.x_{k}=1\right)$ pode ser escrito da seguinte maneira:

$$
\begin{aligned}
& h\left(t / X_{k}=1\right)=h_{o}(t) \cdot e^{\beta_{1} X_{1}+\beta_{2} X_{2}+\ldots+\beta_{k-1} X_{k-1}+\beta_{i} \cdot 1+\beta_{k+1} X_{k+1}+\ldots+\beta_{p} X_{p}} \\
& e \\
& h\left(t / X_{k}=0\right)=h_{o}(t) \cdot e^{\beta_{1} X_{1}+\beta_{2} X_{2}+\ldots+\beta_{k-1} X_{k-1}+\beta_{i} \cdot 0+\beta_{k+1} X_{k+1}+\ldots+\beta_{p} X_{p}}
\end{aligned}
$$

A razão dessas duas equações resulta na razão das funções de risco (HR):

$$
H R\left(X_{k=1}, X_{k=0}\right)=\frac{h\left(t / X_{k}=1\right)}{h\left(t / X_{k}=0\right)}=e^{\beta_{i}}
$$

O processo de modelagem foi iniciado com a variável que apresentava o menor valor de $p$ pelo teste log-rank e, em seguida, foram acrescentadas sucessivamente as demais, até a que exibisse o maior valor de $p$ inferior a 0,25 (processo de modelagem stepwise forward (LEE 1980)). A variável sexo foi incluída no modelo, independentemente do valor de $p$ obtido no teste log-rank, por se tratar da variável de principal interesse deste estudo. As demais variáveis foram mantidas no modelo final quando apresentavam $p \leq 0,05$, de acordo com o teste da razão da máxima verossimilhança (MARUBINI e VALSECCHI 1995), ou quando consideradas de confusão para outras incluídas no modelo, por alterarem os coeficientes dos termos das demais.

Finalmente foram estimadas as razões das funções de risco (HR) para cada uma das variáveis constantes no modelo final de cada desfecho. Para cada HR foi apresentado o seu respectivo intervalo com $95 \%$ de confiança. 


\subsubsection{Softwares utilizados}

$\checkmark$ Epi-data (versão 2.1) para elaboração do banco de dados.

$\checkmark$ Excel para confecção de gráficos.

$\checkmark$ Stata (versão 8.0) para análise estatística.

$\checkmark$ SPSS (versão 11.0) para construção das curvas de sobrevida. 


\section{RESULTADOS}




\section{RESULTADOS}

\subsection{Análise descritiva}

No período compreendido entre janeiro de 1998 e dezembro de 2002, 5512 indivíduos foram atendidos em consulta médica no Serviço de Extensão ao Atendimento de Pacientes com HIV/aids (Casa da Aids), da Divisão de Clínica de Moléstias Infecciosas e Parasitárias do Hospital das Clínicas da Faculdade de Medicina da USP.

Os resultados aqui apresentados provêm da revisão de prontuários médicos evolutivos de 1229 desses indivíduos, sorteados pelo método de amostragem sistemática. Destes, $156(12,7 \%)$ não foram elegíveis para o estudo (14 prontuários não foram encontrados, 113 indivíduos foram acompanhados no serviço por um período inferior a trinta dias, 28 eram soronegativos para a infecção por HIV, um possuía dois registros de identificação diferentes e um não foi atendido no serviço no período de estudo).

Assim, neste estudo, a casuística analisada é composta por 1072 pacientes com HIV/aids, que foram atendidos na Casa da Aids no período acima citado. Vale a pena destacar que a revisão de $980(91,4 \%)$ prontuários médicos foi realizada por um único médico infectologista do serviço.

Este estudo teve como propósito avaliar os pacientes à chegada ao serviço e durante todo o tempo em que foram acompanhados na unidade até 30/03/2003.

A maioria dos indivíduos analisados $(71,1 \%)$ era do sexo masculino, obtendo-se uma razão homens:mulheres igual a aproximadamente 2,5:1.

No momento do diagnóstico de HIV os pacientes tinham, em média, 33,4 anos (desvio padrão: 8,9 anos). Entretanto, as mulheres foram 
diagnosticadas em idades mais jovens, quando comparadas aos homens $(p=0,03)$ (Tabela 3). A maioria dos homens era solteiro $(66,0 \%, n=742)$ e apresentava escolaridade igual ou superior a 11 anos $(53,5 \%, n=723)$. Em contraste, na população feminina, $48,2 \%(n=303)$ das mulheres eram casadas ou amasiadas, $66,6 \%(n=299)$ tinham menos de 11 anos de escolaridade e $23,4 \%$ ( $n=273$ ) eram donas de casa.

No que se refere à categoria de exposição sexual $77,4 \%(n=567)$ dos homens relataram comportamento homossexual ou bissexual. A transfusão sangüínea foi identificada como categoria de exposição para 8 homens e 1 mulher.

Não houve diferença com significância estatística $(p=0,14)$ entre homens e mulheres em relação ao período em que foram diagnosticados como soropositivos para o HIV.

A análise do momento do diagnóstico permitiu identificar que o motivo para a realização do teste sorológico anti-HIV diferiu entre os sexos $(p<0,001)$ (Tabela 4). Enquanto $36,3 \%$ das mulheres o fizeram por possuírem parceiro soropositivo, na população masculina o motivo principal da testagem sorológica $(42,8 \%)$ foi a ocorrência de sintomas sugestivos de infecção por HIV/aids. Observou-se também, dentre os homens, que 110 $(15,8 \%)$ recorreram ao teste por se perceberem sob risco e que $35(11,9 \%)$ mulheres foram diagnosticadas por meio da triagem laboratorial oferecida durante o pré-natal. 
Tabela 3: Distribuição dos pacientes com HIV/aids atendidos na Casa da Aids segundo sexo, idade ao diagnóstico de infecção por HIV, características sócio-demográficas, ano do diagnóstico de infecção por HIV e categoria de exposição ao HIV. São Paulo, 1998 a 2002.

\begin{tabular}{|c|c|c|c|}
\hline \multirow[b]{2}{*}{ VARIÁVEL } & \multicolumn{2}{|c|}{ sexo } & \multirow[b]{2}{*}{$\boldsymbol{p}$} \\
\hline & $\begin{array}{c}\text { feminino }(n=310) \\
n^{\circ}(\%)\end{array}$ & $\begin{array}{c}\text { masculino }(n=762) \\
n^{\circ}(\%)\end{array}$ & \\
\hline $\begin{array}{l}\text { Idade ao diagnóstico de infecção por HIV } \\
\text { (anos)* }\end{array}$ & & & 0,03 \\
\hline$<20$ & $18(5,8)$ & $22(2,9)$ & \\
\hline 20 a 29 & $118(38,3)$ & $250(33,2)$ & \\
\hline 30 a 39 & $111(36,0)$ & $333(44,2)$ & \\
\hline 40 a 49 & $44(14,3)$ & $113(15,0)$ & \\
\hline$\geq 50$ & $17(5,5)$ & $35(4,7)$ & \\
\hline Estado civil & & & $<0,001$ \\
\hline solteiro (a) & $72(23,8)$ & $490(66,0)$ & \\
\hline casado(a)/amasiado(a) & $146(48,2)$ & $192(25,9)$ & \\
\hline viúvo(a) & $41(13,5)$ & $14(1,9)$ & \\
\hline divorciado(a)/desquitado(a) & $44(14,5)$ & $46(6,2)$ & \\
\hline Escolaridade $^{\star \star \star}$ & & & $<0,001$ \\
\hline analfabeto/primário incompleto & $29(9,7)$ & $22(3,0)$ & \\
\hline primário completo ou ginásio incompleto & $79(26,4)$ & $129(17,8)$ & \\
\hline ginásio completo ou colegial incompleto & $91(30,4)$ & $185(25,6)$ & \\
\hline colegial completo ou superior incompleto & $66(22,1)$ & $253(35,0)$ & \\
\hline superior completo & $34(11,4)$ & $134(18,5)$ & \\
\hline Ano do diagnóstico de infecção por HIV & & & 0,14 \\
\hline antes de 1990 & $8(2,6)$ & $34(4,5)$ & \\
\hline entre 1990 e 1996 & $123(39,9)$ & $328(43,6)$ & \\
\hline entre 1997 e 2002 & $177(57,5)$ & $391(51,9)$ & \\
\hline Categoria de exposição ao HIV ${ }^{* \star \star *}$ & & & $<0,001$ \\
\hline sangüínea & $10(3,6)$ & $77(12,0)$ & \\
\hline sexual & $267(96,4)$ & $567(88,0)$ & \\
\hline
\end{tabular}

Dados ignorados para: ${ }^{\star}: 11$ pacientes; ${ }^{\star \star}: 27$ pacientes; ${ }^{\star \star \star}: 50$ pacientes; ${ }^{\star \star \star \star}: 151$ pacientes. 
Tabela 4: Distribuição dos pacientes com HIV/aids atendidos na Casa da Aids segundo sexo e motivo para realização do teste anti-HIV. São Paulo, 1998 a 2002.

\begin{tabular}{|c|c|c|c|}
\hline \multirow[b]{2}{*}{ VARIÁVEL } & \multicolumn{2}{|c|}{ sexo } & \multirow[b]{2}{*}{$\boldsymbol{p}$} \\
\hline & $\begin{array}{c}\text { feminino }(n=295) \\
n^{\circ}(\%)\end{array}$ & $\begin{array}{c}\text { masculino }(n=698) \\
n^{\circ}(\%)\end{array}$ & \\
\hline Motivo para realização do teste anti-HIV & & & $<0,001$ \\
\hline sintomas sugestivos de infecção por HIV/aids & $81(27,5)$ & $299(42,8)$ & \\
\hline triagem sorológica em banco de sangue & $19(6,4)$ & $57(8,2)$ & \\
\hline assintomático com parceiro(a) soropositivo(a) & $107(36,3)$ & $104(14,9)$ & \\
\hline percepção de risco & $14(4,8)$ & $110(15,8)$ & \\
\hline outros & $74(25,1)$ & $128(18,3)$ & \\
\hline
\end{tabular}

A matrícula na Casa da Aids foi efetuada por $47 \%$ dos pacientes em até dois meses após o diagnóstico de infecção por HIV, não se verificando diferença estatisticamente significativa entre os sexos no intervalo entre a data do diagnóstico e a admissão no serviço $(p=0,49)$.

Quando da admissão à Casa da Aids, os homens apresentavam-se mais freqüentemente em fase mais avançada da história natural da infecção. O estadio clínico de aids foi reconhecido em 418 (55,1\%) homens e em 117 $(37,7 \%)$ mulheres $(p<0,001)$ (Tabela 5$)$. Dentre todos os pacientes com aids à matrícula no serviço $(n=535)$, a maioria $(52,2 \%)$ já havia apresentado pelo menos uma afecção oportunista antes da primeira consulta na Casa da Aids.

Ao final do seguimento, de 1066 indivíduos, cujo estadio clínico era conhecido, 691 (64,8\%) tinham aids. Dentre estes, 265 (38,4\%) tiveram o diagnóstico de pelo menos uma afecção oportunista durante o atendimento no serviço, correspondendo a $71(39,4 \%)$ mulheres e $194(38,0 \%)$ homens $(p=0,73)$. 
Tabela 5: Distribuição dos pacientes atendidos na Casa da Aids segundo sexo e estadio clínico. São Paulo, 1998 a 2003.

\begin{tabular}{|c|c|c|c|}
\hline \multirow[b]{2}{*}{ ESTADIO CLÍNICO } & \multicolumn{2}{|c|}{ sexo } & \multirow[b]{2}{*}{ p } \\
\hline & $\begin{array}{c}\text { feminino } \\
n^{\circ}(\%)\end{array}$ & $\begin{array}{c}\text { masculino } \\
n^{\circ}(\%)\end{array}$ & \\
\hline "A matrícula" & & & $<0,001$ \\
\hline sem aids & $193(62,3)$ & $341(44,9)$ & \\
\hline com aids & $117(37,7)$ & $418(55,1)$ & \\
\hline Ao final do seguimento** & & & 0,004 \\
\hline sem aids & $129(41,7)$ & $246(32,5)$ & \\
\hline com aids & $180(58,3)$ & $511(67,5)$ & \\
\hline
\end{tabular}

\subsection{Afecções oportunistas}

Quanto às afecções oportunistas diagnosticadas antes da matrícula no serviço e durante o seguimento, observa-se que tanto antes da admissão ao serviço quanto durante o acompanhamento clínico no mesmo, as três morbidades mais freqüentemente diagnosticadas foram candidíase esofágica, pneumonia por Pneumocystis carinii e tuberculose pulmonar (Figura 2, Tabelas 6 e 7).

Vale a pena destacar que a criptosporidíase intestinal e a demência associada ao HIV foram diagnosticadas mais freqüentemente durante o seguimento clínico no serviço do que previamente à admissão.

Tem-se, também, que um mesmo indivíduo pode ter apresentado mais de uma afecção oportunista tanto à matrícula quanto durante o seguimento na Casa da Aids. 


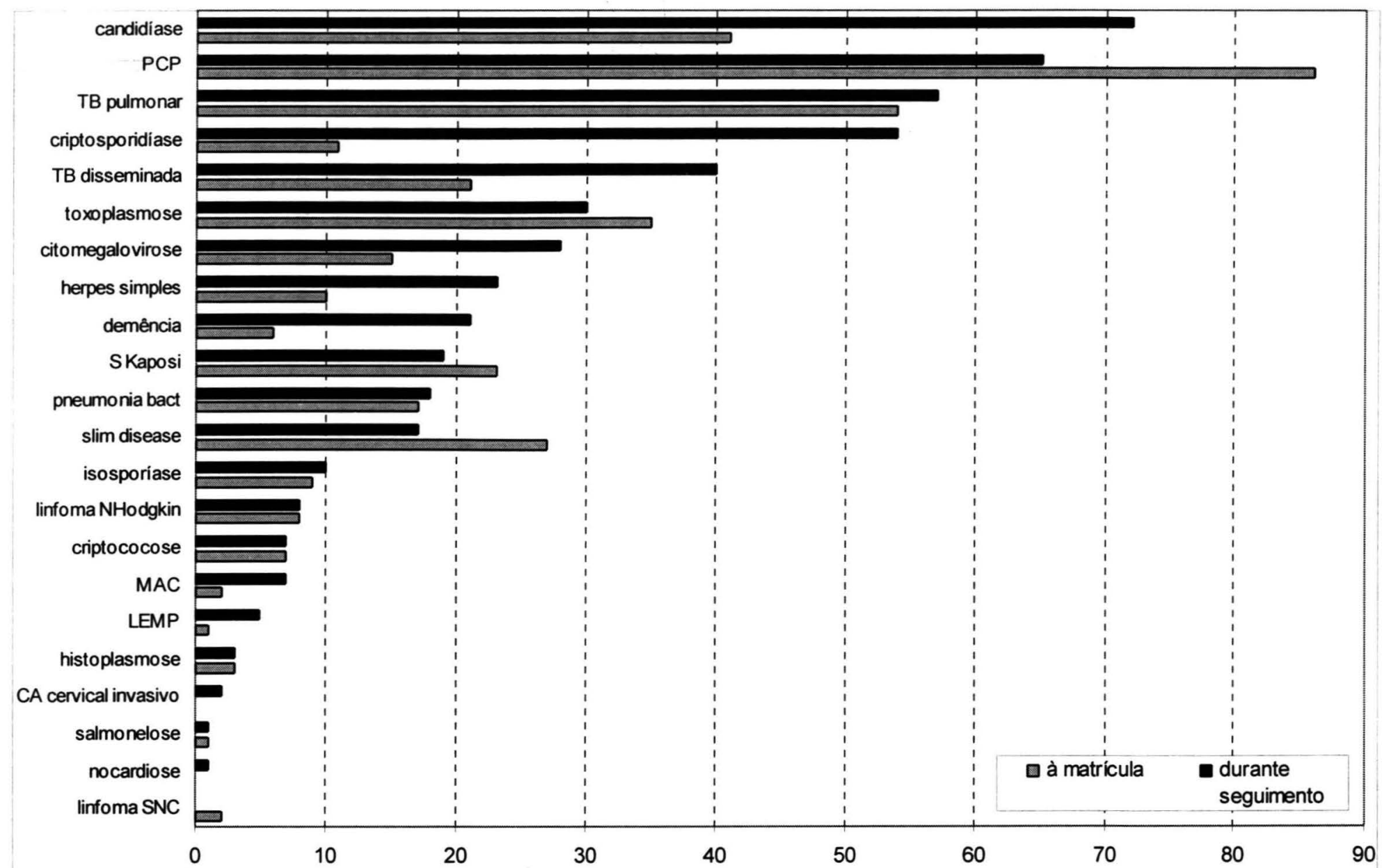

Figura 2: Distribuição do número de casos segundo as afecções oportunistas observadas à matrícula na Casa da Aids e durante seguimento no serviço. São Paulo, 1998 a 2003.

PCP: pneumonia por Pneumocystis carinii; TB: tuberculose; S Kaposi: Sarcoma de Kaposi; bact.: bacteriana; MAC: infecção por Mycobacterium avium-intracellulare; LEMP: leucoencefalopatia multifocal progressiva; CA: câncer; SNC: sistema nervoso central. 
Tabela 6: Número de casos e prevalência (\%) de afecções oportunistas em pacientes com HIV/aids no momento da matrícula na Casa da Aids. São Paulo, 1998 a 2002.

\begin{tabular}{|c|c|c|}
\hline \multirow[b]{2}{*}{ AFECÇÃO OPORTUNISTA } & \multicolumn{2}{|c|}{ sexo } \\
\hline & $\begin{array}{c}\text { feminino }(n=310) \\
n^{\circ}(\%)\end{array}$ & $\begin{array}{c}\text { masculino }(n=761)^{*} \\
n^{\circ}(\%)\end{array}$ \\
\hline Candidíase esofágica, brônquica, traqueal ou pulmonar & $11(3,5)$ & $30(3,9)$ \\
\hline Criptococose extrapulmonar & - & $7(0,9)$ \\
\hline $\begin{array}{l}\text { Criptosporidíase intestinal com diarréia por prazo } \\
\text { superior a } 1 \text { mês }\end{array}$ & $3(1,0)$ & $8(1,0)$ \\
\hline Demência associada ao HIV & $1(0,3)$ & $5(0,7)$ \\
\hline $\begin{array}{l}\text { Doença pelo citomegalovírus, exceto do fígado, baço e } \\
\text { linfonodos }\end{array}$ & $8(2,6)$ & $7(0,9)$ \\
\hline Histoplasmose extrapulmonar & $1(0,3)$ & $2(0,3)$ \\
\hline $\begin{array}{l}\text { Infecção pelo vírus do herpes simples, causando } \\
\text { úlcera mucocutânea (por prazo superior a } 1 \text { mês), } \\
\text { bronquite, pneumonite ou esofagite }\end{array}$ & $1(0,3)$ & $9(1,2)$ \\
\hline Isosporíase com diarréia por prazo superior a 1 mês & $2(0,6)$ & $7(0,9)$ \\
\hline Leucoencefalopatia multifocal progressiva & - & $1(0,1)$ \\
\hline $\begin{array}{l}\text { Micobacteriose disseminada por Mycobacterium } \\
\text { avium-intracellulare ou Mycobacterium kansasii }\end{array}$ & - & $2(0,3)$ \\
\hline $\begin{array}{l}\text { Pneumonia bacteriana recorrente ( } 2 \text { ou mais episódios } \\
\text { em um ano) }\end{array}$ & $1(0,3)$ & $16(2,1)$ \\
\hline Pneumonia por Pneumocystis carinii & $17(5,5)$ & $69(9,1)$ \\
\hline Sepse recorrente por Salmonella não typhi & - & $1(0,1)$ \\
\hline Síndrome consumptiva do HIV & $4(1,3)$ & $23(3,0)$ \\
\hline Toxoplasmose do SNC & $9(2,9)$ & $26(3,4)$ \\
\hline Tuberculose disseminada & $1(0,3)$ & $20(2,6)$ \\
\hline Tuberculose pulmonar & $10(3,2)$ & $44(5,8)$ \\
\hline Linfoma cerebral $1^{\text {ario }}$ & - & $2(0,3)$ \\
\hline $\begin{array}{l}\text { Linfoma não-Hodgkin de células B ou de linfócitos B de } \\
\text { fenótipo imunológico desconhecido }\end{array}$ & - & $8(1,0)$ \\
\hline Sarcoma de Kaposi & $2(0,6)$ & $21(2,8)$ \\
\hline
\end{tabular}

*: dado ignorado para um homem.

SNC: Sistema Nervoso Central 
Tabela 7: Número de casos e prevalência de afecções oportunistas em pacientes com HIV/aids durante seguimento na Casa da Aids. São Paulo, 1998 a 2003.

\begin{tabular}{|c|c|c|}
\hline \multirow[b]{2}{*}{ AFECÇÃO OPORTUNISTA } & \multicolumn{2}{|c|}{ sexo } \\
\hline & $\begin{array}{c}\text { feminino }(n=310) \\
n^{\circ}(\%)\end{array}$ & $\begin{array}{l}\text { masculino }(n=762) \\
n^{\circ}(\%)\end{array}$ \\
\hline Candidíase esofágica, brônquica, traqueal ou pulmonar & $22(7,1)$ & $50(6,6)$ \\
\hline Criptococose extrapulmonar & $3(1,0)$ & $4(0,5)$ \\
\hline $\begin{array}{l}\text { Criptosporidíase intestinal com diarréia por prazo } \\
\text { superior a } 1 \text { mês }\end{array}$ & $16(5,2)$ & $38(5,0)$ \\
\hline Demência associada ao HIV & $4(1,3)$ & $17(2,2)$ \\
\hline $\begin{array}{l}\text { Doença pelo citomegalovírus, exceto do fígado, baço e } \\
\text { linfonodos }\end{array}$ & $9(2,9)$ & $19(2,5)$ \\
\hline $\begin{array}{l}\text { Histoplasmose extrapulmonar } \\
\text { Infecção pelo vírus do herpes simples, causando úlcera }\end{array}$ & - & $3(0,4)$ \\
\hline $\begin{array}{l}\text { mucocutânea (por prazo superior a } 1 \text { mês), bronquite, } \\
\text { pneumonite ou esofagite }\end{array}$ & $4(1,3)$ & $19(2,5)$ \\
\hline Isosporíase com diarréia por prazo superior a 1 mês & $2(0,7)$ & $8(1,1)$ \\
\hline Leucoencefalopatia multifocal progressiva & $1(0,3)$ & $4(0,5)$ \\
\hline $\begin{array}{l}\text { Micobacteriose disseminada por Mycobacterium avium- } \\
\text { intracellulare ou Mycobacterium kansasii }\end{array}$ & $2(0,7)$ & $5(0,7)$ \\
\hline Nocardiose & - & $1(0,1)$ \\
\hline $\begin{array}{l}\text { Pneumonia bacteriana recorrente ( } 2 \text { ou mais episódios } \\
\text { em um ano) }\end{array}$ & $6(1,9)$ & $12(1,6)$ \\
\hline Pneumonia por Pneumocystis carinii & $19(6,1)$ & $46(6,0)$ \\
\hline Sepse recorrente por Salmonella não typhi & - & $1(0,1)$ \\
\hline Síndrome consumptiva do HIV & $1(0,3)$ & $16(2,1)$ \\
\hline Toxoplasmose do SNC & $9(2,9)$ & $21(2,8)$ \\
\hline Tuberculose disseminada & $13(4,2)$ & $27(3,5)$ \\
\hline Tuberculose pulmonar & $13(4,2)$ & $44(5,8)$ \\
\hline Câncer cervical invasivo & $2(0,7)$ & - \\
\hline $\begin{array}{l}\text { Linfoma não-Hodgkin de células B ou de linfócitos B de } \\
\text { fenótipo imunológico desconhecido }\end{array}$ & $1(0,3)$ & $7(0,9)$ \\
\hline Sarcoma de Kaposi & $1(0,3)$ & $18(2,4)$ \\
\hline
\end{tabular}

SNC: Sistema Nervoso Central 


\subsection{Comorbidades}

Diversas outras comorbidades foram reconhecidas durante o período entre o diagnóstico de infecção por HIV e a admissão ao serviço ou durante o acompanhamento no mesmo. Dentre essas destacam-se a candidiase oral $(14,8 \%)$, a pneumonia bacteriana $(8,7 \%)$, o etilismo $(8,1 \%)$ e o herpes zoster $(7,4 \%)$ antes da matrícula no serviço, enquanto no seguimento evolutivo, predominaram os diagnósticos de gastrite $(20,1 \%)$, sinusopatia $(16,4 \%)$, candidíase oral $(15,1 \%)$ e depressão (14,5\%) (Figura 3). 


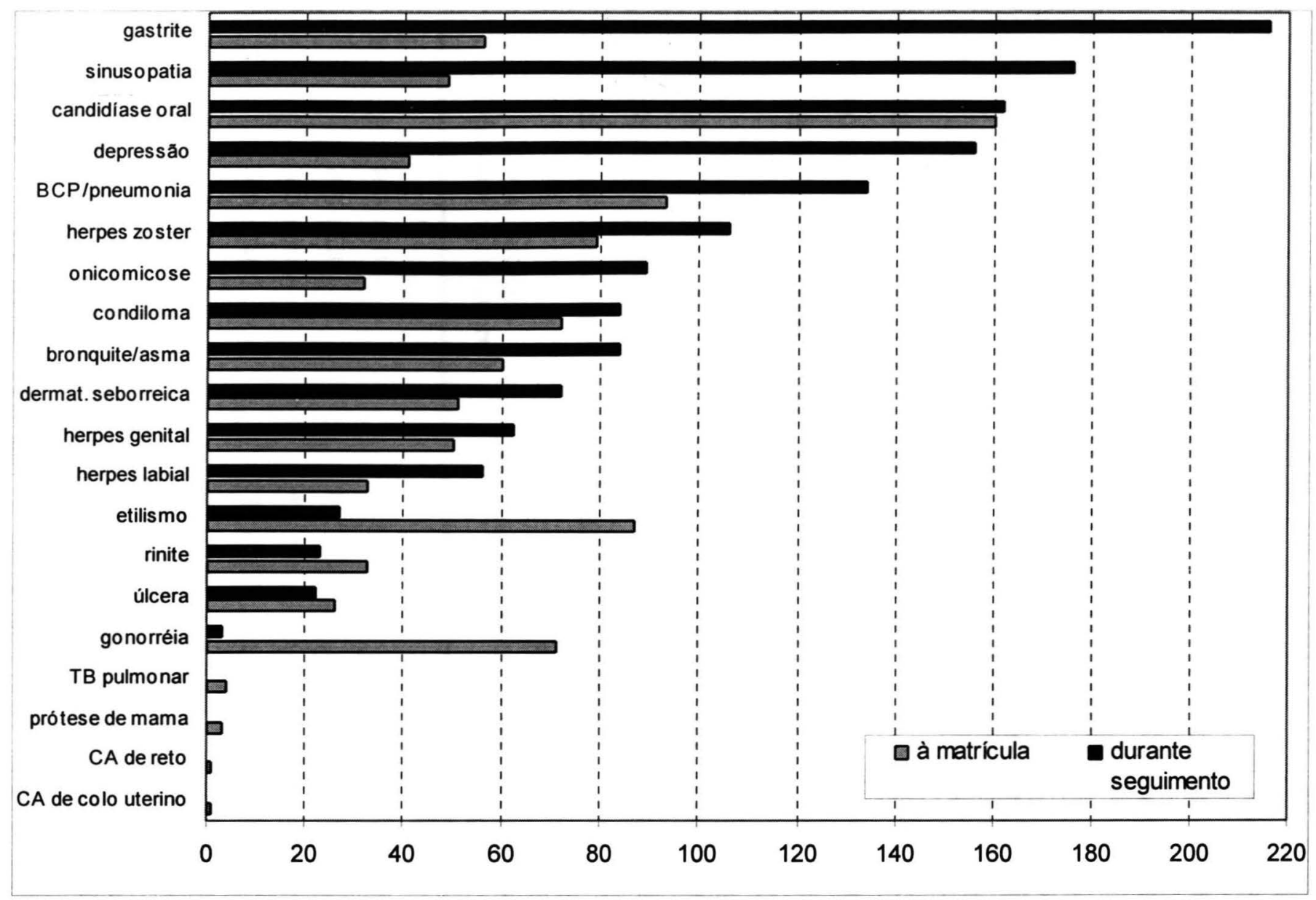

Figura 3: Distribuição do número de casos segundo as comorbidades de maior ocorrência em pacientes com HIV/aids antes e após a matrícula na Casa da Aids. São Paulo, 1998 a 2003.

BCP: broncopneumonia; dermat:: dermatite; TB: tuberculose; $\mathrm{CA}$ : câncer. 


\subsection{Marcadores laboratoriais}

No que se refere à avaliação de marcadores laboratoriais evolutivos da infecção por HIV/aids, pôde-se observar que as mulheres foram admitidas ao serviço com número mais elevado de linfócitos CD4+ em sangue periférico (mediana $=297$ células $/ \mathrm{mm}^{3}$, mínimo $=0$, máximo $=3692$ ) do que os homens (mediana $=233$ células $/ \mathrm{mm}^{3}$, mínimo $=0$, máximo $=1320$, respectivamente) ( $p=0,002$, teste de Mann-Whitney).

Considerando a importância da determinação do número de linfócitos CD4+ em sangue periférico na avaliação do status imunológico do paciente, avaliou-se a distribuição (Tabela 8) de homens e mulheres atendidos no serviço segundo diferentes intervalos de contagem dessas células no momento da admissão.

Tabela 8: Distribuição dos pacientes com HIV/aids segundo sexo e resultado da determinação quantitativa de linfócitos CD4+ no sangue periférico/ $/ \mathrm{mm}^{3}$ à matrícula na Casa da Aids. São Paulo, 1998 a 2002.

\begin{tabular}{|c|c|c|c|}
\hline \multirow[b]{2}{*}{$\begin{array}{c}\text { CD4+ inicial } \\
\text { (número de células } / \mathrm{mm}^{3} \text { ) }\end{array}$} & \multicolumn{2}{|c|}{ sexo } & \multirow[b]{2}{*}{$p$} \\
\hline & $\begin{array}{c}\text { feminino }(n=308) \\
n^{\circ}(\%)\end{array}$ & $\begin{array}{c}\text { masculino }(n=758) \\
n^{\circ}(\%)\end{array}$ & \\
\hline$<100$ & $59(19,2)$ & $202(26,6)$ & 0,008 \\
\hline 100 a 199 & $42(13,6)$ & $142(18,7)$ & \\
\hline 200 a 299 & $54(17,5)$ & $109(14,4)$ & \\
\hline 300 a 399 & $48(15,6)$ & $102(13,5)$ & \\
\hline 400 a 499 & $39(12,7)$ & $87(11,5)$ & \\
\hline$\geq 500$ & $66(21,4)$ & $116(15,3)$ & \\
\hline
\end{tabular}

Durante o acompanhamento no serviço foram avaliados os números de linfócitos CD4+ no sangue periférico/ $\mathrm{mm}^{3}$ referentes ao menor e ao último valor observado para cada indivíduo. As mulheres apresentaram determinações significativamente mais elevadas no menor valor mensurado, não se tendo verificado diferença entre os sexos no tocante ao último valor registrado no seguimento laboratorial (Tabela 9). 
Tabela 9: Médias (DP), medianas, valores mínimos e máximos dos resultados da menor e da última determinação quantitativa de linfócitos CD4+ no sangue periférico/ $/ \mathrm{mm}^{3}$ dos pacientes com HIV/aids durante o seguimento na Casa da Aids segundo sexo. São Paulo, 1998 a 2003.

\begin{tabular}{|c|c|c|c|c|c|c|c|c|c|}
\hline \multirow[b]{2}{*}{ CD4+ } & \multicolumn{4}{|c|}{ feminino } & \multicolumn{4}{|c|}{ masculino } & \multirow{2}{*}{$p^{\#}$} \\
\hline & $\begin{array}{l}\text { média } \\
\text { (DP) }\end{array}$ & mediana & mínimo & máximo & $\begin{array}{l}\text { média } \\
\text { (DP) }\end{array}$ & mediana & mínimo & máximo & \\
\hline menor & $\begin{array}{c}222,2 \\
(171,8)\end{array}$ & 196,5 & 1 & 870 & $\begin{array}{c}201,3 \\
(179,1)\end{array}$ & 163,5 & 0 & 1308 & 0,03 \\
\hline última & $\begin{array}{c}384,7 \\
(234,1)\end{array}$ & 367,5 & 2 & 1122 & $\begin{array}{c}380,0 \\
(247,6)\end{array}$ & 347,0 & 1 & 1899 & 0,50 \\
\hline
\end{tabular}

Dado que o valor de 200 células $\mathrm{CD} 4+/ \mathrm{mm}^{3}$ define o grau de imunossupressão compatível com o diagnóstico de aids, é importante comparar os achados laboratoriais observados no seguimento de homens e mulheres, tomando como base esse ponto de corte. Entretanto, durante o seguimento no serviço, não se observou diferença entre homens e mulheres na proporção de pacientes com o número de células CD4+ inferior a 200 células $/ \mathrm{mm}^{3}$ para a menor e a última determinação (Figura 4).

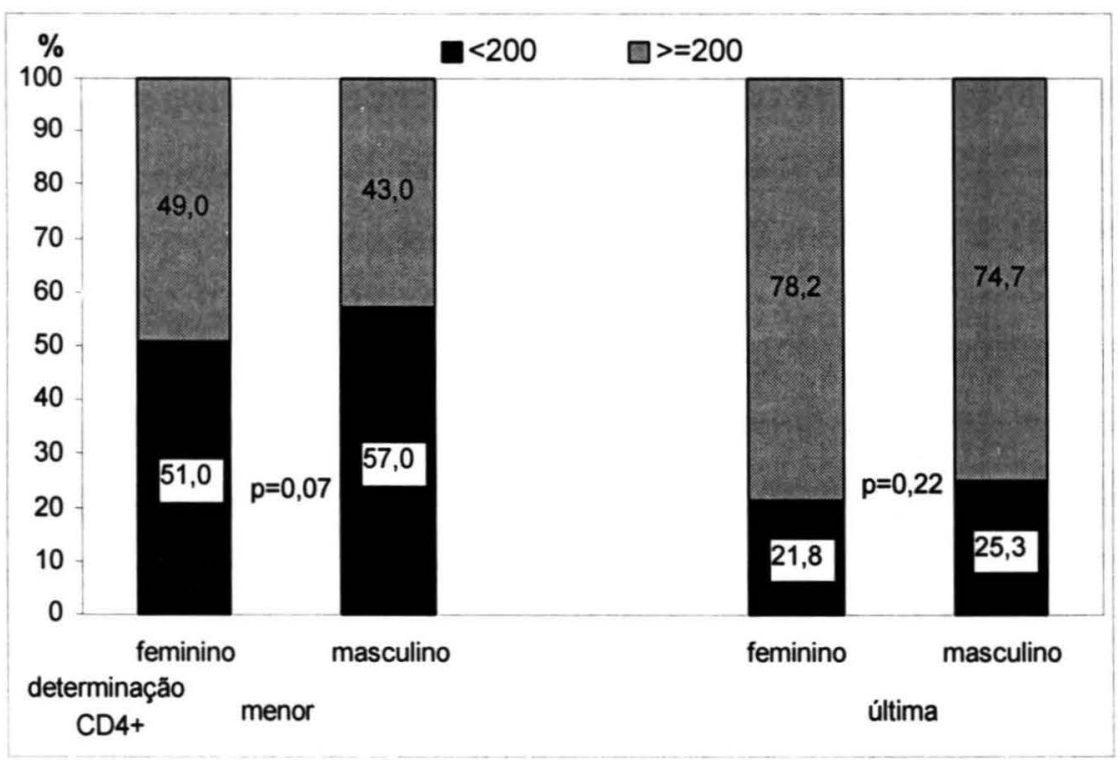

Figura 4: Distribuição dos pacientes* com HIV/aids segundo sexo e resultados da menor e da última determinação quantitativa de linfócitos CD4+ no sangue periférico/ $/ \mathrm{mm}^{3}$ durante acompanhamento na Casa da Aids segundo sexo. São Paulo, 1998 a 2003.

*: 2 mulheres e 4 homens com dados ignorados 
No momento da admissão ao serviço, verificou-se também que as mulheres apresentavam maior proporção de carga viral plasmática de HIV indetectável, quando comparadas aos homens (58 (19,3\%) e 101 (13,6\%), respectivamente; $p=0,02$; dados ignorados para 9 mulheres e 18 homens).

Dentre os 159 pacientes com carga viral indetectável na avaliação inicial no serviço, $42(26,4 \%)$ encontravam-se sob tratamento anti-retroviral (31 com HAART), não havendo diferença entre os sexos $(p=0,22)$. Assim, nota-se que independentemente do uso de medicamentos anti-retrovirais, as mulheres apresentavam com maior freqüência ausência de viremia plasmática.

Da mesma forma, dentre aqueles com carga viral detectável $(n=886)$, observou-se que as mulheres ( $\log$ da carga viral plasmática: mediana $=4,3$ cópias $/ \mathrm{mL}$, mínimo $=2,0$, máximo $=6,6$ ) apresentaram viremia plasmática menor que os homens (mediana=4,5 cópias $/ \mathrm{mL}$, mínimo=1,9, máximo=6,7, respectivamente) ( $p=0,02$, teste de Mann-Whitney).

Padrão análogo foi observado também durante o seguimento na Casa da Aids, havendo maior proporção de indivíduos do sexo feminino com carga viral plasmática indetectável em relação ao masculino (75,7\% e 64,9\%, respectivamente; $p<0,001$; dados ignorados para 9 mulheres e 18 homens).

Os boxplots (Figura 5), segundo sexo, ilustram as determinações de carga viral de HIV, dentre os pacientes com viremia plasmática detectável, em três grupos categorizados segundo valor mensurado: menor valor $(n=334)$, maior valor $(n=1002)$ e último valor registrado $(n=547)$. 


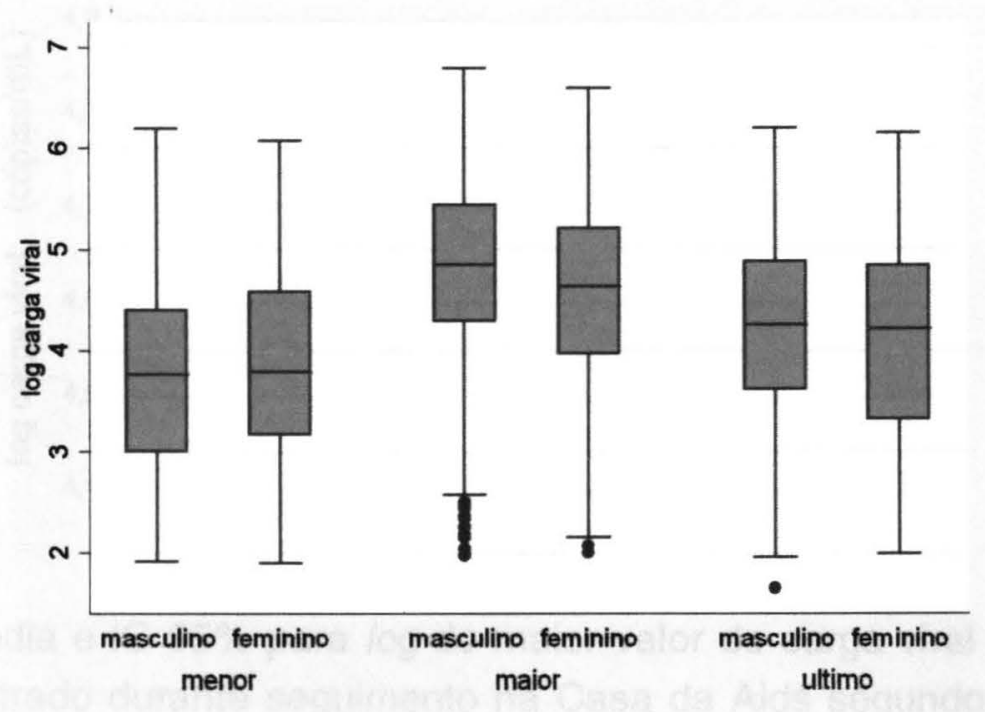

Figura 5: Boxplots dos valores detectáveis (menor, maior e último) do log da carga viral plasmática de HIV durante o seguimento na Casa da Aids segundo sexo. São Paulo, 1998 a 2003.

Em relação ao maior valor registrado durante o seguimento, observou-se que a viremia plasmática das mulheres foi menor do que a dos homens $(p<0,001)$ (Tabela 10 e Figura 6). Entretanto, não foi detectada diferença entre os sexos para o menor e o último valor registrado $(p=0,35 \mathrm{e}$ $p=0,36$, respectivamente).

Tabela 10: Médias (DP), medianas, valores mínimos e máximos dos resultados da menor, maior e última determinação do log da carga viral plasmática de HIV dos pacientes com HIV/aids durante o seguimento na Casa da Aids segundo sexo. São Paulo, 1998 a 2003.

\begin{tabular}{|c|c|c|c|c|c|c|c|c|c|}
\hline \multirow{2}{*}{$\begin{array}{c}\text { Carga } \\
\text { viral }(\text { log) } \\
\text { (cópias } / \mathrm{mL})\end{array}$} & \multicolumn{4}{|c|}{ feminino } & \multicolumn{4}{|c|}{ masculino } & \multirow[b]{2}{*}{$\boldsymbol{p}^{\#}$} \\
\hline & $\begin{array}{l}\text { média } \\
\text { (DP) }\end{array}$ & mediana & mínimo & máximo & $\begin{array}{l}\text { média } \\
\text { (DP) }\end{array}$ & mediana & mínimo & máximo & \\
\hline menor & $\begin{array}{c}3,88 \\
(0,98)\end{array}$ & 3,80 & 1,90 & 6,08 & $\begin{array}{c}3,76 \\
(0,98)\end{array}$ & 3,77 & 1,91 & 6,20 & 0,35 \\
\hline maior & $\begin{array}{c}4,55 \\
(0,95)\end{array}$ & 4,63 & 2,00 & 6,59 & $\begin{array}{c}4,77 \\
(0,88)\end{array}$ & 4,85 & 1,97 & 6,79 & $<0,001$ \\
\hline último & $\begin{array}{c}4,17 \\
(0,98)\end{array}$ & 4,22 & 1,99 & 6,15 & $\begin{array}{c}4,23 \\
(0,90)\end{array}$ & 4,25 & 1,65 & 6,20 & 0,36 \\
\hline
\end{tabular}




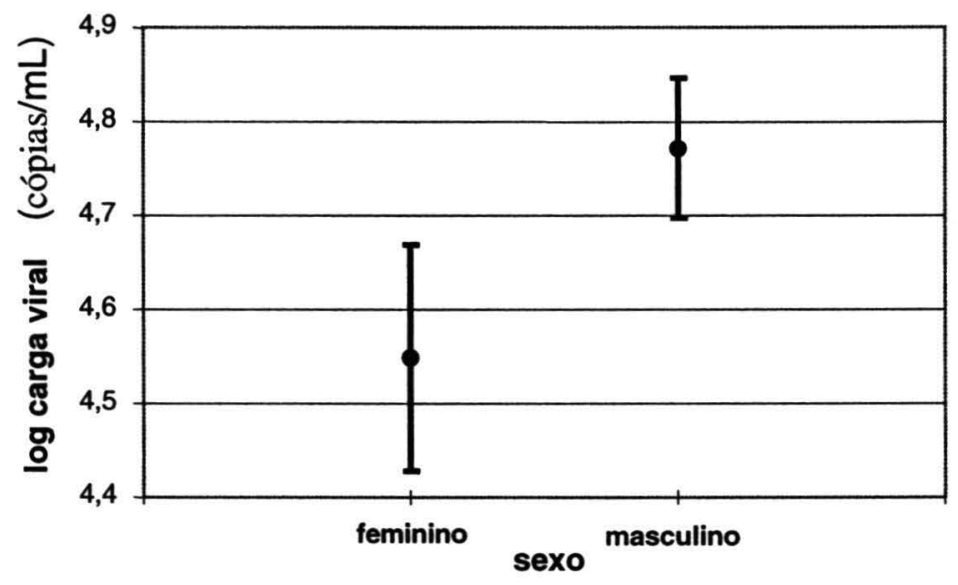

Figura 6: Média e IC 95\% para log do maior valor de carga viral plasmática de HIV registrado durante seguimento na Casa da Aids segundo sexo. São Paulo, 1998 a 2003.

Os resultados de exames laboratoriais, coletados por ocasião da admissão dos pacientes na Casa da Aids, procurando avaliar a presença de marcadores séricos de outras infecções de transmissão sexual ou sangüínea foram observados (Tabela 11). Dos 20 casos com triagem sorológica positiva para HTLV pelo método de ensaio imunoenzimático (Elisa), 14 foram submetidos à avaliação pelo método de Western Blot, com confirmação dessa infecção retroviral em $11(78,6 \%)$ pacientes, sendo seis do sexo feminino.

Houve maior prevalência de marcadores sorológicos de infecção pregressa e de infecção atual pelo vírus da hepatite $B$ e de soropositividade para sifilis entre os homens. 
Tabela 11: Número e porcentagem de pacientes HIV/aids com marcadores sorológicos de infecções de transmissão sangüínea e/ou sexual atendidos na Casa da Aids segundo sexo. São Paulo, 1998 a 2003.

\begin{tabular}{|c|c|c|c|c|c|}
\hline \multirow{3}{*}{ Marcador Sorológico } & \multicolumn{4}{|c|}{ sexo } & \multirow{3}{*}{$p$} \\
\hline & \multicolumn{2}{|c|}{ feminino } & \multicolumn{2}{|c|}{ masculino } & \\
\hline & $\mathbf{n}$ & $\begin{array}{c}\text { reagente } \\
n^{\circ}(\%)\end{array}$ & $\mathbf{n}$ & $\begin{array}{c}\text { reagente } \\
\mathbf{n}^{\circ}(\%)\end{array}$ & \\
\hline HTLV Elisa & 105 & $10(9,5)$ & 199 & $10(5,0)$ & 0,13 \\
\hline Hepatite B (anti-HBc) & 275 & $50(18,2)$ & 654 & $344(52,6)$ & $<0,001$ \\
\hline Hepatite B (Ag-HBs) & 271 & $8(3,0)$ & 641 & $57(8,9)$ & 0,001 \\
\hline Hepatite C (anti-HCV) & 289 & $34(11,8)$ & 690 & $114(16,5)$ & 0,06 \\
\hline Anti-Treponema & 252 & $24(9,5)$ & 583 & $193(33,1)$ & 0,001 \\
\hline Chagas & 179 & $4(2,2)$ & 387 & $9(2,3)$ & 0,95 \\
\hline
\end{tabular}

Particularmente entre os usuários de drogas injetáveis, a prevalência de marcadores sorológicos de hepatite $\mathrm{C}$ foi mais elevada (Tabela 12).

Apenas $42,8 \%$ ( $n=459)$ dos pacientes realizaram o teste tuberculínico de PPD e desses, $22,2 \%$ ( $n=102)$ apresentaram resultado positivo. Não se observou diferença entre os sexos $(p=0,61)$.

Tabela 12: Número e prevalência (\%) de pacientes usuários de drogas injetáveis com HIV/aids atendidos na Casa da Aids segundo presença de marcadores sorológicos de infecção pelos vírus das hepatites B e C. São Paulo, 1998 a 2003.

\begin{tabular}{llrr}
\hline \multirow{2}{*}{ Marcador sorológico } & \multirow{n}{*}{} & \multicolumn{2}{c}{ reagente } \\
\cline { 3 - 4 } & & $\mathbf{n}^{\mathbf{0}}$ & \multicolumn{1}{c}{$\%$} \\
\hline Hepatite B (anti-HBc) & 68 & 34 & 50,0 \\
Hepatite B (Ag-HBs) & 65 & 6 & 9,2 \\
Hepatite C (anti-HCV) & 72 & 52 & 72,2 \\
\hline
\end{tabular}




\subsection{Tratamento anti-retroviral}

Quanto à abordagem terapêutica, 204 (19,0\%) pacientes encontravam-se em tratamento anti-retroviral à admissão ao serviço, com diferença proporcional $(p=0,001)$ entre homens e mulheres $(21,5 \%$ e $12,9 \%$, respectivamente) (Figura 7 ).

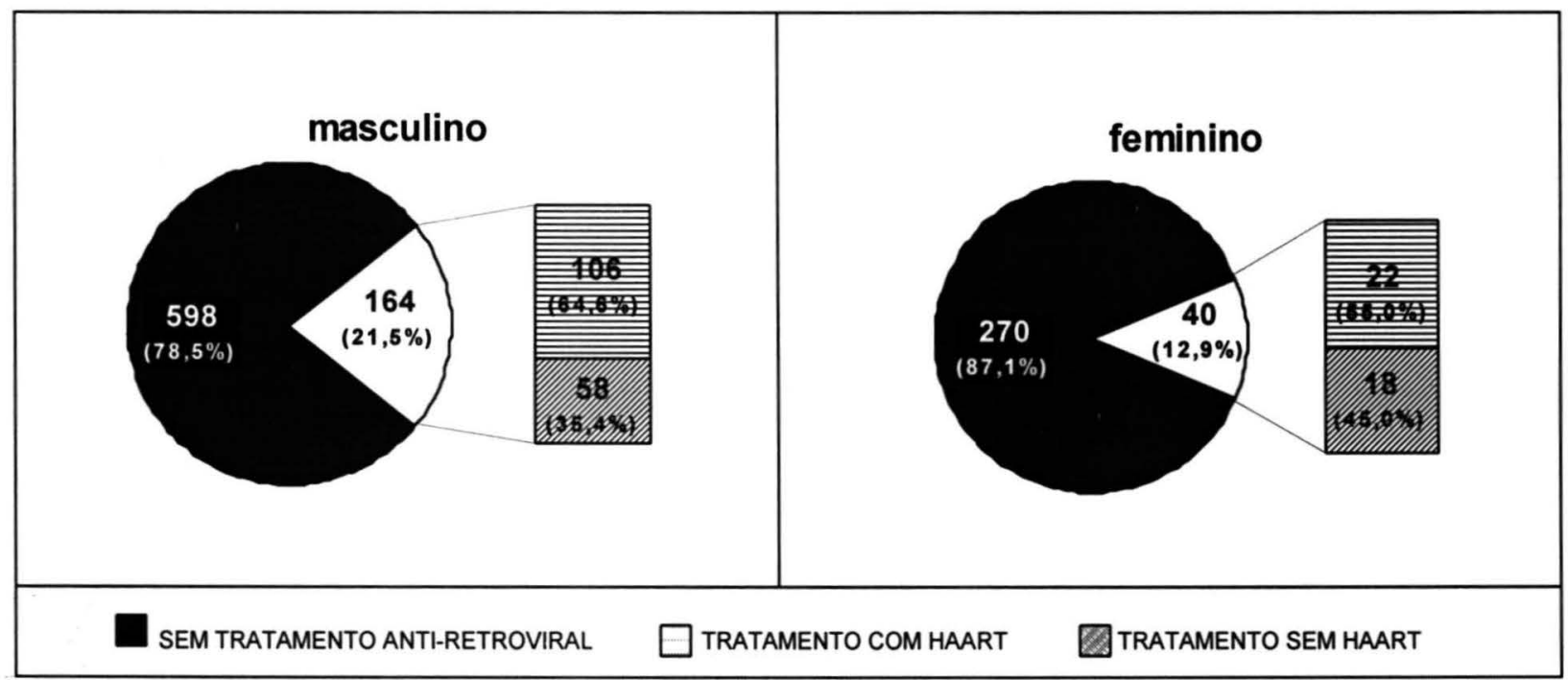

HAART: terapia anti-retroviral de alta potência

Figura 7: Distribuição de pacientes HIV/aids atendidos na Casa da Aids segundo sexo e tipo de tratamento anti-retroviral recebido antes da matrícula no serviço. São Paulo, 1998 a 2002.

Estratificando-se os pacientes segundo estadio clínico à matrícula, verificou-se não haver diferença entre os sexos para o tipo de tratamento anti-retroviral recebido (Tabela 13).

Dos casos admitidos ao serviço com aids e sem história de tratamento anti-retroviral $(n=386)$, a metade havia recebido o diagnóstico de infecção por HIV há menos de 40 dias. 
Tabela 13: Distribuição dos pacientes com HIV/aids segundo sexo, estadio clínico e tratamento anti-retroviral recebido à matrícula e ao final do seguimento na Casa da Aids. São Paulo, 1998 a 2003.

\begin{tabular}{|c|c|c|c|}
\hline \multirow{2}{*}{$\begin{array}{l}\text { ESTADIO CLÍNICO e } \\
\text { TRATAMENTO RECEBIDO }\end{array}$} & \multicolumn{2}{|c|}{ sexo } & \multirow[b]{2}{*}{$p$} \\
\hline & $\begin{array}{c}\text { feminino } \\
\mathbf{n}^{\circ}(\%)\end{array}$ & $\begin{array}{c}\text { masculino } \\
\mathrm{n}^{\circ}(\%)\end{array}$ & \\
\hline \multicolumn{4}{|l|}{ "A matrícula" } \\
\hline SEM AIDS $(n=534)$ & & & 0,22 \\
\hline sem TARV & $179(92,8)$ & $301(88,3)$ & \\
\hline com TARV sem HAART & $7(3,6)$ & $24(7,0)$ & \\
\hline com TARV com HAART & $7(3,6)$ & $16(4,7)$ & \\
\hline COM AIDS $(n=535)$ & & & 0,12 \\
\hline sem TARV & $91(77,8)$ & $295(70,6)$ & \\
\hline com TARV sem HAART & $11(9,4)$ & $34(8,1)$ & \\
\hline com TARV com HAART & $15(12,8)$ & $89(21,3)$ & \\
\hline \multicolumn{4}{|l|}{ Ao final do seguimento } \\
\hline SEM AIDS $(n=345)$ & & & 0,24 \\
\hline sem TARV & $30(23,2)$ & $67(27,2)$ & \\
\hline com TARV sem HAART & $25(19,4)$ & $32(13,0)$ & \\
\hline com TARV com HAART & $74(57,4)$ & $147(59,8)$ & \\
\hline COM AIDS $(n=692)$ & & & 0,93 \\
\hline sem TARV & $5(2,8)$ & $12(2,4)$ & \\
\hline com TARV sem HAART & $5(2,8)$ & $13(2,5)$ & \\
\hline com TARV com HAART & $170(94,4)$ & $487(95,1)$ & \\
\hline
\end{tabular}

TARV: tratamento anti-retroviral; HAART: terapia anti-retroviral de alta potência Dados ignorados: *: 3 homens; ${ }^{\star *}: 4$ homens e 1 mulher

Ao final do seguimento na Casa da Aids, a maioria (89,6\%) dos pacientes recebia tratamento anti-retroviral, sem diferença na distribuição entre homens e mulheres $(89,5 \%$ e $88,7 \%$, respectivamente, $p=0,70)$ (Figura 8). No que se refere ao tipo de tratamento recebido, não se notou diferença entre os sexos após estratificação por estadio clínico da doença (Tabela 13). 


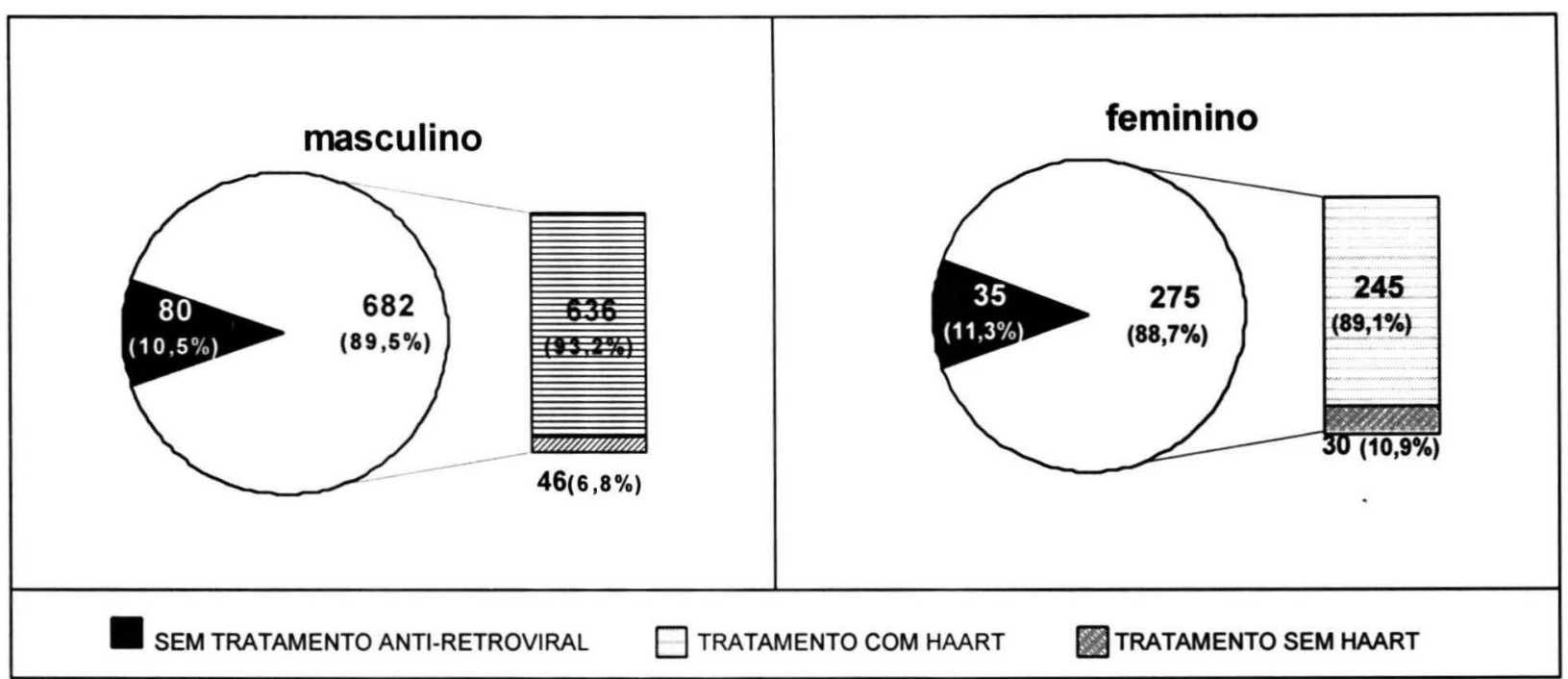

HAART: terapia anti-retroviral de alta potência

Figura 8: Distribuição de pacientes HIV/aids atendidos na Casa da Aids segundo sexo e tipo de tratamento anti-retroviral recebido ao final do seguimento no serviço. São Paulo, 1998 a 2003.

Houve 17 pacientes, que embora diagnosticados com aids, não receberam tratamento anti-retroviral durante o acompanhamento no serviço. Destes, nove (6 homens e 3 mulheres) desenvolveram afecções oportunistas definidoras de aids, porém apresentaram o menor valor de células CD4+ periféricas superior ao indicativo de tratamento segundo os critérios terapêuticos da época, enquanto os demais abandonaram $\circ$ seguimento.

Dos 18 casos com aids submetidos à terapêutica anti-retroviral não HAART, 10 não apresentaram indicação para a terapia de alta potência segundo as recomendações da época, dois possuíam contra-indicações ao uso desse esquema e seis abandonaram o seguimento no serviço. 


\subsection{Internações}

Um outro aspecto de relevância clínica, que vale a pena destacar, refere-se às admissões hospitalares ocorridas durante o acompanhamento dos pacientes no serviço. Pôde-se identificar que 432 (40,3\%) pacientes da casuística analisada estiveram internados em algum momento. Alguns destes o foram mais de uma vez, resultando em 696 episódios de internação hospitalar (Tabela 14); contudo a proporção segundo o número de internações não diferiu entre os sexos $(p=0,16)$.

Tabela 14: Distribuição do número e porcentagem de pacientes com HIV/aids atendidos na Casa da Aids segundo sexo e número de internações.

\begin{tabular}{|c|c|c|c|}
\hline \multirow{2}{*}{$\begin{array}{l}\text { Número de } \\
\text { internações }\end{array}$} & \multicolumn{2}{|c|}{ sexo } & \multirow{2}{*}{$\begin{array}{l}\text { Total } \\
n^{\circ}(\%)\end{array}$} \\
\hline & $\begin{array}{c}\text { feminino } \\
n^{\circ}(\%)\end{array}$ & $\begin{array}{c}\text { masculino } \\
\mathbf{n}^{\circ}(\%)\end{array}$ & \\
\hline 0 & $175(56,5)$ & $465(61,0)$ & $640(59,7)$ \\
\hline 1 & $95(30,7)$ & $182(23,9)$ & $277(25,8)$ \\
\hline 2 & $26(8,4)$ & $72(9,4)$ & $98(9,1)$ \\
\hline 3 & $6(1,9)$ & $26(3,4)$ & $32(3,0)$ \\
\hline$>3$ & $8(2,6)$ & $17(2,2)$ & $25(2,3)$ \\
\hline Total & $310(100)$ & $762(100)$ & $1072(100)$ \\
\hline
\end{tabular}

Apesar de os homens terem representado $68,7 \%$ dos pacientes internados, a proporção de mulheres hospitalizadas dobrou quando se compararam os períodos pré e pós-HAART $(p=0,002)$ (Tabela 15).

Tabela 15: Distribuição dos 432 pacientes internados segundo sexo e período de ocorrência.

\begin{tabular}{|c|c|c|c|}
\hline \multirow{2}{*}{$\begin{array}{l}\text { Ano de } \\
\text { ocorrência }\end{array}$} & \multicolumn{2}{|c|}{ sexo } & \multirow{2}{*}{$\begin{array}{l}\text { Total } \\
n^{\circ}(\%)\end{array}$} \\
\hline & $\begin{array}{c}\text { feminino } \\
n^{\circ}(\%)\end{array}$ & $\begin{array}{c}\text { masculino } \\
n^{\circ}(\%)\end{array}$ & \\
\hline antes 1997 & $16(17,8)$ & $73(82,2)$ & $90(100)$ \\
\hline a partir de 1997 & $119(34,8)$ & $223(65,2)$ & $342(100)$ \\
\hline Total & $135(31,3)$ & $297(68,7)$ & $432(100)$ \\
\hline
\end{tabular}

As dez doenças registradas em maior freqüência como diagnóstico à internação em cada período encontram-se detalhadas na tabela 16. 
Em relação a essas afeç̧ões mais identificadas no momento da internação, quando comparados os períodos pré-HAART e pós-HAART, notou-se aumento na freqüência do diagnóstico tanto de doenças definidoras como de condições não-definidoras de aids, à exceção da tuberculose pulmonar que se manteve estável.

Tabela 16: Distribuição dos 696 episódios de internação de pacientes acompanhados na Casa da Aids segundo período de ocorrência e morbidade.

\begin{tabular}{cc}
$N^{\circ}(\%)$ de episódios \\
\hline Antes $1997(n=206) \quad \begin{array}{c}\text { Jan/1997 a Mar/2003 } \\
(n=490)\end{array}$
\end{tabular}

\begin{tabular}{lcc}
\hline \hline $\begin{array}{l}\text { Doenças definidoras de AIDS } \\
\text { Pneumonia por Pneumocystis carinii }\end{array}$ & $16(7,8)$ & $58(11,8)$ \\
$\quad$ Toxoplasmose do Sistema Nervoso & $11(5,3)$ & $29(5,9)$ \\
Central & $11(5,3)$ & $26(5,3)$ \\
Tuberculose pulmonar & $3(1,5)$ & $18(3,7)$ \\
Tuberculose disseminada & $4(1,9)$ & $17(3,5)$ \\
Candidíase esofágica & $2(1,0)$ & $14(2,9)$ \\
Linfoma & $2(1,0)$ & $13(2,7)$ \\
Doença por citomegalovírus & - & $11(2,2)$ \\
Criptococose extrapulmonar & - & $7(1,4)$ \\
Sarcoma de Kaposi & - & $5(1,0)$ \\
Leucoencefalopatia multifocal & & \\
progressiva & $13(6,3)$ & \\
Doenças não definidoras de AIDS & $2(1,0)$ & $58(11,8)$ \\
Pneumonia/Broncopneumonia & $2(1,0)$ & $15(3,1)$ \\
Bacteriemia/Septicemia & - & $11(2,2)$ \\
Candidíase oral & - & $11(2,2)$ \\
Infecção do trato urinário & $3(1,5)$ & $10(2,0)$ \\
Pancreatite & $2(1,0)$ & $9(1,8)$ \\
Tuberculose do Sistema Nervoso Central & $1(0,5)$ & $8(1,6)$ \\
Herpes zoster & $5(2,4)$ & $8(1,6)$ \\
Convulsão & & $32(6,5)$ \\
Parto & &
\end{tabular}


Pôde-se verificar que o parto foi um dos principais motivos de internação das pacientes acompanhadas no serviço. Durante o seguimento, $64(20,6 \%)$ mulheres ficaram grávidas. Destas, 37,5\% tinha escolaridade abaixo de 8 anos e, para $35,9 \%$, o diagnóstico de HIV/aids foi efetuado durante a triagem laboratorial conduzida no pré-natal.

Nove mulheres tiveram duas gestações no período de seguimento analisado na Casa da Aids e outras duas, três gestações. 


\subsection{Progressão para aids}

A avaliação da evolução da história natural da infecção pelo HIV até o desenvolvimento da aids pôde ser realizada nesse trabalho para o grupo de 534 pacientes (341 (63,9\%) homens e 261 (49,6\%) com diagnóstico de infecção por HIV anterior ao ano de 1997), que não preenchiam os critérios diagnósticos de aids à matrícula no serviço. Nesses indivíduos, em um tempo de seguimento total de 2.455 pessoas-ano, foram registrados de 156 casos novos da doença, obtendo-se, assim, um coeficiente de incidência de aids de 63,5/1.000 pessoas-ano.

Não foi observada diferença $(p=0,12)$ entre os coeficientes de incidência da doença obtidos para os homens $(57,8 / 1.000$ pessoas-ano [IC $95 \%: 46,6$ - 70,8]) e para as mulheres $(74,6 / 1.000$ pessoas-ano [IC $95 \%$ : $57,3-95,4])$.

Para um terço dos 156 casos novos identificados nesse estudo de coorte, o diagnóstico de aids baseou-se no reconhecimento de pelo menos uma afecção oportunista definidora da doença. Entre essas, as de maior incidência foram a criptosporidíase intestinal, a pneumonia por Pneumocystis carinii, a candidíase esofágica, brônquica, traqueal ou pulmonar e a tuberculose pulmonar.

$\mathrm{Na}$ curva de probabilidade acumulada para desenvolvimento da aids (Figura 9), para os 534 pacientes em análise nessa etapa do estudo, verifica-se que o tempo mediano de progressão para aids foi de 10,3 anos (IC 95\%: 9,0-12,7), sendo este de 9,0 anos para as mulheres e 10,6 para os homens. 


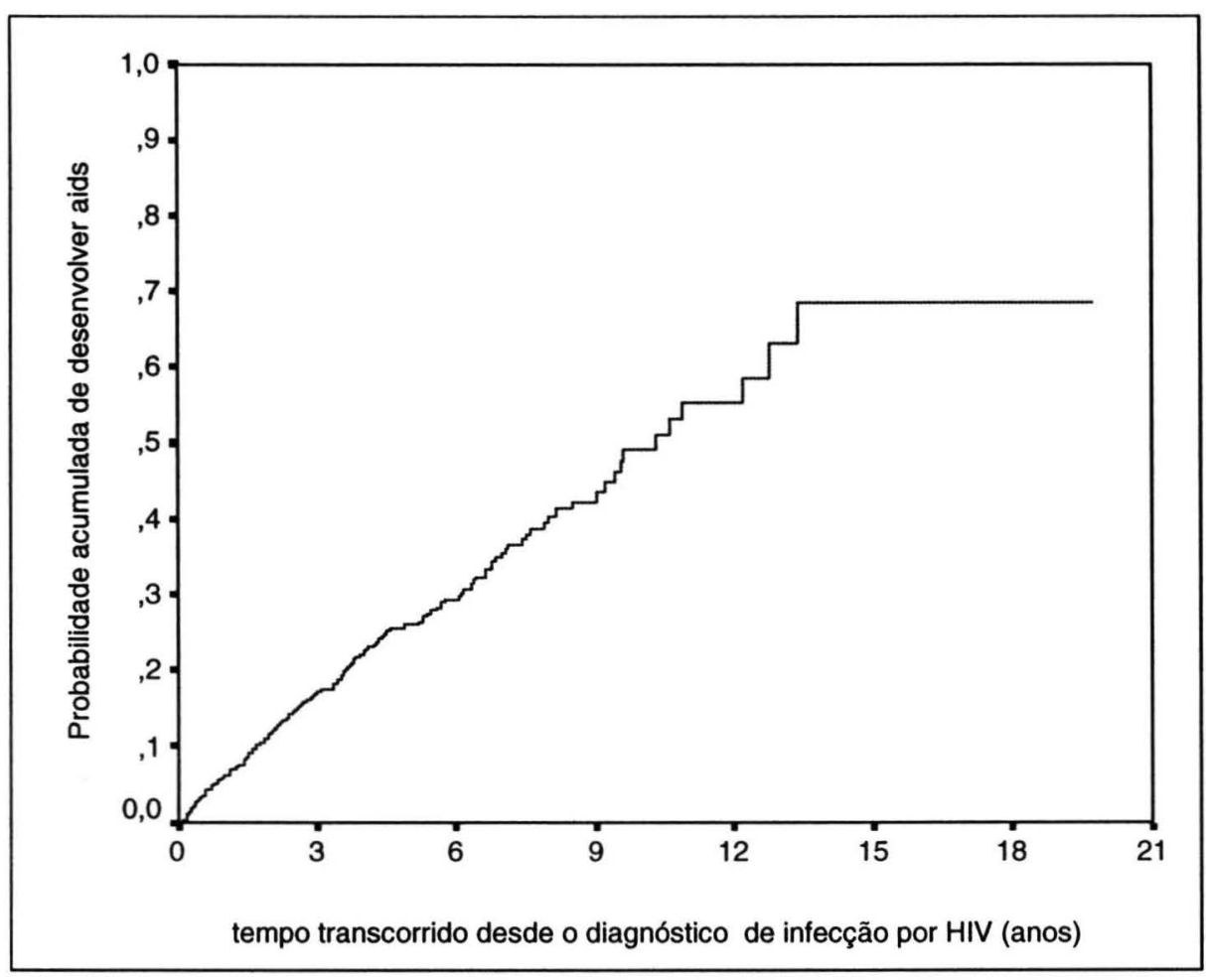

Figura 9: Probabilidade geral acumulada de desenvolver aids segundo tempo transcorrido desde o diagnóstico de HIV. Casa da Aids, São Paulo, 1998 a 2003.

Não se observou diferença estatisticamente significativa no tempo de sobrevida livre de aids segundo estado civil, escolaridade, categoria de exposição ao HIV, idade ao diagnóstico dessa infecção retroviral e soropositividade para HCV (Tabela 17).

Em contraste, os pacientes com maior carga viral plasmática de HIV igual ou superior a 100.000 cópias $/ \mathrm{mL}$ ( $\log =5$ cópias $/ \mathrm{mL}$ ) apresentaram maior probabilidade de progressão para aids $(p<0,001)$. Verificou-se também diferença no tempo de sobrevida livre de aids segundo tratamento antiretroviral recebido até o final do seguimento no serviço $(p<0,001)$.

As curvas de Kaplan-Meier que ilustram os resultados apresentados na tabela 17, são apresentadas nas figuras 10 a 17. 
Tabela 17: Número de pacientes com infecção por HIV e número de casos novos de aids durante o seguimento na Casa da Aids, segundo características sócio-demográficas, categoria de exposição ao HIV, maior carga viral plasmática de HIV observados, presença de marcador sorológico de infecção pelo vírus da hepatite $\mathrm{C}$ e tratamento anti-retroviral ao final do seguimento. Casa da Aids, São Paulo, 1998 a 2003.

\begin{tabular}{|c|c|c|c|}
\hline & $\begin{array}{c}\mathbf{n}^{\circ} \\
\text { pacientes }\end{array}$ & $\begin{array}{l}\mathrm{n}^{\circ} \text { casos } \\
\text { de aids }\end{array}$ & $\begin{array}{c}\text { valor de } \boldsymbol{p} \\
\text { (teste log-rank) }\end{array}$ \\
\hline Sexo & & & 0,10 \\
\hline masculino & 341 & 93 & \\
\hline feminino & 193 & 63 & \\
\hline Idade ao diagnóstico de infecção por HIV (anos)* & & & $0,49^{\#}$ \\
\hline$<20$ & 28 & 9 & \\
\hline 20 a 29 & 215 & 75 & \\
\hline 30 a 39 & 200 & 47 & \\
\hline 40 a 49 & 65 & 18 & \\
\hline$\geq 50$ & 18 & 6 & \\
\hline Solteiro(a) ${ }^{\star \star}$ & & & 0,32 \\
\hline não & 235 & 75 & \\
\hline $\operatorname{sim}$ & 284 & 78 & \\
\hline Escolaridade ${ }^{\star \star \star}$ & & & $0,41^{\#}$ \\
\hline$<4$ anos & 19 & 5 & \\
\hline de 4 a 7 anos & 106 & 33 & \\
\hline$\geq 8$ anos & 388 & 107 & \\
\hline Categoria de exposição ao HIV $V^{\star \star \star \star}$ & & & 0,12 \\
\hline sexual & 430 & 117 & \\
\hline sangüínea & 39 & 17 & \\
\hline Maior carga viral de HIV no serviço ${ }^{+}(\log )$ & & & $<0,001$ \\
\hline$<5$ cópias $/ \mathrm{mL}$ & 377 & 85 & \\
\hline$\geq 5$ cópias $/ \mathrm{mL}$ & 145 & 65 & \\
\hline Hepatite C (anti-HCV) ${ }^{++}$ & & & 0,08 \\
\hline negativo & 422 & 110 & \\
\hline positivo & 71 & 30 & \\
\hline Tratamento ao final do seguimento & & & $<0,001$ \\
\hline sem TARV & 153 & 57 & \\
\hline com TARV sem HAART & 112 & 53 & \\
\hline HAART em menos de $50 \%$ do tempo em TARV & 61 & 19 & \\
\hline HAART em $50 \%$ ou mais do tempo em TARV & 208 & 27 & \\
\hline
\end{tabular}

TARV: tratamento anti-retroviral; HAART: terapia anti-retroviral de alta potência

Dados ignorados: * 8 pacientes; ${ }^{\star *} 15$ pacientes; ${ }^{* * *} 21$ pacientes; ${ }^{* \star *} 65$ pacientes; ${ }^{+} 12$ pacientes; ${ }^{++} 41$ pacientes. \#: teste log-rank para tendência 


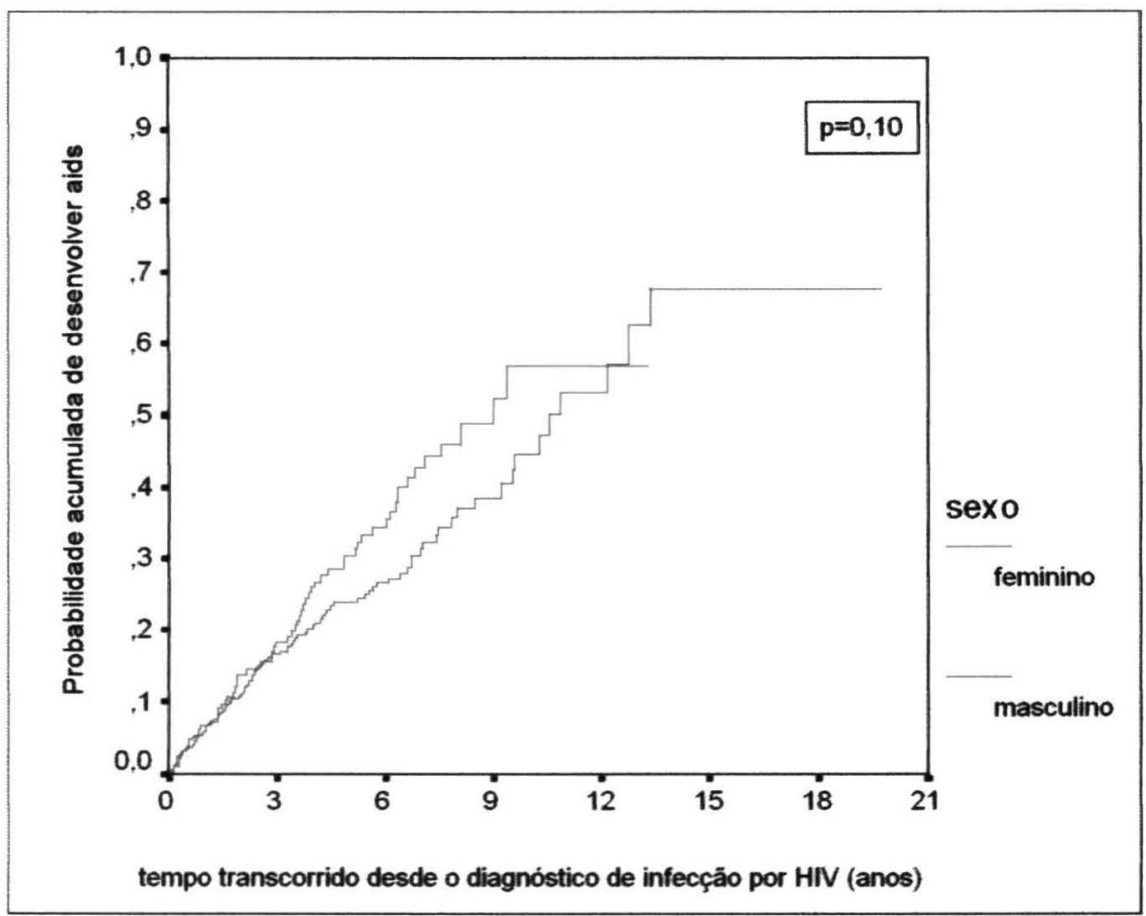

Figura 10: Probabilidade acumulada de desenvolver aids segundo tempo transcorrido desde o diagnóstico de infecção por HIV e sexo. Casa da Aids, São Paulo, 1998 a 2003.

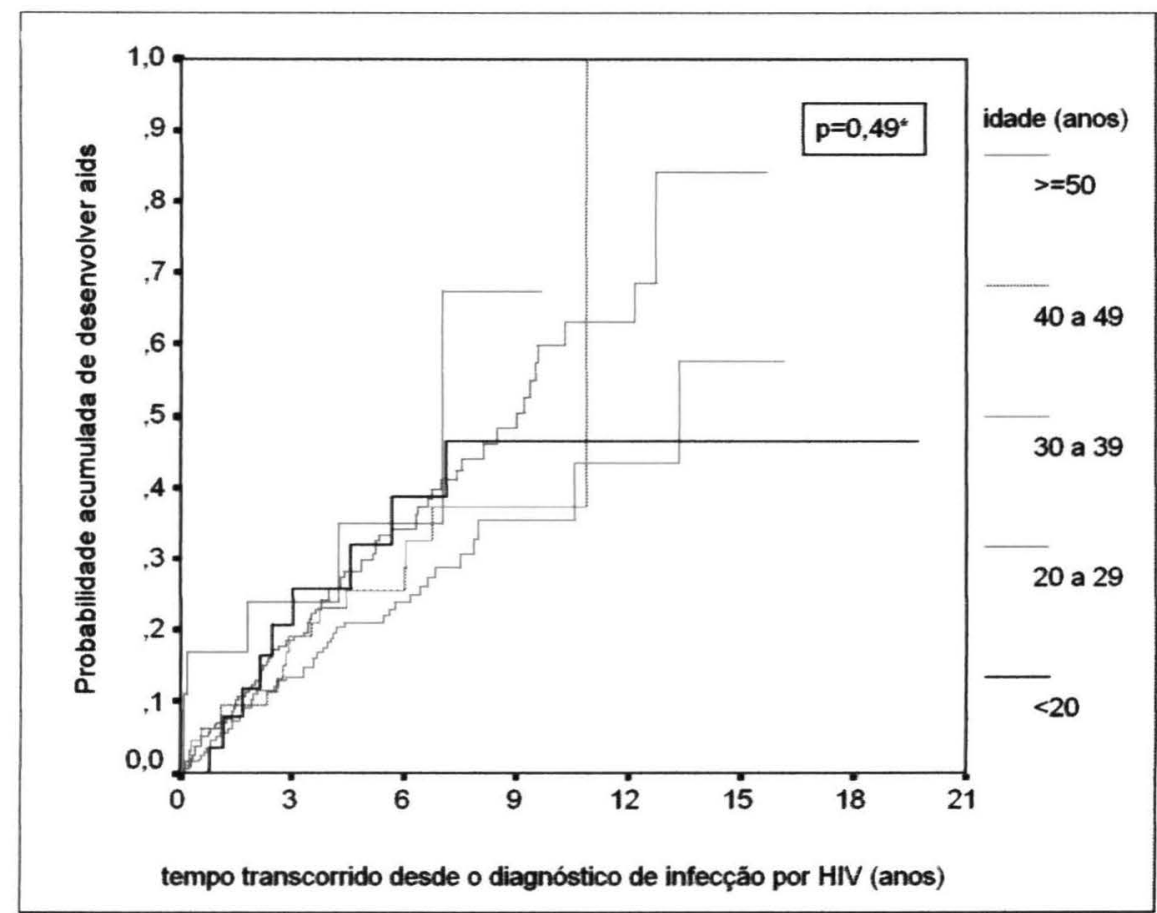

*: teste log-rank para tendência

Figura 11: Probabilidade acumulada de desenvolver aids segundo tempo transcorrido desde o diagnóstico de infecção por HIV e idade a este diagnóstico. Casa da Aids, São Paulo, 1998 a 2003. 


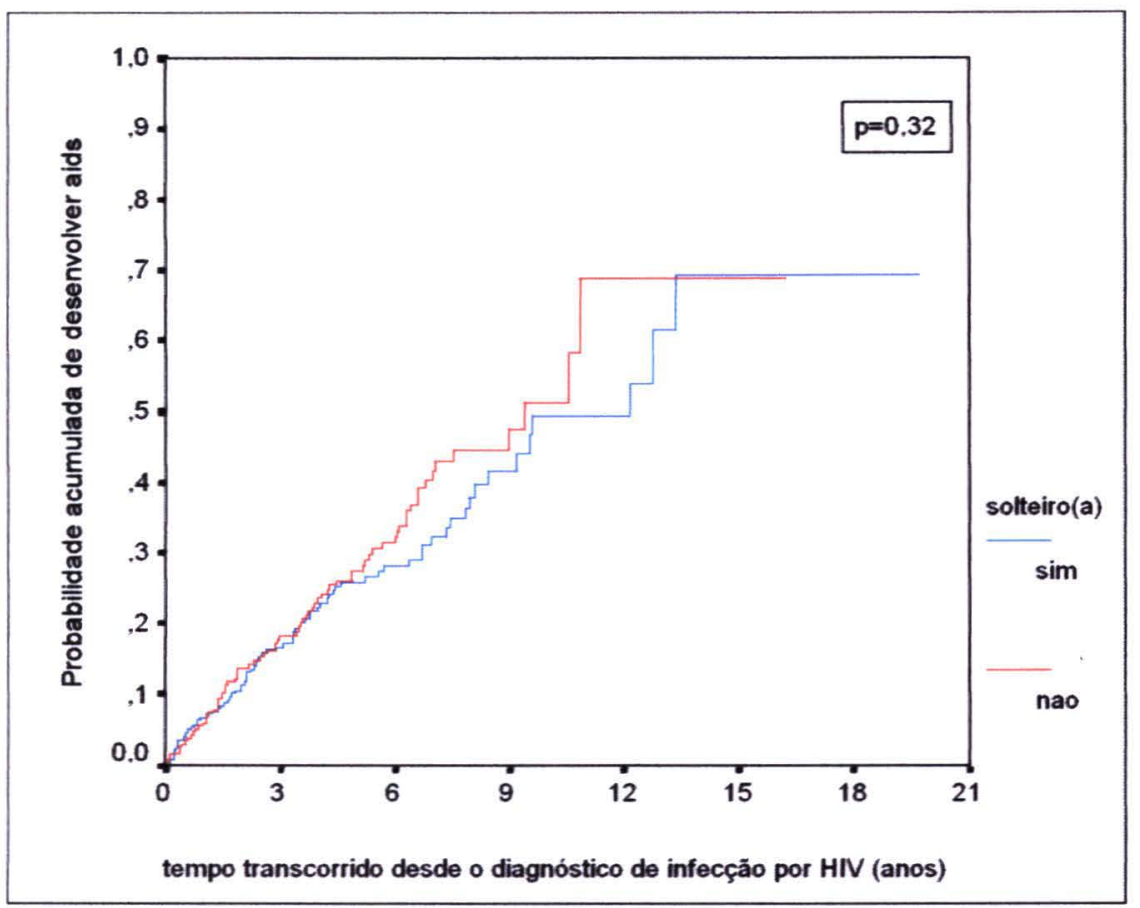

Figura 12: Probabilidade acumulada de desenvolver aids segundo tempo transcorrido desde o diagnóstico de infecção por HIV e estado civil. Casa da Aids, São Paulo, 1998 a 2003.

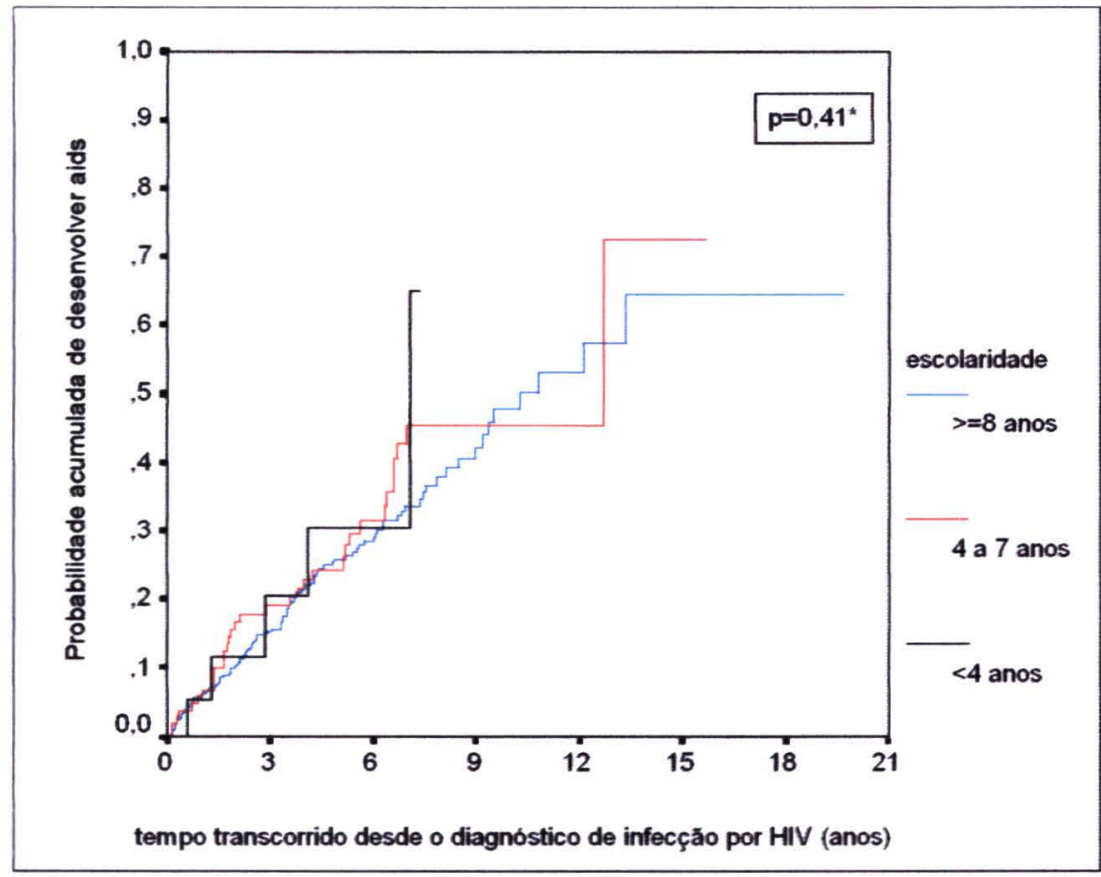

*: teste log-rank para tendência

Figura 13: Probabilidade acumulada de desenvolver aids segundo tempo transcorrido desde o diagnóstico de infecção por HIV e escolaridade. Casa da Aids, São Paulo, 1998 a 2003. 


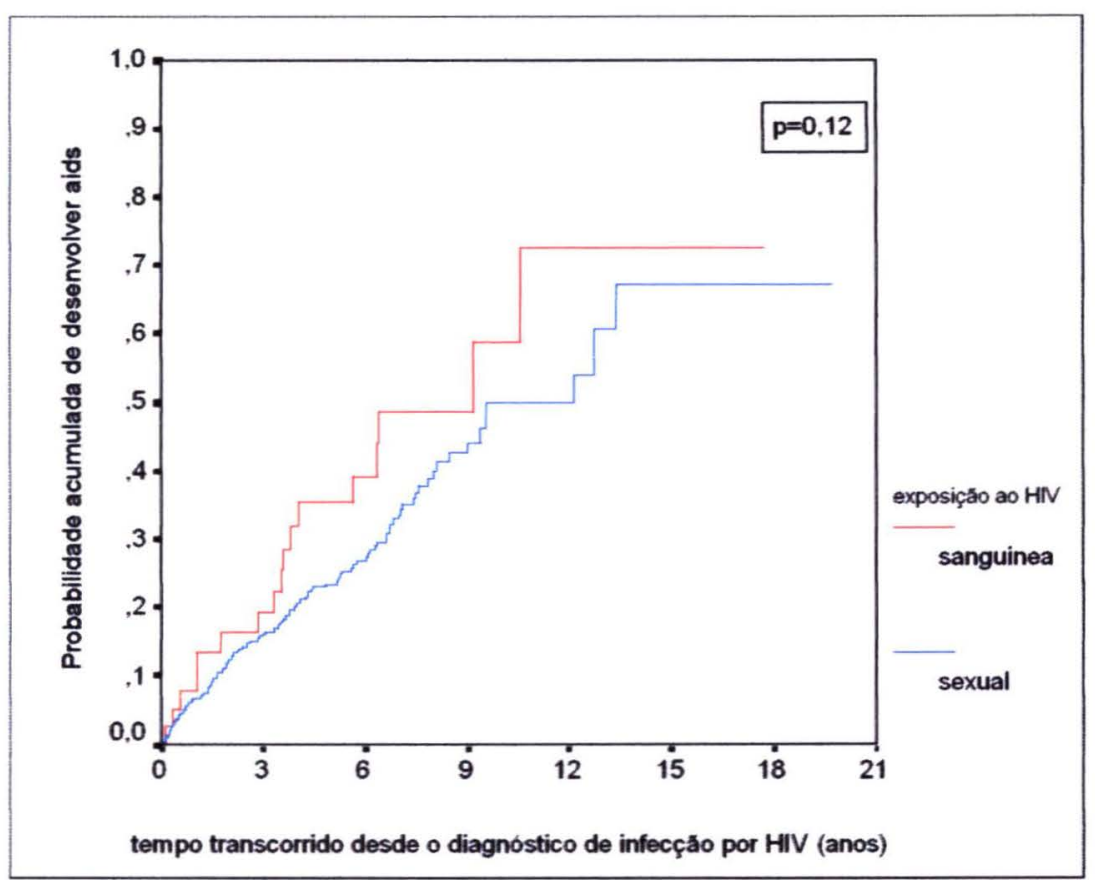

Figura 14: Probabilidade acumulada de desenvolver aids segundo tempo transcorrido desde o diagnóstico de infecção por HIV e categoria de exposição ao HIV. Casa da Aids, São Paulo, 1998 a 2003.

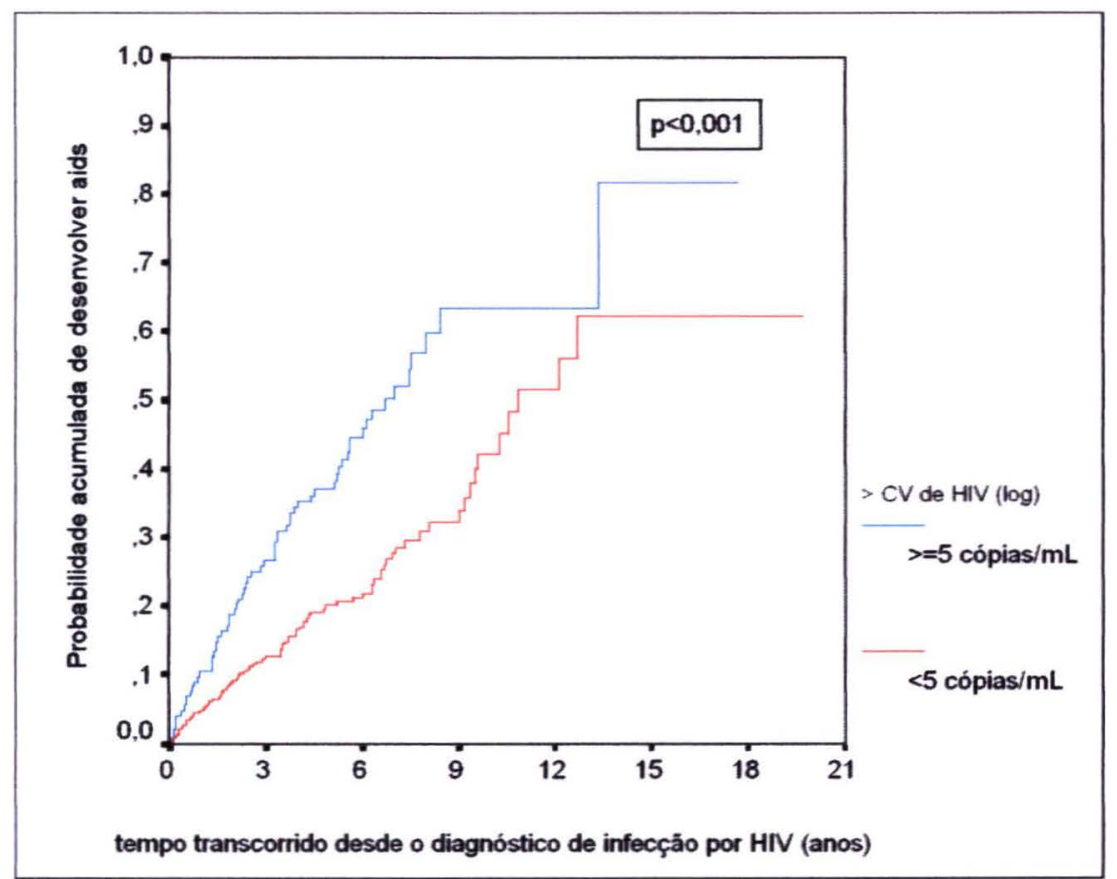

Figura 15: Probabilidade acumulada de desenvolver aids segundo tempo transcorrido desde o diagnóstico de infecção por HIV e valor da maior carga viral de HIV durante seguimento no serviço. Casa da Aids, São Paulo, 1998 a 2003. 


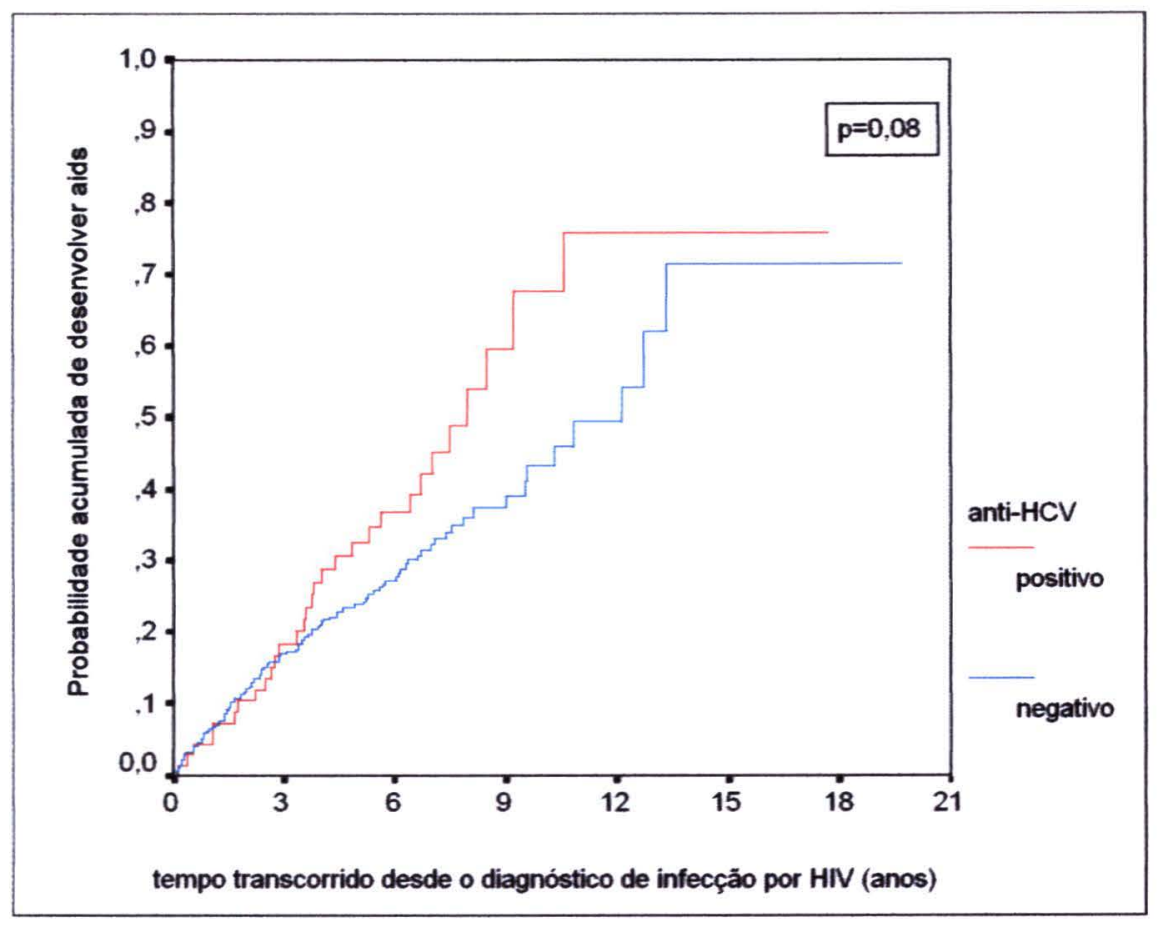

Figura 16: Probabilidade acumulada de desenvolver aids segundo tempo transcorrido desde o diagnóstico de infecção por HIV e soropositividade para infecção pelo vírus da hepatite C. Casa da Aids, São Paulo, 1998 a 2003.

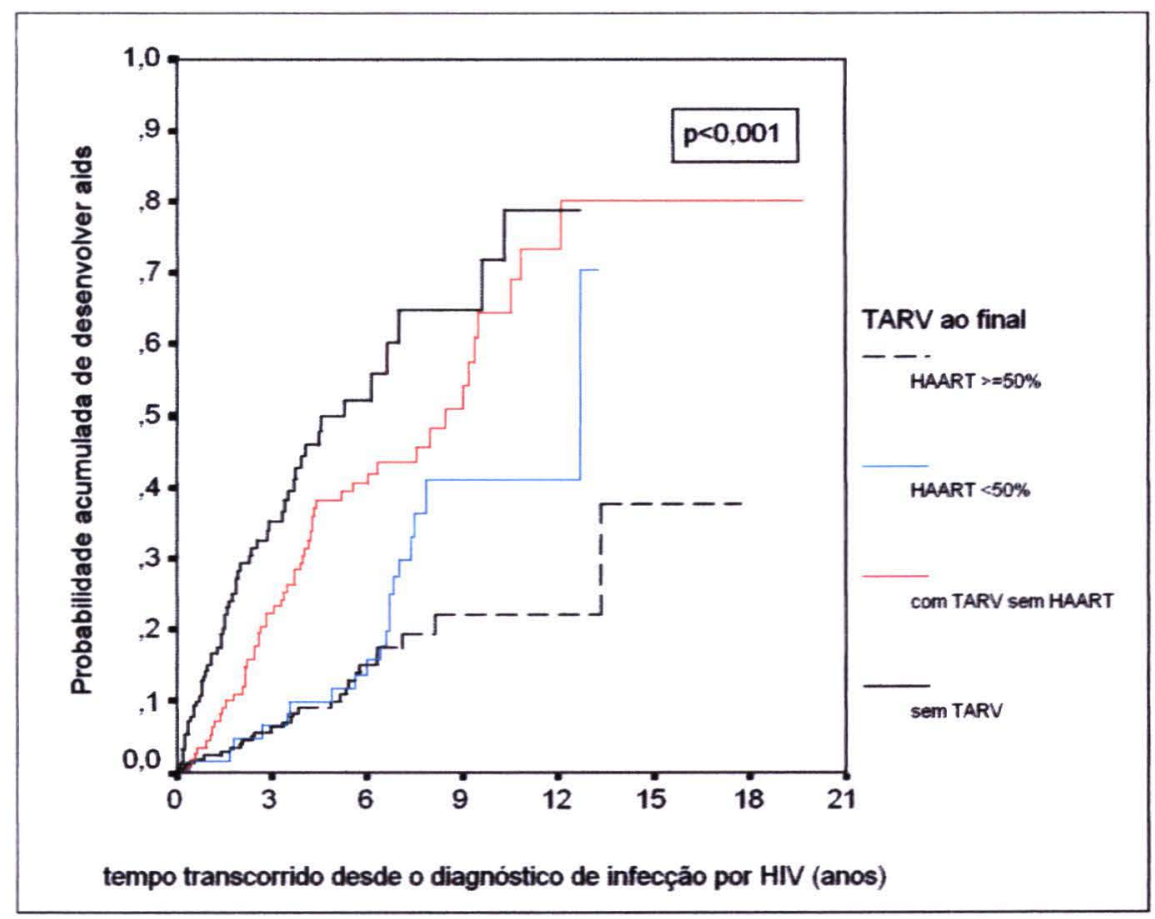

TARV: tratamento anti-retroviral; HAART: terapia anti-retroviral de alta potência

Figura 17: Probabilidade acumulada de desenvolver aids segundo tempo transcorrido desde o diagnóstico de infeç̧ão por HIV e tratamento anti-retroviral ao final do seguimento. Casa da Aids, São Paulo, 1998 a 2003. 
Verificou-se o pressuposto de proporcionalidade dos riscos no decorrer do tempo para cada uma das variáveis analisadas (Anexo 5).

Em seguida, calcularam-se as estimativas dos Hazard Ratios, com os respectivos intervalos com $95 \%$ de confiança, para as variáveis que apresentaram valores de $p$ abaixo de 0,25 no teste log-rank (Tabela 18).

Tabela 18: Análise bivariada, pelo modelo de Cox de fatores potencialmente associados à evolução para aids na população estudada de 534 pacientes com infecção por HIV. Casa da Aids, São Paulo, 1998 a 2002.

\begin{tabular}{|c|c|c|c|}
\hline & HR & IC $95 \%$ & valor de $p$ \\
\hline Sexo & & & 0,10 \\
\hline masculino & 1,00 & & \\
\hline feminino & 1,31 & $0,95-1,81$ & \\
\hline Categoria de exposição ao HIV & & & 0,14 \\
\hline sexual & 1,00 & & \\
\hline sangūínea & 1,49 & $0,90-2,48$ & \\
\hline Maior carga viral de HIV no serviço (log) & & & $<0,001$ \\
\hline$<5$ cópias $/ \mathrm{mL}$ & 1,00 & & \\
\hline$\geq 5$ cópias $/ \mathrm{mL}$ & 2,14 & $1,55-2,96$ & \\
\hline Hepatite C (anti-HCV) & & & 0,09 \\
\hline negativo & 1,00 & & \\
\hline positivo & 1,43 & $0,96-2,15$ & \\
\hline Tratamento ao final do seguimento & & & $<0,001$ \\
\hline sem TARV & 1,00 & & \\
\hline com TARV sem HAART & 0,60 & $0,41-0,88$ & \\
\hline HAART em menos de $50 \%$ do tempo em TARV & 0,31 & $0,18-0,52$ & \\
\hline HAART em $50 \%$ ou mais do tempo em TARV & 0,17 & $0,11-0,27$ & \\
\hline
\end{tabular}

HR: hazard ratio (razão das funções de risco); TARV: tratamento anti-retroviral;

HAART: terapia anti-retroviral de alta potência

Essas variáveis também foram consideradas na análise multivariável pelo modelo de riscos proporcionais de Cox com a finalidade de avaliar as variáveis que podem servir como preditoras independentes do desenvolvimento de aids na população estudada.

Assim, identificou-se que a progressão para a doença mostrou-se associada, de forma independente e controlada para a variável sexo, com a 
determinação mais elevada da carga viral de HIV superando 100.000 cópias/mL durante o seguimento na Casa da Aids $\left(\mathrm{HR}_{\mathrm{aj}}=2,64\right.$ [IC 95\%: 1,91$3,67])$. Verificou-se também que os indivíduos submetidos à terapia antiretroviral apresentaram menor risco de evolução para aids (com esquema terapêutico diferente de HAART: $\mathrm{HR}_{\mathrm{aj}}=0,54$ [IC 95\%: 0,36-0,80]; tratado com HAART em menos de $50 \%$ do total de tempo sob tratamento: $\mathrm{HR}_{\mathrm{aj}}=0,30$ [IC 95\%: 0,18-0,52]; tratado com HAART em pelo menos $50 \%$ do total de tempo sob tratamento: $\mathrm{HR}_{\mathrm{aj}}=0,14$ [IC 95\%: 0,09-0,23]) (Tabela 19).

Tabela 19: Análise multivariável pelo modelo de riscos proporcionais de Cox segundo fatores preditivos do desenvolvimento de aids na população estudada de 534 portadores do HIV. São Paulo, 1998 a 2002.

\begin{tabular}{|c|c|c|c|c|}
\hline & $H_{R_{b r}}$ & $H R_{a j}$ & IC $95 \%\left(H_{\mathrm{aj}}\right)$ & valor de $p$ \\
\hline Sexo & & & & 0,09 \\
\hline masculino & 1,00 & 1,00 & & \\
\hline feminino & 1,31 & 1,34 & $0,96-1,86$ & \\
\hline Maior carga viral de HIV no serviço (log) & & & & $<0,001$ \\
\hline$<5$ cópias $/ \mathrm{mL}$ & 1,00 & 1,00 & & \\
\hline$\geq 5$ cópias $/ \mathrm{mL}$ & 2,14 & 2,63 & $1,90-3,65$ & \\
\hline \multicolumn{5}{|l|}{ Tratamento ao final do seguimento } \\
\hline sem TARV & 1,00 & & & $<0,001$ \\
\hline com TARV sem HAART & 0,60 & 0,54 & $0,36-0,80$ & \\
\hline HAART em menos de $50 \%$ do tempo em TARV & 0,31 & 0,30 & $0,18-0,52$ & \\
\hline HAART em $50 \%$ ou mais do tempo em TARV & 0,17 & 0,14 & $0,09-0,23$ & \\
\hline
\end{tabular}

$\mathrm{HR}_{\mathrm{br}}$ hazard ratio bruto; $\mathrm{HR}_{\mathrm{aj}}$, hazard ratio ajustado; hazard ratio: razão das funções de risco; TARV: tratamento anti-retroviral; HAART: terapia anti-retroviral de alta potência 


\subsection{Mortalidade}

No que se refere à avaliação da mortalidade na coorte estudada, constatou-se que, ao final da pesquisa, em 30/03/2003, $859(80,1 \%)$ dos 1072 pacientes acompanhados continuavam vivos, 91 (8,5\%) tinham falecido por doenças relacionadas à aids e 16 (1,5\%) (uma mulher e 15 homens) por causas não relacionadas à doença. Não foi possível obter informações relativas ao desfecho no momento do encerramento do estudo para 106 pacientes (29 mulheres e 77 homens), o quê corresponde a uma perda de $9,9 \%$ da amostra analisada (Figura 18).

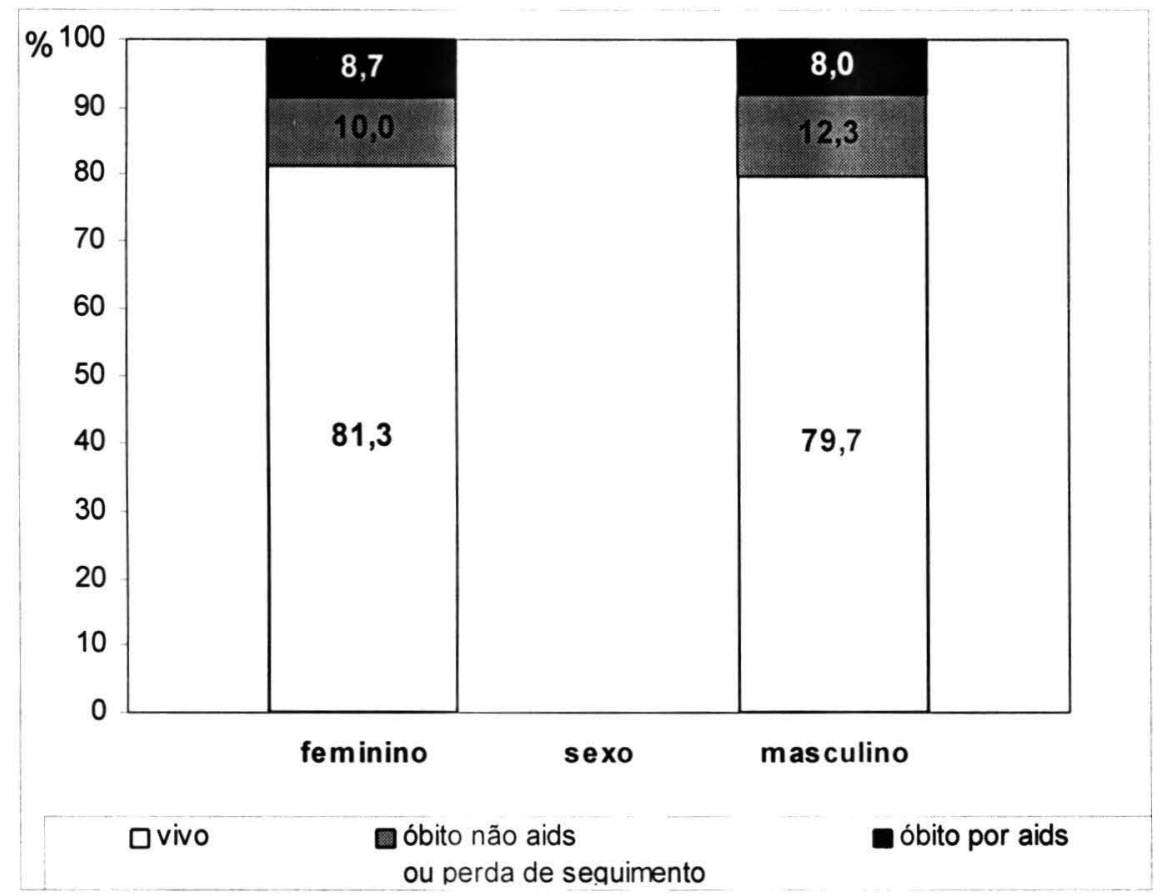

Figura 18: Distribuição percentual dos pacientes com HIV/aids atendidos na Casa da Aids segundo desfecho à avaliação de mortalidade e sexo. São Paulo, 1998 a 2003.

Dos 91 óbitos por aids (63 homens e 28 mulheres), 87 (96\%) tiveram como causa básica relatada a doença pelo HIV (Tabela 20). Nos restantes o óbito foi decorrente de doença oportunista definidora de aids (tuberculose pulmonar, tuberculose miliar ou meningoencefalite por toxoplasma) ou 
afecção não definidora de aids, porém reconhecidamente relacionada à infecção pelo HIV (neoplasia maligna do reto).

Tabela 20: Distribuição dos 91 óbitos por aids segundo CID-10. Casa da Aids, São Paulo, 1998 a 2003.

\begin{tabular}{llc}
\hline $\begin{array}{l}\text { Classificação } \\
\text { CID-10 }\end{array}$ & & $\mathbf{n}^{\circ}$ \\
\hline A16.2 & Tuberculose pulmonar sem menção de confirmação bacteriológica ou histológica & 1 \\
A19.9 & Tuberculose miliar não especificada & 1 \\
B20.0 & Doença pelo HIV resultando em infecções micobacterianas & 4 \\
B20.1 & Doença pelo HIV resultando em outras infecções bacterianas & 10 \\
B20.3 & Doença pelo HIV resultando em outras infecções virais & 2 \\
B20.4 & Doença pelo HIV resultando em candidíase & 1 \\
B20.5 & Doença pelo HIV resultando em outras micoses & 3 \\
B20.6 & Doença pelo HIV resultando em Pneumonia por Pneumocystis carinii & 3 \\
B20.7 & Doença pelo HIV resultando em infecções múltiplas & 19 \\
B20.8 & Doença pelo HIV resultando em outras doenças infecciosas e parasitárias & 17 \\
B21.0 & Doença pelo HIV resultando em sarcoma de Kaposi & 1 \\
B21.1 & Doença pelo HIV resultando em linfoma de Burkitt & 1 \\
B21.2 & Doença pelo HIV resultando em outros tipos de linfoma não-Hodgkin & 4 \\
B21.7 & Doença pelo HIV resultando em múltiplas neoplasias malignas & 1 \\
B22.2 & Doença pelo HIV resultando em síndrome de emaciação & 2 \\
B22.7 & Doença pelo HIV resultando em doenças múltiplas classificadas em outra parte & 9 \\
B23.8 & Doença pelo HIV resultando em outras afecções especificadas & 4 \\
B24 & Doença pelo HIV não especificada & 6 \\
B58.2 & Meningocefalite por Toxoplasma & 1 \\
C20 & Neoplasia maligna do reto & 1 \\
\hline CID-10:10 & & 4 \\
\hline
\end{tabular}

CID-10: $10^{a}$ Revisão da Classificação Internacional de Doenças

Após um tempo de seguimento de 1.658 pessoas-ano para o sexo feminino e de 4.347 pessoas-ano para o masculino, observou-se que não houve diferença $(p=0,50)$ entre o coeficiente de mortalidade por aids das mulheres em relação à dos homens (16,9/1.000 pessoas-ano [IC 95\%: 11,224,4] e 14,5/1.000 pessoas-ano [IC 95\%: 11,1-18,5], respectivamente). 
4.9 Avaliação da sobrevida da população estudada de portadores de HIV

As noventa e uma falhas, ou seja, pacientes que evoluíram para o óbito em decorrência da aids, foram observadas em um total de 6.004 pacientes-ano de acompanhamento.

Verificou-se que o tempo de sobrevida dos pacientes até a data final do estudo (30/03/2003), variou de aproximadamente dois meses a 20 anos. Observou-se que após 15 anos do diagnóstico de infecção por HIV, a proporção de sobreviventes foi de 75,4\% (Tabela 21 e Figura 19).

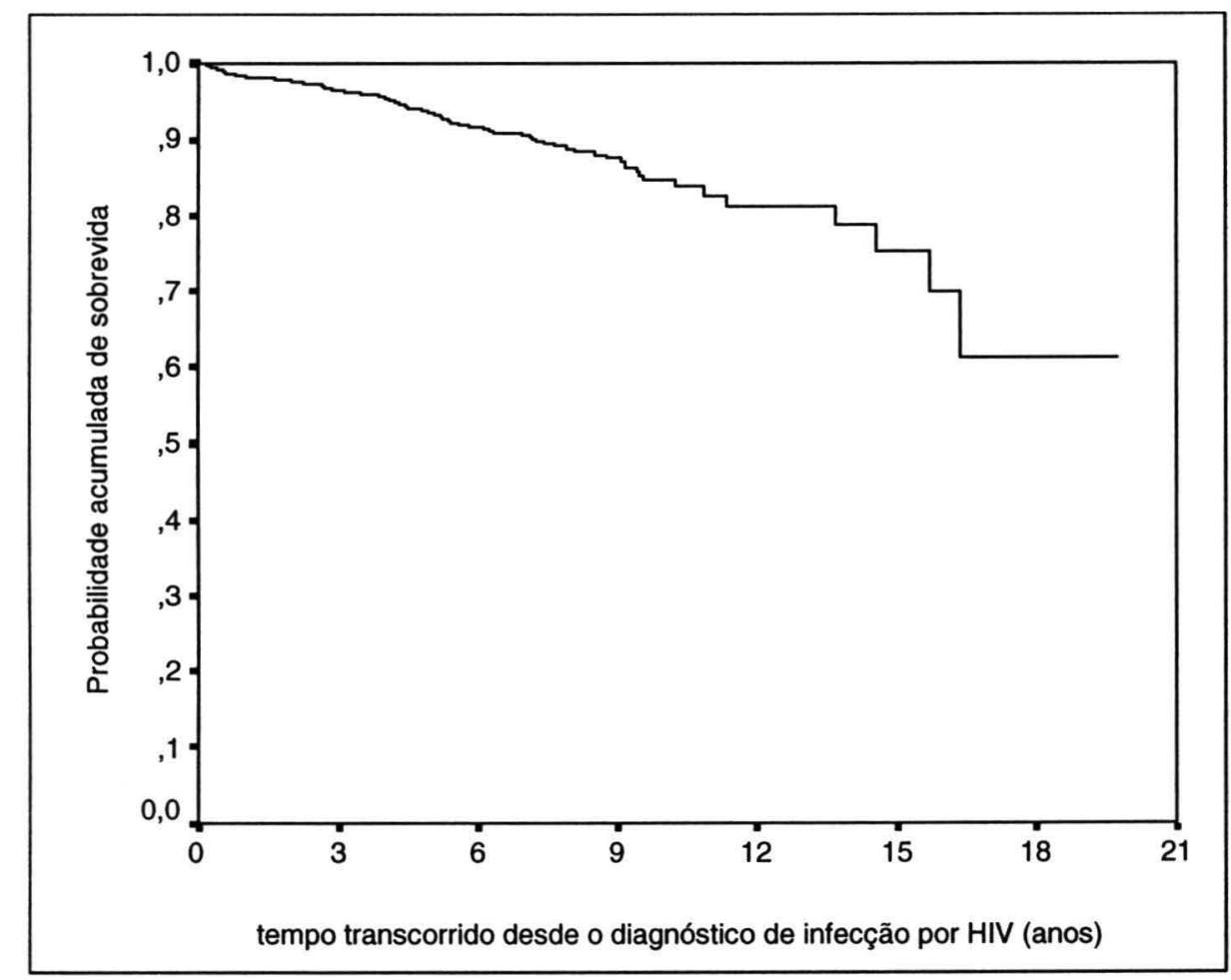

Figura 19: Probabilidade acumulada de sobrevivência em pacientes HIV. Casa da Aids, São Paulo, 1998 a 2003. 
Tabela 21: Proporção de sobreviventes entre pacientes HIV atendidos na Casa da Aids segundo tempo de acompanhamento. São Paulo, 1998 a 2003.

\begin{tabular}{cc}
\hline Tempo (anos) & Sobreviventes (\%) \\
\hline 1 & 98,3 \\
2 & 97,6 \\
5 & 93,5 \\
10 & 84,6 \\
15 & 75,4 \\
\hline
\end{tabular}

\subsubsection{Avaliação da sobrevida em análise bivariada}

Os dados aqui obtidos não mostraram associação entre a sobrevida dos portadores do HIV da Casa da Aids e as variáveis sexo $(p=0,39)$, estado civil $(p=0,41)$, escolaridade $(p=0,79)$, principal categoria de exposição do paciente ao vírus $(p=0,18)$ e tratamento anti-retroviral recebido até o final do seguimento $(p=0,19)$. Por outro lado, quanto mais jovem $o$ indivíduo ao diagnóstico da retrovirose, maior foi a sobrevida $(p=0,01)$ (Tabela 22).

As ilustrações para essas análises encontram-se nas Figuras 20 a 25 com as curvas de estimativa de sobrevida pelo método de Kaplan-Meier para cada uma das variáveis de interesse do estudo. 
Tabela 22: Número de óbitos por aids segundo variáveis sócio-demográficas e principal categoria de exposição ao HIV. São Paulo, 1998 a 2003.

\begin{tabular}{|c|c|c|c|}
\hline & $\begin{array}{c}\mathbf{n}^{\circ} \\
\text { pacientes }\end{array}$ & $\begin{array}{l}\mathrm{n}^{\circ} \text { óbitos } \\
\text { por aids }\end{array}$ & $\begin{array}{c}\text { valor de } \boldsymbol{p} \\
\text { (teste log-rank) }\end{array}$ \\
\hline Sexo & & & 0,39 \\
\hline feminino & 310 & 28 & \\
\hline masculino & 762 & 63 & \\
\hline Idade ao diagnóstico de infecção por HIV (anos)* & & & $0,01^{\#}$ \\
\hline$<20$ & 40 & 2 & \\
\hline 20 a 29 & 368 & 29 & \\
\hline 30 а 39 & 444 & 39 & \\
\hline 40 a 49 & 157 & 15 & \\
\hline$\geq 50$ & 52 & 6 & \\
\hline Solteiro(a) $)^{\star \star}$ & & & 0,41 \\
\hline não & 483 & 43 & \\
\hline $\operatorname{sim}$ & 562 & 46 & \\
\hline Escolaridade $^{\star \star \star}$ & & & $0,79^{\#}$ \\
\hline$<4$ anos & 51 & 18 & \\
\hline de 4 a 7 anos & 208 & 2 & \\
\hline$\geq 8$ anos & 763 & 55 & \\
\hline Categoria de exposição ao HIV & & & 0,18 \\
\hline sexual & 834 & 66 & \\
\hline sangüínea & 87 & 12 & \\
\hline Tratamento ao final do seguimento & & & 0,19 \\
\hline sem TARV & 112 & 1 & \\
\hline com TARV sem HAART & 76 & 5 & \\
\hline HAART em menos de $50 \%$ do tempo em TARV & 127 & 20 & \\
\hline HAART em $50 \%$ ou mais do tempo em TARV & 757 & 65 & \\
\hline
\end{tabular}

TARV: tratamento anti-retroviral; HAART: terapia anti-retroviral de alta potência

Dados ignorados: *: 11 pacientes; ${ }^{\star \star}: 27$ pacientes; ${ }^{\star \star \star}: 50$ pacientes; ${ }^{\star \star \star \star}: 151$ pacientes.

\#: teste log-rank para tendência 


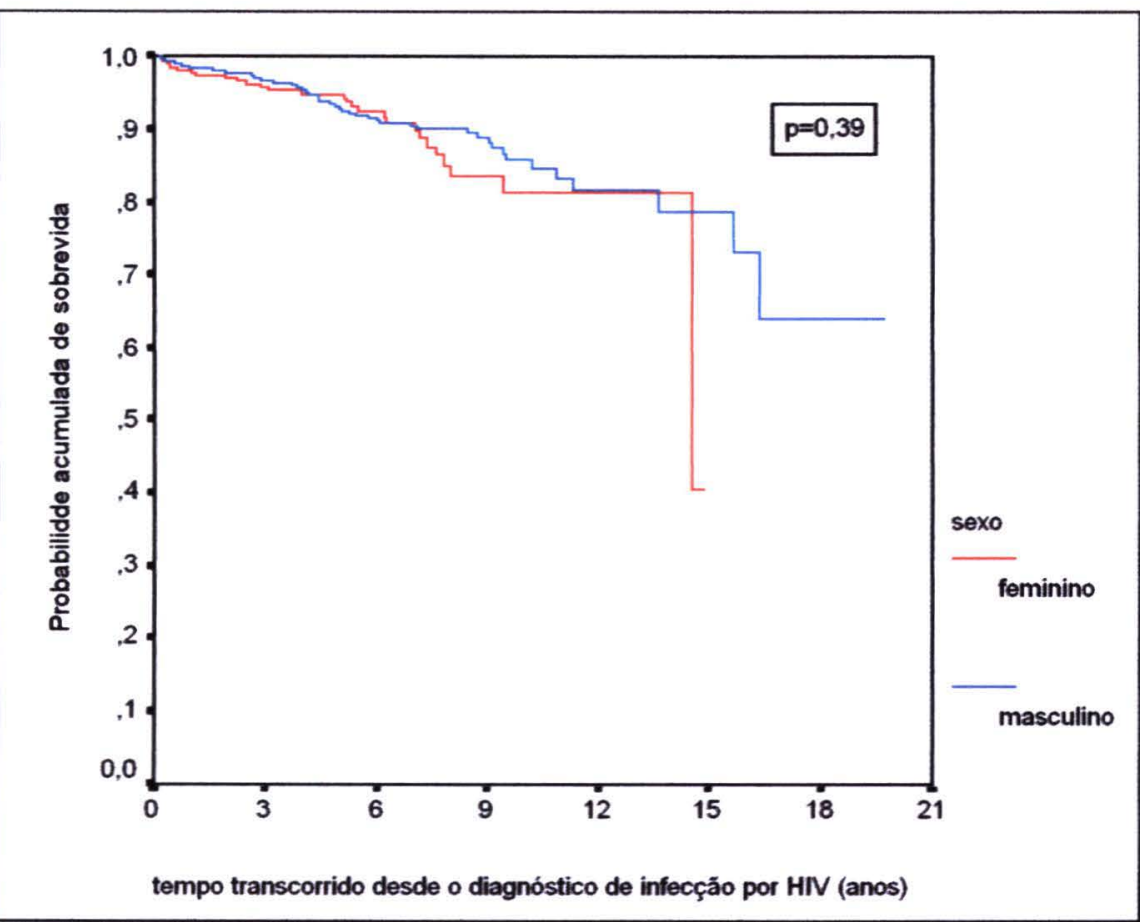

Figura 20: Probabilidade acumulada de sobrevida para pacientes com infecção por HIV, segundo sexo. Casa da Aids, São Paulo, 1998 a 2003.

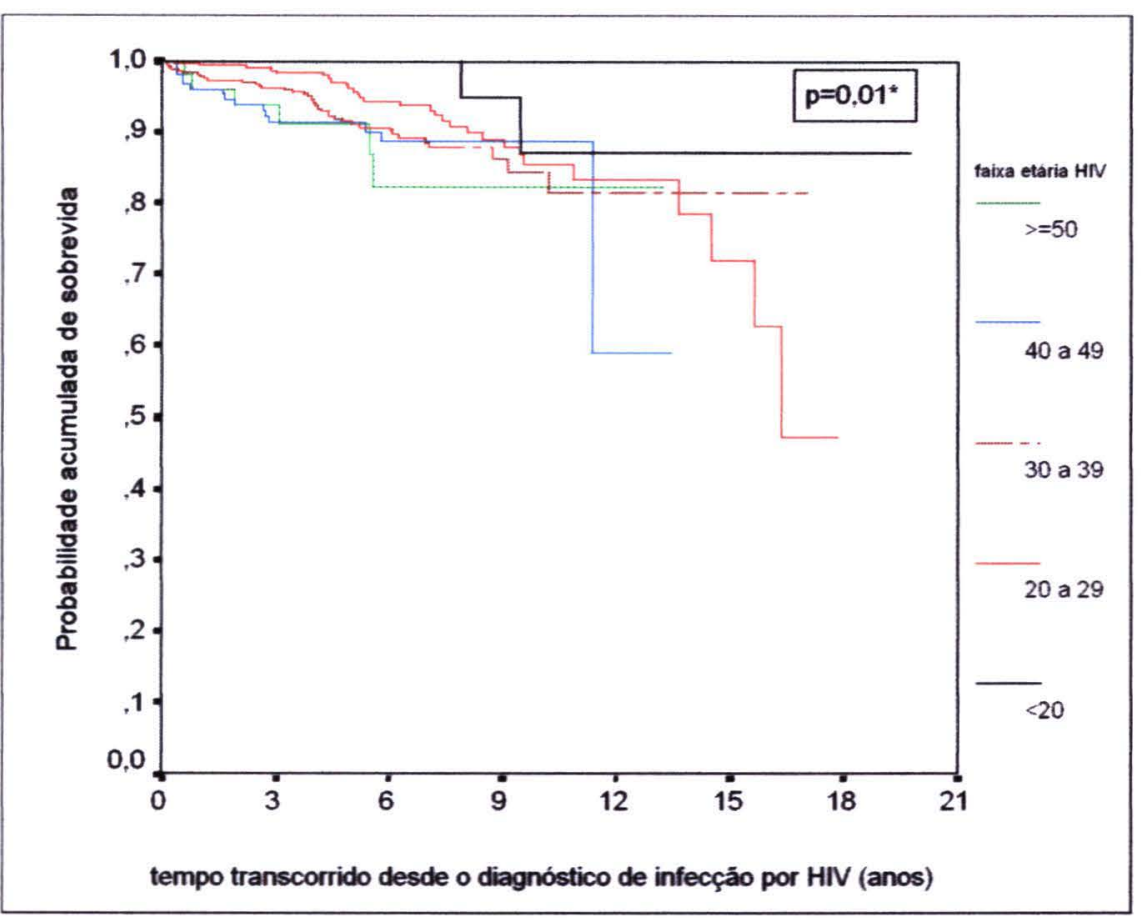

*: teste log-rank para tendência

Figura 21: Probabilidade acumulada de sobrevida para pacientes com infecção por HIV, segundo idade ao diagnóstico de infecção por HIV (anos). Casa da Aids, São Paulo, 1998 a 2003. 


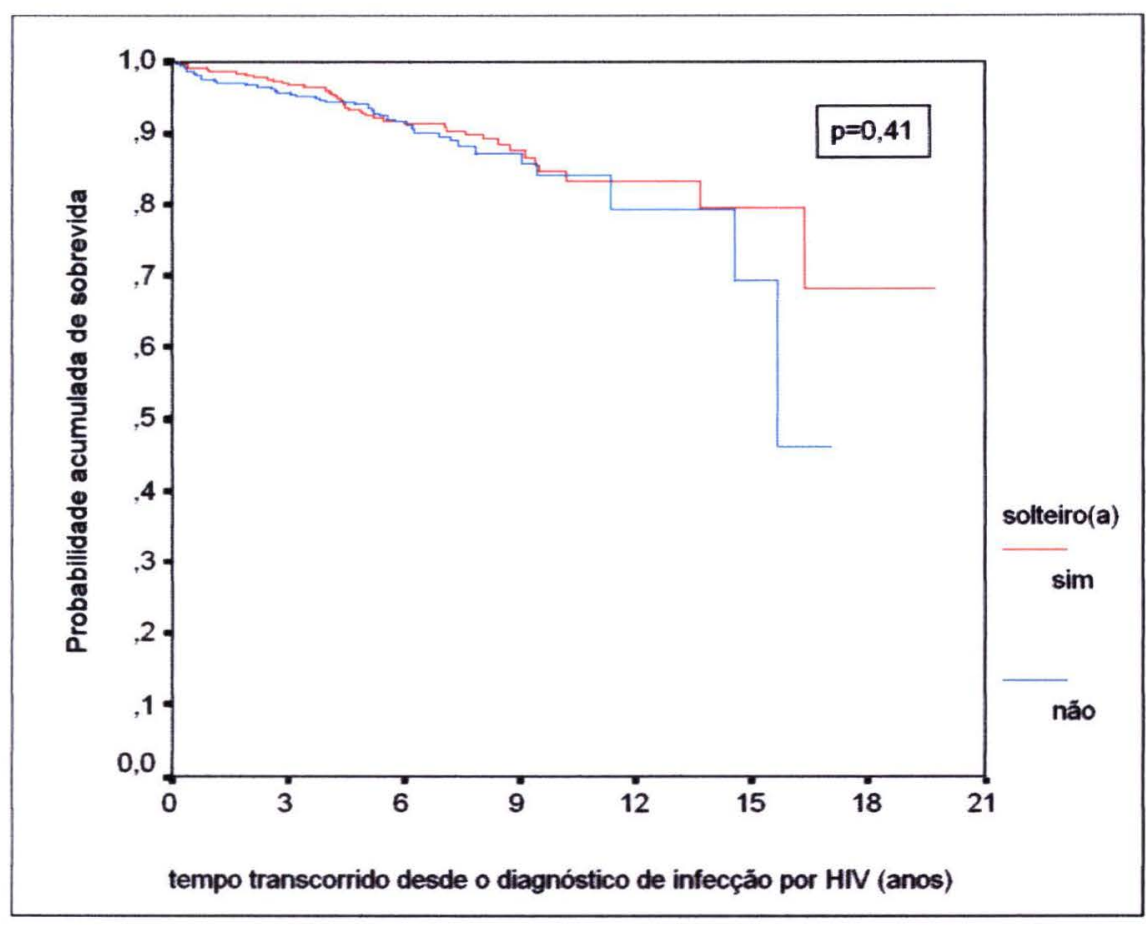

Figura 22: Probabilidade acumulada de sobrevida para pacientes com infecção por HIV, segundo estado civil à matrícula na Casa da Aids. São Paulo, 1998 a 2003.

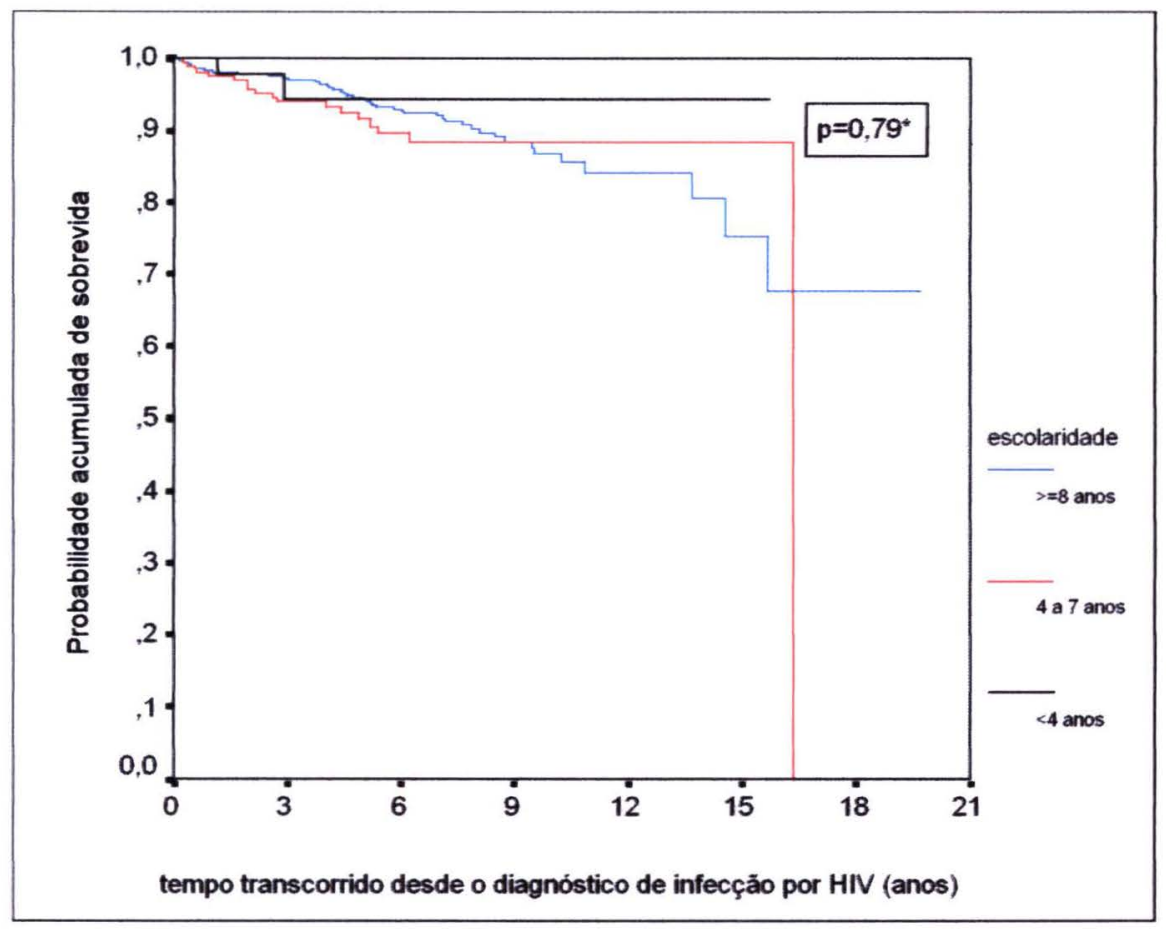

: teste log-rank para tendência

Figura 23: Probabilidade acumulada de sobrevida para pacientes com infecção por HIV, segundo escolaridade (anos) à matrícula na Casa da Aids. São Paulo, 1998 a 2003. 


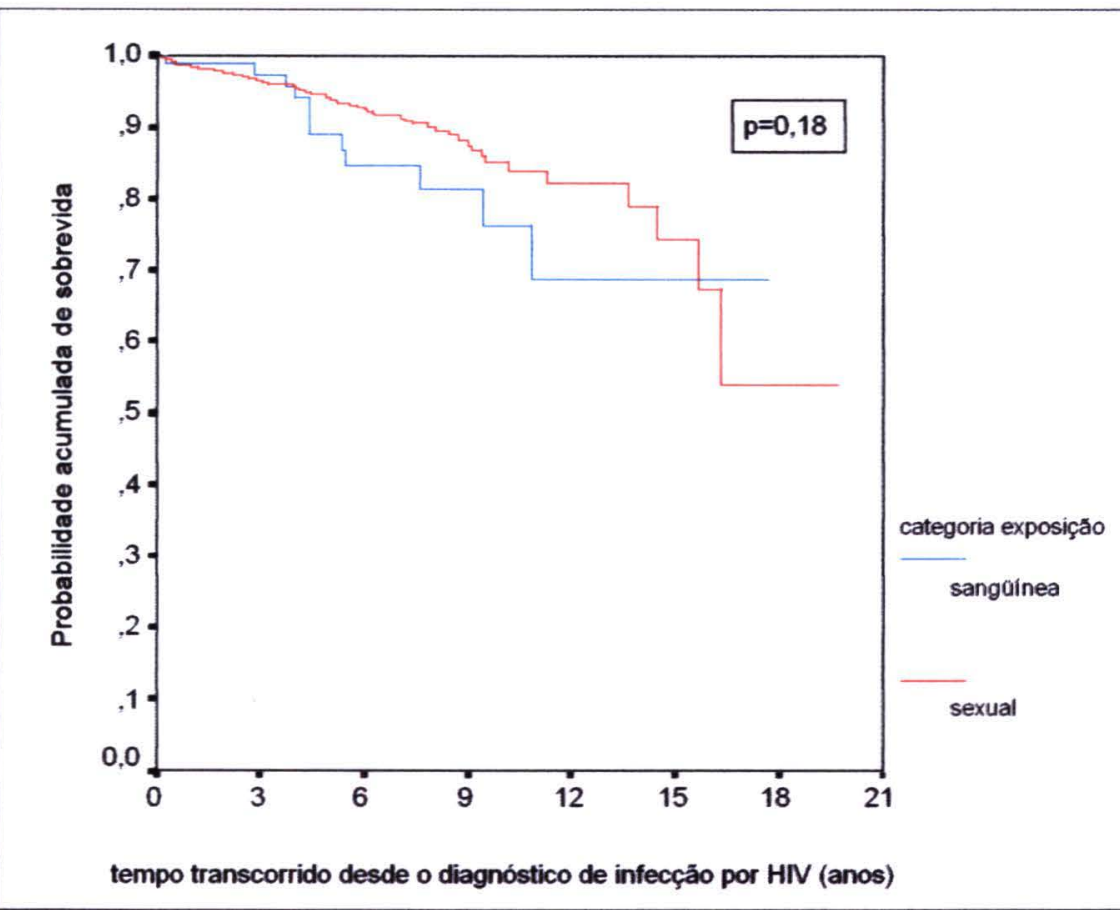

Figura 24: Probabilidade acumulada de sobrevida para pacientes com infecção por HIV, segundo categoria de exposição a essa retrovirose. Casa da Aids, São Paulo, 1998 a 2003.

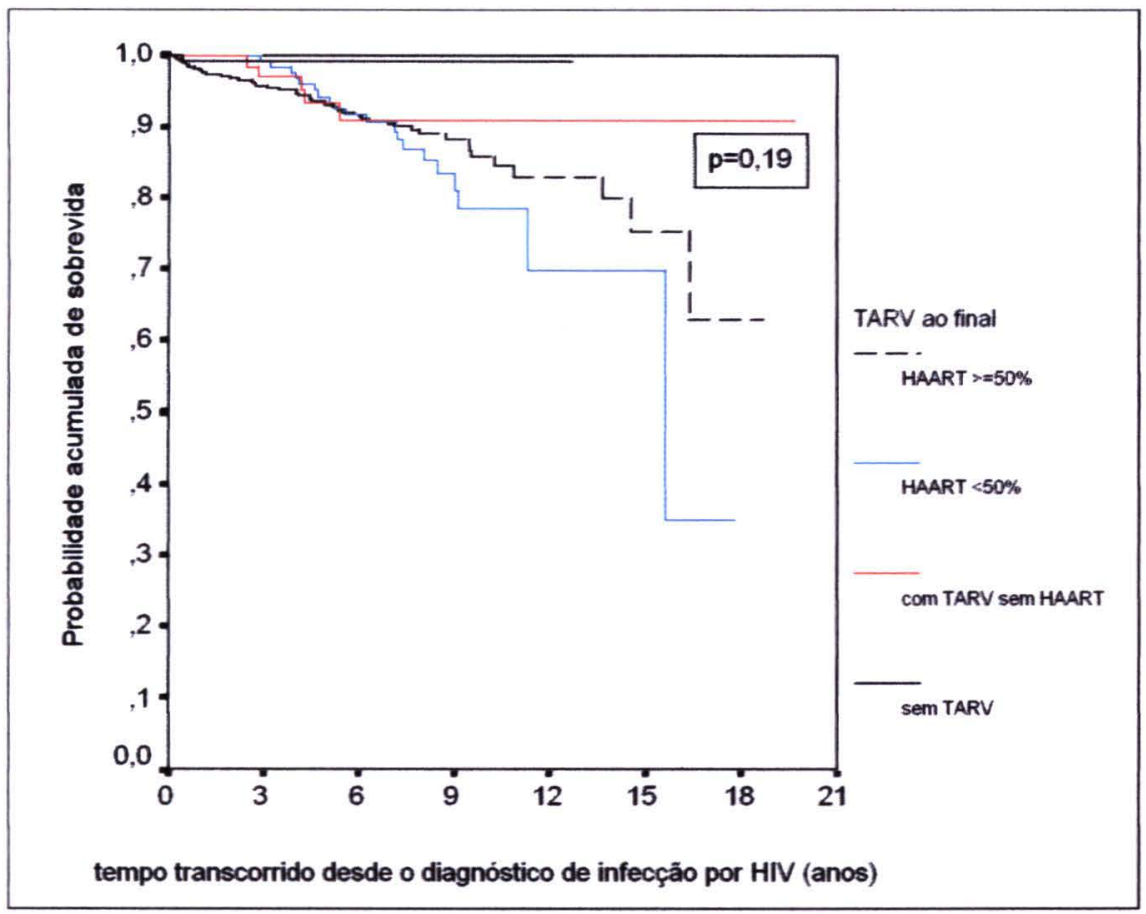

TARV: tratamento anti-retroviral; HAART: terapia anti-retroviral de alta potência

Figura 25: Probabilidade acumulada de sobrevida para pacientes com infecção por HIV, segundo tratamento anti-retroviral ao final do seguimento. Casa da Aids, São Paulo, 1998 a 2003. 
Verificou-se o pressuposto de proporcionalidade dos riscos no decorrer do tempo para cada uma das variáveis analisadas (Anexo 6).

Em seguida, para as variáveis para as quais foram constatados valores de $p$ menores que 0,25 no teste log-rank foram calculadas as estimativas dos Hazard Ratios com seus respectivos intervalos com 95\% de confiança (IC 95\%). Para a variável sexo, esses cálculos foram realizados independentemente do valor de $p$ obtido no teste log-rank, por se tratar da variável de principal interesse desse estudo (Tabela 23).

Tabela 23: Análise bivariada, pelo modelo de Cox, de fatores potencialmente associados à evolução para óbito por aids. Casa da Aids, São Paulo, 1998 a 2003.

\begin{tabular}{|c|c|c|c|}
\hline & HR & IC 95\% & valor de $p$ \\
\hline Sexo & & & 0,39 \\
\hline masculino & 1,00 & & \\
\hline feminino & 1,22 & $0,78-1,91$ & \\
\hline Idade ao diagnóstico de infecção por HIV (anos)* & & & $0,01^{\#}$ \\
\hline$<20$ & 1,00 & & \\
\hline 20 a 29 & 2,22 & $0,52-9,42$ & \\
\hline 30 a 39 & 3,10 & $0,73-13,10$ & \\
\hline 40 a 49 & 3,72 & $0,83-16,65$ & \\
\hline$\geq 50$ & 4,65 & $0,92-23,57$ & \\
\hline Categoria de exposição ao HIV ** & & & 0,19 \\
\hline sexual & 1,00 & & \\
\hline sangüínea & 1,52 & $0,82-2,82$ & \\
\hline Tratamento ao final do seguimento & & & 0,11 \\
\hline sem TARV & 1,00 & & \\
\hline com TARV sem HAART & 3,47 & $0,40-29,84$ & \\
\hline HAART em menos de $50 \%$ do tempo em TARV & 6,15 & $0,82-46,10$ & \\
\hline HAART em $50 \%$ ou mais do tempo em TARV & 4,71 & $0,65-34,08$ & \\
\hline
\end{tabular}

$\mathrm{HR}_{\mathrm{br}}$ hazard ratio bruto; $\mathrm{HR}_{\mathrm{aj}}$ hazard ratio ajustado; hazard ratio: razão das funções de risco; TARV: tratamento anti-retroviral; HAART: terapia anti-retroviral de alta potência Dados ignorados: *: 11 pacientes; ${ }^{\star *}: 151$ pacientes.

\#: teste log-rank para tendência 
Prosseguindo-se na análise bivariada de fatores associados à mortalidade por aids na coorte estudada, analisaram-se os resultados de exames laboratoriais evolutivos da infecção pelo HIV, a avaliação clínica dos pacientes e outros marcadores laboratoriais de interesse (Tabelas 24 e 25 e Figuras 26 a 33).

A sobrevida dos portadores do HIV da Casa da Aids mostrou-se não associada, segundo a técnica de Kaplan-Meier, à presença de marcadores sorológicos de infecção pelo vírus da hepatite $B(p=0,09)$, da hepatite $C$ $(p=0,51)$ e de sífilis $(p=0,91)$. Entretanto, os pacientes com determinações quantitativas de células CD4+ em sangue periférico inferiores a 200 células $/ \mathrm{mm}^{3}(p<0,001)$ no momento da matrícula e os com diagnóstico de alguma afeç̧ão oportunista $(p<0,001)$, prévio à admissão no serviço, apresentaram menor sobrevida. De forma análoga, os indivíduos que apresentaram, durante o acompanhamento na Casa da Aids, a menor determinação de células CD4+ periféricas inferior a 200 células $/ \mathrm{mm}^{3}$ $(p<0,001)$, a maior carga viral plasmática de HIV igual ou superior a 100.000 cópias $/ \mathrm{mL}(p<0,001)$ ou diagnóstico de alguma afecção oportunista $(p<0,001)$ apresentaram menor sobrevida. 
Tabela 24: Número de pacientes com infecção por HIV, número de óbitos por aids segundo marcadores clínicos e laboratoriais. Casa da Aids, São Paulo, 1998 a 2003.

\begin{tabular}{|c|c|c|c|}
\hline & $\begin{array}{c}\mathbf{n}^{\circ} \\
\text { pacientes }\end{array}$ & $\begin{array}{l}\mathrm{n}^{\circ} \text { óbitos } \\
\text { por aids }\end{array}$ & $\begin{array}{c}\text { valor de } p \\
\text { (teste log-rank) }\end{array}$ \\
\hline $\mathrm{N}^{\circ}$ de células CD4+ à matrícula no serviço* & & & $<0,001$ \\
\hline$\geq 200 / \mathrm{mm}^{3}$ & 621 & 26 & \\
\hline$<200 / \mathrm{mm}^{3}$ & 445 & 64 & \\
\hline Afeç̧ão oportunista prévia à admissão no serviço ${ }^{\star \star \star}$ & & & $<0,001$ \\
\hline não & 792 & 46 & \\
\hline $\operatorname{sim}$ & 279 & 44 & \\
\hline Menor $n^{\circ}$ de células CD4+ no serviço* & & & $<0,001$ \\
\hline$\geq 200 / \mathrm{mm}^{3}$ & 477 & 7 & \\
\hline$<200 / \mathrm{mm}^{3}$ & 589 & 83 & \\
\hline Maior carga viral de HIV no serviço $(\log )$ *** & & & $<0,001$ \\
\hline$<5$ cópias $/ \mathrm{mL}$ & 638 & 27 & \\
\hline$\geq 5$ cópias $/ \mathrm{mL}$ & 408 & 57 & \\
\hline Afecção oportunista no serviço & & & $<0,001$ \\
\hline não & 806 & 34 & \\
\hline $\operatorname{sim}$ & 266 & 57 & \\
\hline Hepatite C (anti-HCV) ${ }^{+}$ & & & 0,51 \\
\hline negativo & 831 & 62 & \\
\hline positivo & 148 & 15 & \\
\hline Hepatite B (anti-HBc) ${ }^{++}$ & & & 0,09 \\
\hline negativo & 536 & 38 & \\
\hline positivo & 393 & 41 & \\
\hline Sífilis (anti-antígeno treponêmico) ${ }^{+++}$ & & & 0,91 \\
\hline negativo & 618 & 41 & \\
\hline positivo & 217 & 16 & \\
\hline
\end{tabular}

*: 6 pacientes com dados ignorados; ${ }^{* *}$ : 1 paciente com dados ignorados; ${ }^{* \star *}: 26$ pacientes com dados ignorados; +: 93 pacientes com dados ignorados; ++: 143 pacientes com dados ignorados; +++: 237 pacientes com dados ignorados. 


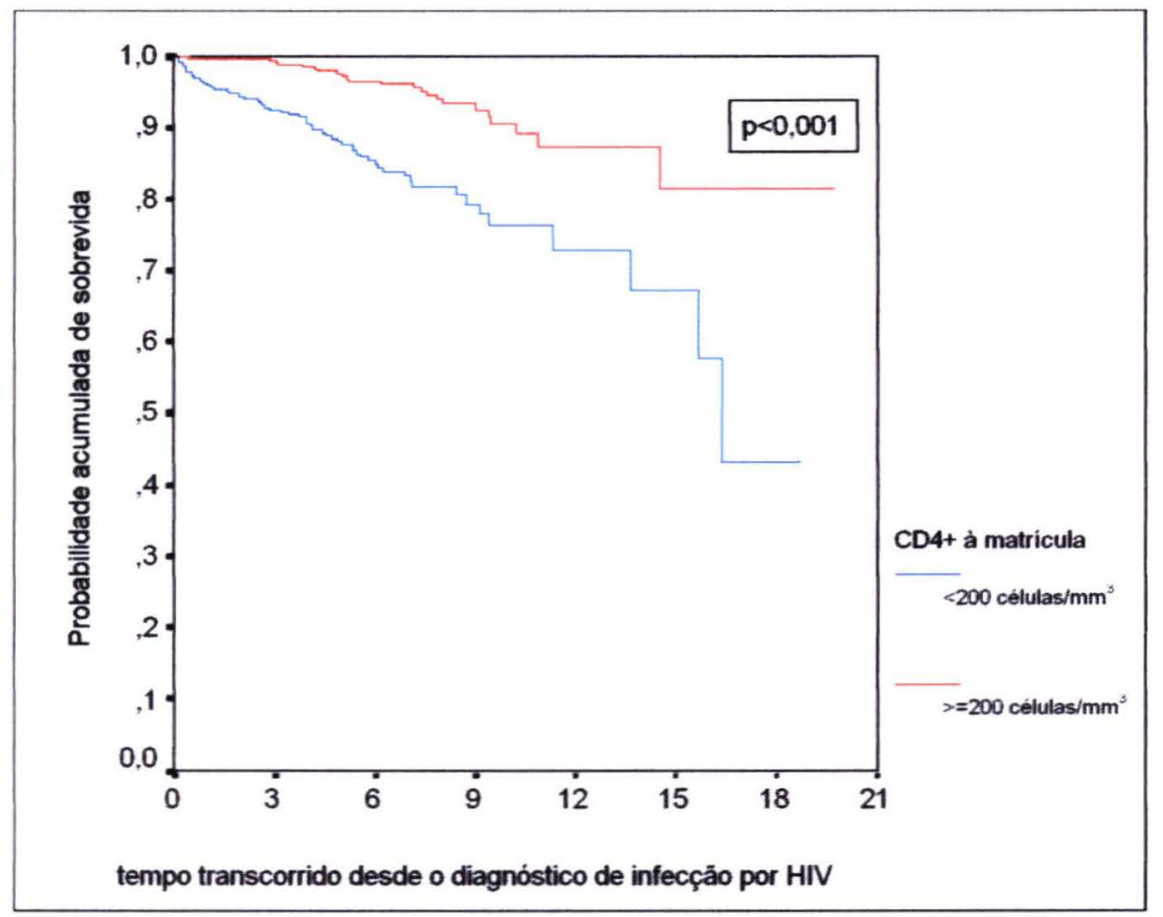

Figura 26: Probabilidade acumulada de sobrevida para pacientes com infecção por HIV, segundo número de linfócitos CD4+ periféricos à matrícula na Casa da Aids. São Paulo, 1998 a 2003.

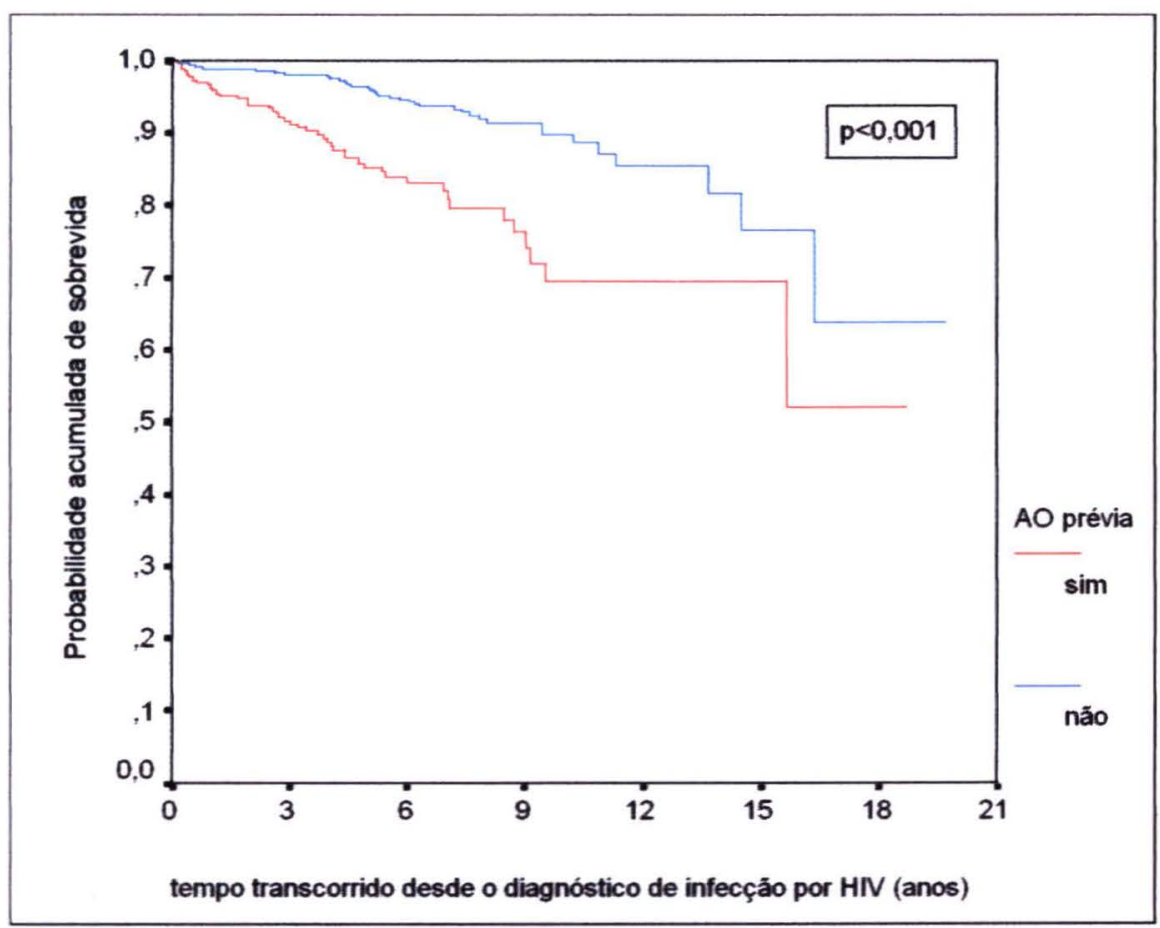

Figura 27: Probabilidade acumulada de sobrevida para pacientes com infecção por HIV, segundo diagnóstico de afecção oportunista $(\mathrm{AO})$ prévio à admissão na Casa da Aids. São Paulo, 1998 a 2003. 


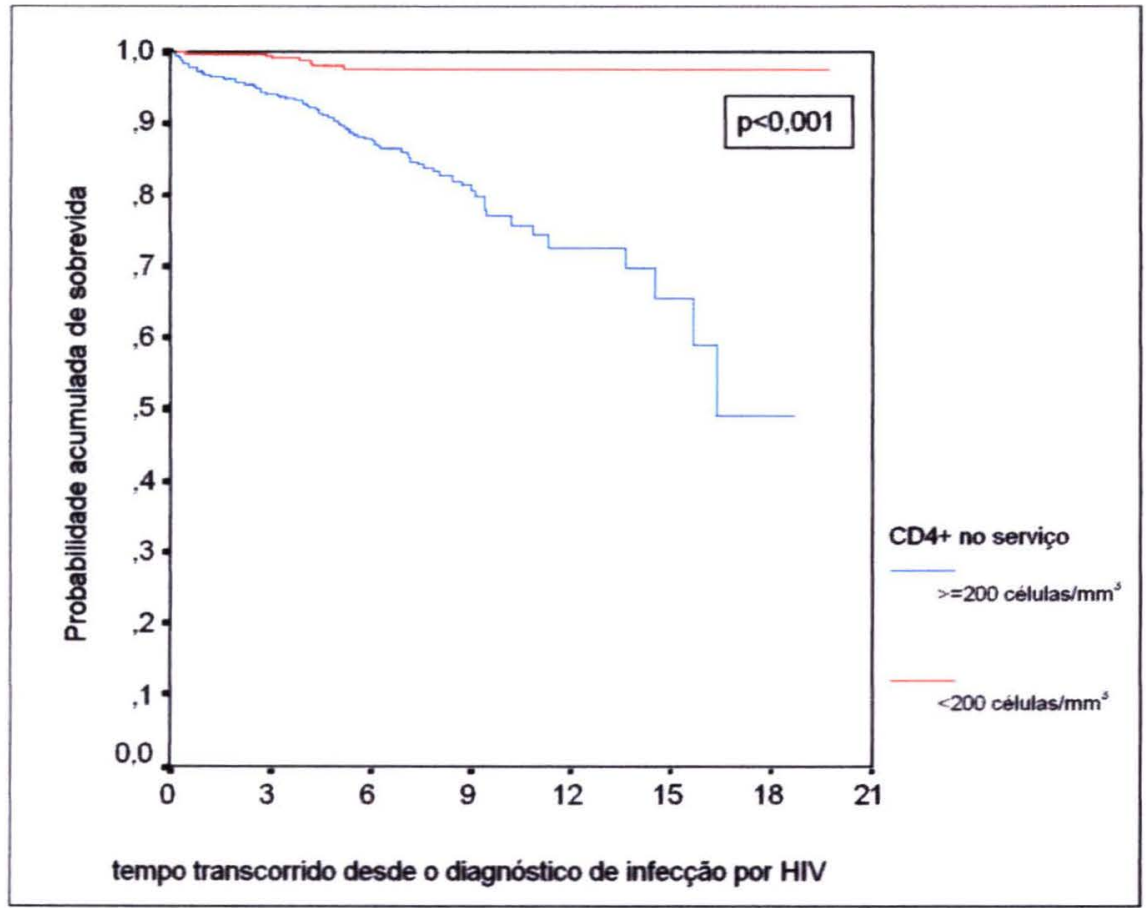

Figura 28: Probabilidade acumulada de sobrevida para pacientes com infecção por HIV, segundo menor número de linfócitos CD4+ periféricos durante seguimento na Casa da Aids. São Paulo, 1998 a 2003.

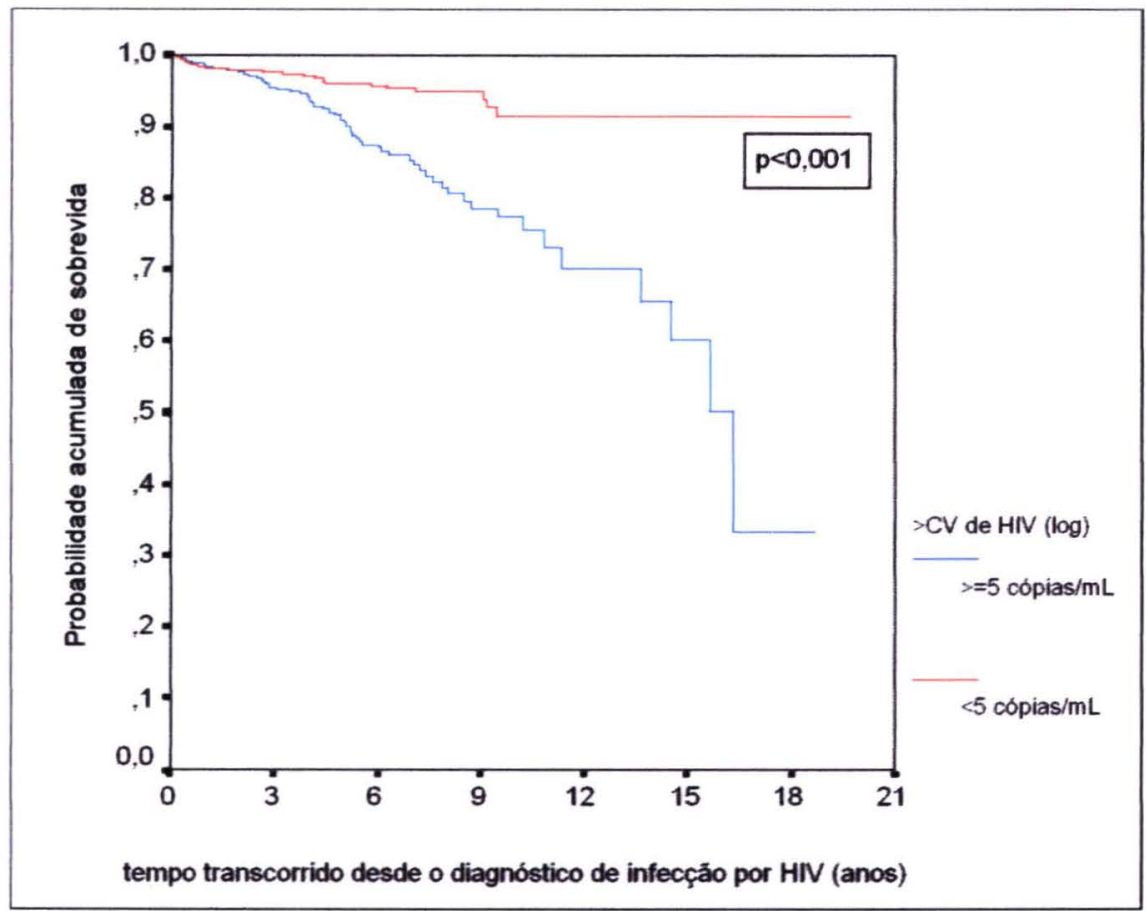

Figura 29: Probabilidade acumulada de sobrevida para pacientes com infecção por HIV, segundo valor do log da maior carga viral de HIV observada na Casa da Aids. São Paulo, 1998 a 2003. 


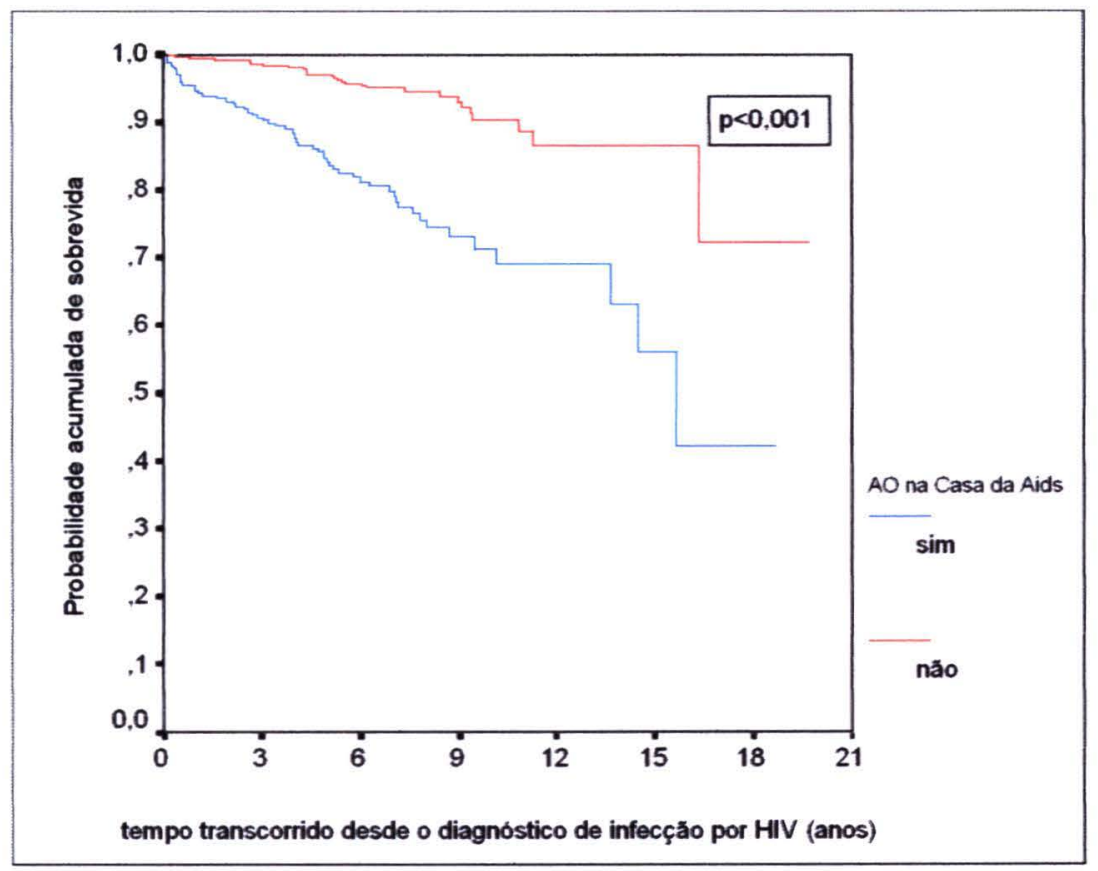

Figura 30: Probabilidade acumulada de sobrevida para pacientes com infecção por HIV, segundo diagnóstico de afecção oportunista $(A O)$ durante seguimento na Casa da Aids. São Paulo, 1998 a 2003.

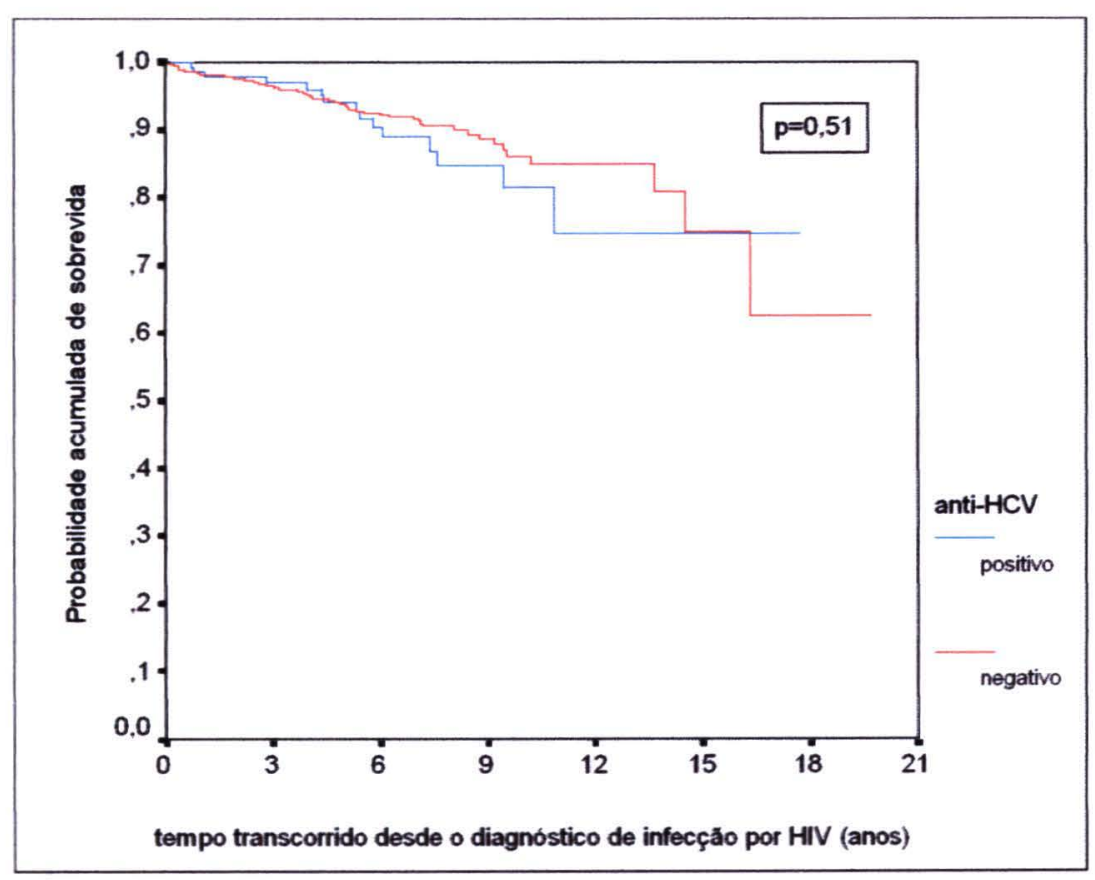

Figura 31: Probabilidade acumulada de sobrevida para pacientes com infecção por HIV, segundo soropositividade para infecção pelo vírus da hepatite C. Casa da Aids, São Paulo, 1998 a 2003. 


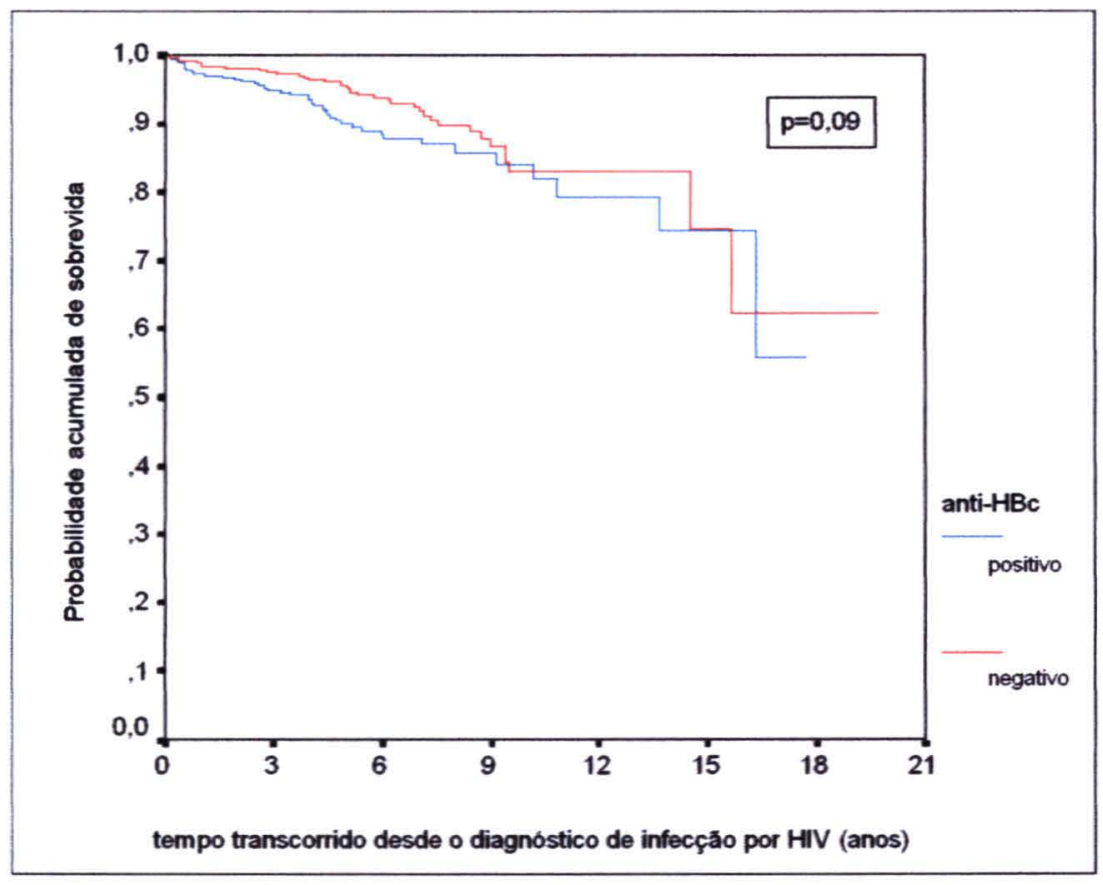

Figura 32: Probabilidade acumulada de sobrevida para pacientes com infecção por HIV, segundo presença de anticorpos anti-HBc. Casa da Aids, São Paulo, 1998 a 2003.

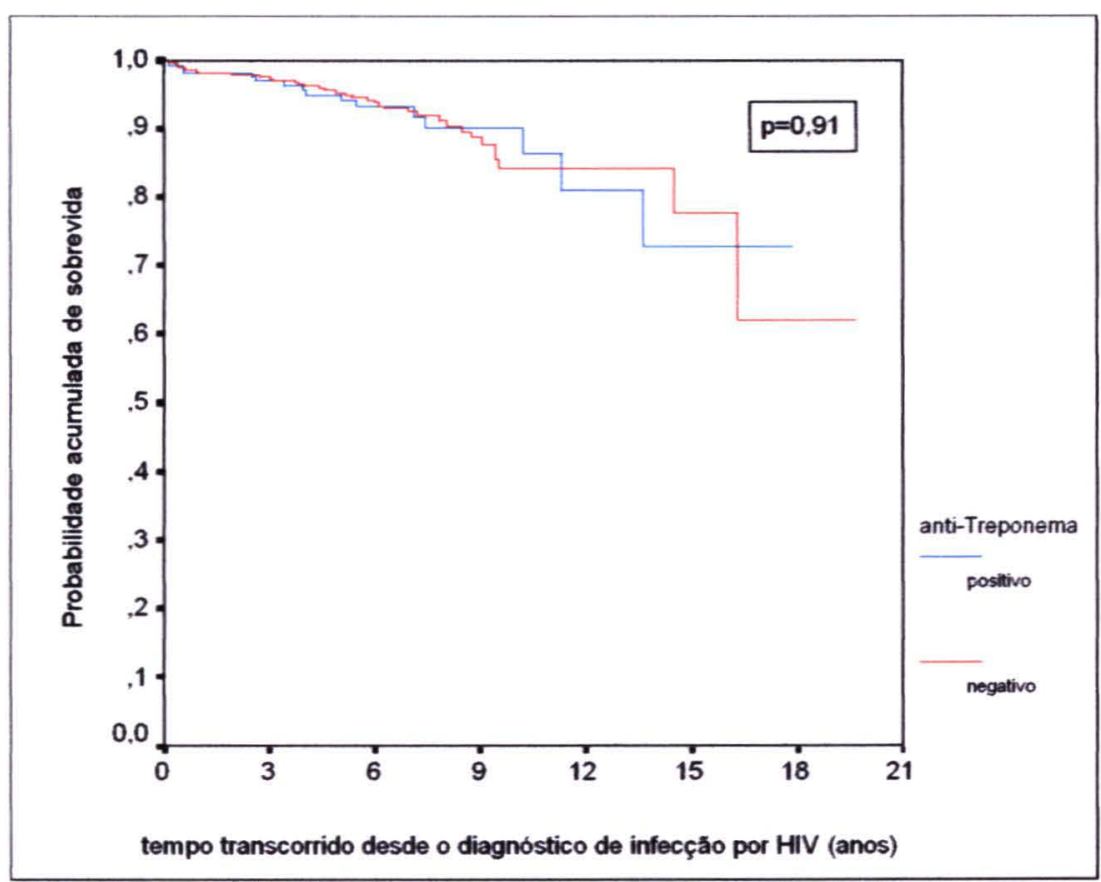

Figura 33: Probabilidade acumulada de sobrevida para pacientes com infecção por HIV, segundo presença de anticorpos anti-Treponema. Casa da Aids, São Paulo, 1998 a 2003. 
Em seguida, realizou-se a análise bivariada pelo modelo de riscos proporcionais de Cox para as variáveis com $p<0,25$ (teste log-rank) (Tabela 23).

Os indivíduos que à matrícula na Casa da Aids apresentavam número de células CD4+ periféricas inferior a 200/ $\mathrm{mm}^{3}$ (HR=3,80; IC 95\%: 2,41$6,00)$ e com história de diagnóstico de afecção oportunista (HR=3,06; IC 95\%: 2,02-4,61) sobreviveram menos tempo. $O$ mesmo foi observado para aqueles que, durante $o$ atendimento no serviço, apresentaram a menor determinação quantitativa de células CD4+ periféricas inferiores a 200 células $/ \mathrm{mm}^{3}$ (HR=3,80; IC 95\%: 2,41-6,00), a maior carga viral de HIV igual ou superior a 100.000 cópias $/ \mathrm{mL}$ (HR=3,15; IC 95\%: 1,99-4,99) ou que desenvolveram alguma afecção oportunista ( $H R=4,37$; IC 95\%: 2,85-6,68).

Embora sem significância estatística, observou-se também maior risco de morte para os pacientes com a presença de marcadores sorológicos de infecção pregressa pelo vírus da hepatite $B$ (HR=1,47; IC 95\%: 0,95-2,29). 
Tabela 25: Análise bivariada, pelo modelo de Cox, da associação entre marcadores clínicos e laboratoriais e a evolução para óbito por aids. Casa da Aids, São Paulo, 1998 a 2003.

\begin{tabular}{|c|c|c|c|}
\hline & HR & IC 95\% & valor de $p$ \\
\hline $\mathrm{N}^{\circ}$ de células CD4+ à matrícula no serviço & & & $<0,001$ \\
\hline$\geq 200 / \mathrm{mm}^{3}$ & 1,00 & & \\
\hline$<200 / \mathrm{mm}^{3}$ & 3,80 & $2,41-6,00$ & \\
\hline Menor $n^{\circ}$ de células CD4+ no serviço & & & $<0,001$ \\
\hline$\geq 200 / \mathrm{mm}^{3}$ & 1,00 & & \\
\hline$<200 / \mathrm{mm}^{3}$ & 8,16 & $3,77-17,65$ & \\
\hline Maior carga viral de HIV no serviço (log) & & & $<0,001$ \\
\hline$<5$ cópias $/ \mathrm{mL}$ & 1,00 & & \\
\hline$\geq 5$ cópias $/ m L$ & 3,15 & $1,99-4,99$ & \\
\hline Afecção oportunista prévia à admissão no serviço & & & $<0,001$ \\
\hline não & 1,00 & & \\
\hline $\operatorname{sim}$ & 3,06 & $2,02-4,61$ & \\
\hline Afeç̧ão oportunista no serviço & & & $<0,001$ \\
\hline não & 1,00 & & \\
\hline $\operatorname{sim}$ & 4,37 & $2,85-6,68$ & \\
\hline Hepatite B (anti-HBc) & & & 0,09 \\
\hline negativo & 1,00 & & \\
\hline positivo & 1,47 & $0,95-2,29$ & \\
\hline
\end{tabular}

HR (hazard ratio): razão das funções de risco 


\subsubsection{Avaliação da sobrevida em análise multivariável}

Com a finalidade de avaliar as variáveis que pudessem servir como preditivas independentes do óbito por aids na população estudada, procedeu-se à análise multivariável pelo modelo dos riscos proporcionais de Cox, considerando a variável sexo e todas as variáveis que apresentaram valor de $p<0,25$ à análise bivariada.

No modelo final com as variáveis prognósticas ajustadas (Tabela 26), constatou-se que dentre os indivíduos com infecção pelo HIV atendidos na Casa da Aids entre janeiro de 1998 e dezembro de 2002, as mulheres apresentaram maior risco de óbito por aids que os homens $\left(\mathrm{HR}_{\mathrm{aj}}=1,86\right.$; IC 95\%: 1,14-3,03). Analogamente os pacientes com diagnóstico de infecção por HIV em idades entre 20 e 29 anos, 30 e 39, 40 e 49 e 50 ou mais exibiram, respectivamente, 5,$1 ; 8,8 ; 10,0$ e 10,2 vezes o risco de morrer, se comparados aos diagnosticados antes dos 20 anos.

Após controle por sexo, idade ao diagnóstico de infecção por HIV, tratamento anti-retroviral ao final do seguimento e pelas demais variáveis incluídas no modelo final, apresentaram maior risco de óbito por aids os pacientes com diagnóstico de afecção oportunista prévia à admissão $\left(\mathrm{HR}_{\mathrm{aj}}\right.$ $=2,19$; IC 95\%: 1,39-3,45) ou durante o seguimento no serviço $\left(\mathrm{HR}_{\mathrm{aj}}=3,09\right.$; IC 95\%: 1,91-5,00). O mesmo foi verificado para os indivíduos que na Casa da Aids apresentaram menor número de células CD4+ periféricas inferior a 200/mm ${ }^{3}\left(\mathrm{HR}_{\mathrm{aj}}=6,60\right.$; IC 95\%: 2,45-17,74) ou a maior carga viral plasmática de HIV igual ou superior a 100.000 cópias $/ m L\left(H R_{a j}=1,96\right.$; IC $95 \%: 1,19$ 3,22). 
Tabela 26: Análise multivariável pelo modelo de riscos proporcionais de Cox, segundo fatores preditivos de evolução para o óbito por aids. Casa da Aids, São Paulo, 1998 a 2003.

\begin{tabular}{|c|c|c|c|c|}
\hline & $\mathbf{H R}_{\mathbf{b r}}$ & $\mathbf{H R}_{\mathrm{aj}}$ & IC $95 \%\left(H_{\mathrm{R}_{\mathrm{aj}}}\right)$ & valor de $p$ \\
\hline Sexo & & & & 0,02 \\
\hline masculino & 1,00 & 1,00 & & \\
\hline feminino & 1,22 & 1,86 & $1,14-3,03$ & \\
\hline Idade ao diagnóstico de infecção por HIV (anos) & & & & $0,005^{*}$ \\
\hline$<20$ & 1,00 & 1,00 & & \\
\hline 20 a 29 & 2,22 & 5,11 & $0,67-38,69$ & \\
\hline 30 a 39 & 3,10 & 8,82 & $1,17-66,76$ & \\
\hline 40 a 49 & 3,72 & 9,96 & $1,22-81,36$ & \\
\hline$\geq 50$ & 4,65 & 10,16 & $1,17-88,35$ & \\
\hline Menor $n^{\circ}$ de células CD4+ no serviço & & & & $<0,001$ \\
\hline$\geq 200 / \mathrm{mm}^{3}$ & 1,00 & 1,00 & & \\
\hline$<200 / \mathrm{mm}^{3}$ & 8,16 & 6,60 & $2,45-17,74$ & \\
\hline Maior carga viral de HIV no serviço (log) & & & & 0,007 \\
\hline < 5 cópias $/ \mathrm{mL}$ & 1,00 & 1,00 & & \\
\hline$\geq 5$ cópias $/ \mathrm{mL}$ & 3,15 & 1,96 & $1,19-3,22$ & \\
\hline $\begin{array}{l}\text { Afecção oportunista prévia à admissão no } \\
\text { serviço }\end{array}$ & & & & $<0,001$ \\
\hline não & 1,00 & 1,00 & & \\
\hline $\operatorname{sim}$ & 3,06 & 2,19 & $1,39-3,45$ & \\
\hline Afecção oportunista no serviço & & & & $<0,001$ \\
\hline não & 1,00 & 1,00 & & \\
\hline $\operatorname{sim}$ & 4,37 & 3,09 & $1,91-5,00$ & \\
\hline Tratamento ao final do seguimento & & & & 0,08 \\
\hline sem TARV & 1,00 & 1,00 & & \\
\hline com TARV sem HAART & 3,47 & 1,02 & $0,09-11,58$ & \\
\hline HAART em menos de $50 \%$ do tempo em TARV & 6,15 & 0,86 & $0,11-7,01$ & \\
\hline HAART em $50 \%$ ou mais do tempo em TARV & 4,71 & 0,44 & $0,05-3,48$ & \\
\hline
\end{tabular}

$\mathrm{HR}_{\mathrm{br}}$ : hazard ratio bruto; $\mathrm{HR}_{\mathrm{br}}$, hazard ratio ajustado; hazard ratio: razão das funções de risco TARV: tratamento anti-retroviral; HAART: terapia anti-retroviral de alta potência \#: teste log-rank para tendência 


\section{DISCUSSÃO}




\section{DISCUSSÃO}

Decorridos vinte e cinco anos da descrição dos primeiros casos de aids, os vários estudos epidemiológicos sobre a infecção pelo HIV e a aids já realizados mostraram-se úteis na elucidação dos modos de transmissão do vírus, dos fatores de risco mais importantes para aquisição da infecção, da história natural da doença, dos marcadores de progressão e dos efeitos dos agentes antivirais.

Tais estudos contribuíram também para a elucidação dos processos biológicos, sociais e comportamentais envolvidos na transmissão do HIV e de como medidas de prevenção podem ser eficazes na desaceleração da disseminação dessa infecção retroviral.

Contudo, a epidemia permanece extremamente dinâmica; não há país que não tenha sido por ela afetado.

Apesar de se contarem hoje com significativos investimentos/recursos e estratégias mais efetivas para a prevenção e o tratamento da doença, o número de pessoas vivendo com HIV/aids continua aumentando no mundo todo. Constata-se, entretanto, que os países que possuem políticas públicas de favorecimento ao acesso à terapêutica antiretroviral vêm apresentando declínio nos coeficientes de morbidade e mortalidade por aids. Infelizmente essa possibilidade continua inatingivel a muitos países em desenvolvimento. Apesar do notável aumento no número de pessoas recebendo terapia antiretroviral nesses países durante o segundo semestre de 2004 (passando de 440 mil a $700 \mathrm{mil}$ ), apenas $12 \%$ do total de indivíduos com indicação de tratamento foram até o momento beneficiados (UNITED NATIONS 2005).

O Brasil, em 1991, foi o primeiro país em desenvolvimento a adotar políticas de acesso gratuito e universal à terapia antiretroviral, tendo estendido progressivamente esse benefício até alcançar 170 mil pessoas nos dias atuais (MINISTÉRIO DA SAÚDE 2005). 
Nos estudos sobre a dinâmica da disseminação da aids, destaca-se a expansão da epidemia na população feminina (ONUSIDA 2004, QUINN e OVERBAUGH 2005, UNAIDS 2004a, UNAIDS 2004c, UNITED NATIONS 2005). Hoje aproximadamente $50 \%$ das pessoas vivendo com HIV em todo o mundo são mulheres. No Brasil, a feminização da epidemia pode ser observada em várias regiões (DORING 1998, ANJOS 2000, TANCREDI 2003).

Todavia ainda não se encontra totalmente esclarecido se a infecção apresenta comportamento semelhante quando atinge homens e mulheres. Segundo PRINS e cols. (2005), enquanto a comparação entre homens e mulheres da evolução clínica da doença no período pré-HAART fornecia subsídios para o conhecimento da história natural da infecção pelo HIV, no período pós-HAART esta indica se há igualdade ou não entre os gêneros nos benefícios auferidos com o tratamento anti-retroviral.

Com a feminização da doença e os sucessos alcançados a partir de intervenções difundidas pelo Programa Nacional de DST/aids no cuidado a pessoas com HIV/aids em nosso país, torna-se relevante saber se os resultados obtidos com tais medidas diferiram entre os sexos. $O$ delineamento do perfil do paciente à matrícula em serviços especializados de tratamento e a avaliação dos benefícios das intervenções em ambos os sexos podem contribuir para elucidar melhor essa questão, possibilitando identificar perfis distintos de vulnerabilidade ao cuidado que possam subsidiar aprimoramentos na atenção prestada.

Com esse objetivo, o presente estudo consiste na análise de sobrevida de uma coorte retrospectiva de pacientes adultos atendidos em um serviço de referência do Município de São Paulo. Esse serviço localizase na região central da cidade (local com alta prevalência da doença) e possui expressivo número de pacientes. $O$ estudo comparou o perfil clínico evolutivo e a sobrevida de uma amostra aleatória de 1072 homens e mulheres vivendo com HIV/aids atendidos na unidade entre janeiro de 1998 e dezembro de 2002. 
$\mathrm{Na}$ amostra sorteada, a razão homens:mulheres foi de 2,5:1, refletindo a observada no total de pacientes do serviço $(2,3: 1)$. Esse resultado foi superior à razão mundial de 1,2:1 (Tabela 27); porém, semelhante à de 2,7:1 encontrada por MARINS et al. (2003) em estudo realizado em dezoito cidades brasileiras e à da população com HIV/aids do Município de São Paulo (2,8:1) (BOLETIM EPIDEMIOLÓGICO DE AIDS DO MUNICÍPIO DE SÃO PAULO 2004).

Tabela 27: Razão entre homens e mulheres de 15 a 49 anos vivendo com HIV/aids segundo região.

\begin{tabular}{lrrc}
\hline REGIÃO & homens & mulheres & H:M \\
\hline \hline Africa do Norte e Oriente Médio & 240.000 & 220.000 & 1,1 \\
África subsaariana & 10.800 .000 & 13.500 .000 & 0,8 \\
América Latina & 1.220 .000 & 580.000 & 2,1 \\
América do Norte & 900.000 & 300.000 & 3,0 \\
Ásia (leste) & 740.000 & 160.000 & 4,6 \\
Ásia (sul e sudeste) & 5.320 .000 & 1.900 .000 & 2,8 \\
Caribe & 140.000 & 140.000 & 1,0 \\
Europa Ocidental e Central & 510.000 & 190.000 & 2,7 \\
Europa Oriental e Ásia Central & 1.140 .000 & 440.000 & 2,6 \\
Oceania & 31.000 & 39.000 & 0,8 \\
\hline TOTAL & 21.000 .000 & 17.500 .000 & 1,2 \\
\hline
\end{tabular}

Fonte: UNAIDS 2005.

$H: M$ razão entre homens e mulheres

Assim como relataram pesquisadores de outros países (DUNNE e cols. 1997, MOCROFT e cols. 2000, MOORE e cols. 2003, NICASTRI e cols. 2005), neste estudo as mulheres mostraram-se mais jovens que os homens ao diagnóstico de infecção por HIV. A mucosa genital das meninas mais jovens é mais delgada em relação à das mulheres mais velhas e, portanto, mais vulnerável à aquisição do HIV (PAHO 2000). Além disso, sabe-se que a chance de uma jovem se infectar é maior que a de um rapaz da mesma idade. Na África do Sul, Zâmbia e Zimbábue, entre jovens de 15 a 24 anos, as mulheres apresentam risco de infecção entre 3 e 6 vezes maior que os homens (ONUSIDA 2004). 
Adicionalmente à vulnerabilidade biológica própria do sexo feminino, questões sociocomportamentais relacionadas a desigualdades de gênero podem justificar essa diferença. As mulheres jovens geralmente se relacionam sexualmente com homens mais velhos que, por sua vez, apresentam maior probabilidade de ter contraído alguma doença sexualmente transmissível (DST) em suas relações anteriores (TÜRMEN 2003). Reconhece-se que um indivíduo com DST apresenta um risco dez vezes aumentado de adquirir ou de transmitir o HIV (UNAIDS 2003).

Ao lado disso, em parcerias sexuais entre mulheres jovens e homens mais velhos, freqüentemente se verifica disparidade econômica, que resulta em menor poder de negociação por parte da mulher pelo uso do preservativo (TÜRMEN 2003). Segundo PARKER e GALVÃO (1996), no Brasil esse domínio dos homens em relação à utilização ou não da camisinha procede das desigualdades nas relações de poder e de gênero.

Vale a pena destacar que hoje se tem a maior geração jovem da história; mais da metade da população mundial tem menos de 25 anos de idade (UNFPA 2005). Portanto, é importante também lembrar que alguns estudos vêm apresentando o desconhecimento dos jovens em relação à utilização de preservativos e à aquisição de DSTs, o que torna ainda maior a vulnerabilidade das meninas ao HIV (UNAIDS 2004b). Todavia, no Brasil, houve acréscimo na freqüência de uso de camisinhas na primeira relação sexual entre os jovens (PASCOM e cols. 2005). Enquanto a proporção de jovens de 16 a 25 anos que faziam uso desse instrumento de prevenção em 1986 era de $9 \%$, em 2004 , foi de $51 \%$.

Em relação à população estudada, observou-se ainda que os homens, em geral, eram solteiros, homossexuais ou bissexuais e apresentavam oito ou mais anos de escolaridade, ao passo que as mulheres eram mais freqüentemente casadas ou amasiadas, donas de casa, apresentavam a heterossexualidade como principal forma de exposição ao vírus e tinham baixa escolaridade. 
No que tange à distribuição das categorias de exposição ao HIV entre os sexos, resultados semelhantes foram descritos em estudos realizados no Rio de Janeiro (SANTORO-LOPES e cols. 1998), no Canadá (MOCROFT e cols. 2000) e em Londres, no Reino Unido (MOORE e cols. 2002). Contudo, no Brasil, esse perfil foi predominante no período compreendido entre 1980 e 1992; desde então a população masculina passou a apresentar aumento na incidência de casos entre os heterossexuais, que hoje totalizam a maioria dos casos de aids do país (BOLETIM EPIDEMIOLÓGICO-AIDS e DST 2005).

Essa divergência em relação ao observado no conjunto da casuística brasileira de aids não parece devida ao tempo de diagnóstico dos pacientes analisados neste estudo, dado que apenas $12 \%$ dos homens foram identificados com a doença até 1992. Sugere-se, assim, haver uma característica particular da clientela do serviço com maior representação percentual da categoria homossexual/bissexual entre os homens ali assistidos.

O predomínio de mulheres casadas e de menor escolaridade na amostra avaliada aparentemente reflete o contexto atual da epidemia brasileira de HIV/aids, denotando a particular vulnerabilidade social exibida pela população feminina.

Em entrevistas realizadas por NASCIMENTO e cols. (2005) em Camaragibe, Região Metropolitana de Recife, com 16 mulheres casadas, dependentes dos maridos e com rendas de até dois salários mínimos, observaram-se evidências da maior vulnerabilidade feminina frente à infecção pelo HIV/aids. Essas mulheres identificaram o casamento como barreira contra a doença e chegaram até mesmo a desconhecer sua etiologia e os modos de contágio. Não se percebiam sob risco de adquirir a infecção e viam a aids como doença dos outros.

A evolução temporal da epidemia de aids no Brasil segundo sexo, ocupação, status socioeconômico e categoria de exposição, descrita por 
FONSECA e cols. (2003), aponta também para a pauperização. Os maiores aumentos nos coeficientes de incidência da doença deram-se entre aqueles com menor status socioeconômico para ambos os sexos. Os homens "desempregados" apresentaram crescimento anual percentual de $23 \%$ entre 1991 e 1996. Os pesquisadores também encontraram predominância feminina entre aqueles indivíduos sem participação no mercado de trabalho; a categoria "afazeres domésticos" apresentou os maiores coeficientes de incidência da doença e o maior crescimento percentual anual (22\%). Em contraste, para as pessoas classificadas entre as $20 \%$ mais ricas da população brasileira, houve expressiva redução nas taxas de crescimento da doença.

Um aspecto relevante deste estudo diz respeito às diferenças observadas entre os sexos nos motivos que levam as pessoas a buscar o teste diagnóstico de infecção por HIV. Enquanto os homens, mais freqüentemente, realizaram o teste sorológico anti-HIV por apresentarem algum indício clínico da infecção ou por se perceberem sob risco, as mulheres o fizeram após conhecimento da soropositividade do parceiro ou durante rastreamento na assistência pré-natal. A baixa busca espontânea pelo diagnóstico na população feminina provavelmente reflete, mais uma vez, a falta de percepção de risco entre elas, o que pode acarretar retardo no reconhecimento da infecção e conseqüentemente no acesso às intervenções profiláticas e terapêuticas, aumentando a vulnerabilidade ao adoecimento na população feminina.

Apesar disso, na coorte estudada, as mulheres chegaram ao serviço em estadio clínico menos avançado da infecção por HIV, quando comparadas aos homens. Tal fato era entretanto esperado, visto que, como descrito acima, foram levadas ao teste ainda assintomáticas, mais freqüentemente na triagem sorológica conduzida durante o pré-natal ou por solicitação médica por possuírem parceiros soropositivos.

O estadio clínico menos avançado aparece também refletido nos marcadores laboratoriais avaliados à matrícula no serviço. As mulheres 
foram admitidas na Casa da Aids com maior número de linfócitos CD4+ em sangue periférico e, em maior proporção, com carga viral plasmática de HIV indetectável, quando comparadas aos homens. Analogamente, em estudo desenvolvido na Itália, NICASTRI e cols. (2005) encontraram melhores resultados nos marcadores laboratoriais evolutivos para a população feminina à avaliação inicial.

Esse panorama persistiu durante todo o acompanhamento laboratorial no serviço, incluindo a menor determinação de células CD4+, a frequência de pacientes que alcançaram viremia indetectável e a maior carga viral plasmática observada. Em todos esses marcadores houve evidência de evolução mais favorável entre as mulheres. Porém, à ultima avaliação efetuada para cada paciente, não se observou diferença com significância estatística nos resultados da contagem de linfócitos CD4+ em sangue periférico e na viremia plasmática na comparação entre os sexos. Tais achados permitem supor que, ao longo do tempo de seguimento no serviço, a evolução laboratorial observada entre as mulheres torna-se desfavorável quando comparada à dos homens.

No que se refere à coorte de pacientes livres de aids quando da admissão ao serviço, o coeficiente de incidência da doença encontrado neste estudo foi de 63,5/1.000 pessoas-ano. Tal incidência foi superior à encontrada na Suíça (40,0/1.000 pessoas-ano), na Itália (39,0/1.000 pessoas-ano) (LEDERGERBER e cols. 1999, NICASTRI e cols. 2005) e na Espanha entre UDI (38,0/1.000 pessoas-ano para as mulheres e 51,0/1.000 pessoas-ano para os homens) (HERA e cols. 2004).

$\mathrm{Na}$ amostra estudada de pacientes da Casa da Aids, os coeficientes de incidência da doença não diferiram, com significância estatística, entre os sexos. Foram, no entanto, identificados como preditores de evolução para aids a determinação mais elevada da carga viral de HIV durante o seguimento superando 100.000 cópias $/ \mathrm{mL}$ e o tipo de tratamento antiretroviral recebido, tendo havido menor probabilidade de progressão para 
aids entre os que receberam HAART por período igual ou superior a $50 \%$ do tempo de terapêutica.

A inexistência de diferença no risco de progressão para aids entre os sexos parece consensual entre os trabalhos relatados na literatura. Analogamente ao observado nesta coorte, outros pesquisadores não encontraram diferenças relacionadas ao gênero na história natural da doença e progressão para aids (LEPRI e cols. 1994, MOCROFT e cols. 2000, PORTER e cols. 2003, SIGHEM e cols. 2003, NICASTRI e cols. 2005).

Tanto a carga viral plasmática como o tratamento anti-retroviral tem sido também reconhecidos como importantes fatores associados à evolução para aids em investigações conduzidas em outros países (MELLORS e cols. 1995, MOCROFT e cols. 2003, PORTER e cols. 2003).

Nossos achados apontam ainda melhores resultados para o sexo masculino no que diz respeito às internações. Embora os homens tenham apresentado maior freqüência de internações durante todo o acompanhamento no serviço, verificou-se declínio na proporção de internações masculinas após o início da distribuição do tratamento antiretroviral de alta potência (HAART). As mulheres, ao contrário, apresentaram aumento proporcional de aproximadamente $100 \%$ no número de internações entre os períodos pré e pós-HAART.

Embora alterações ao longo do tempo no perfil de morbidade nas admissões hospitalares de pacientes com aids tenham sido objeto recente de análise na Suíça (NUESCH e cols. 2002) e no Brasil (NOBRE e cols. 2003), tais estudos não se ativeram a considerações relativas a eventuais diferenças de gênero na ocorrência de internações hospitalares.

Outro aspecto a ser destacado na análise comparativa entre os sexos diz respeito ao acesso dos pacientes à terapia anti-retroviral, tendo em vista 
o forte impacto que essa intervenção determina sobre o prognóstico da infecção.

Apesar de as pacientes do sexo feminino deste estudo terem obtido o diagnóstico da infecção pelo HIV mais recentemente que os homens, a avaliação do acesso ao tratamento anti-retroviral à admissão ao serviço não identificou diferença entre os sexos quanto ao uso de HAART após estratificação da amostra segundo o estadio clínico da doença. Da mesma forma, ao final do seguimento na Casa da Aids, a distribuição dos pacientes de ambos os sexos em relação ao tipo de tratamento recebido foi semelhante.

No Brasil a política de distribuição de anti-retrovirais garante o acesso universal e gratuito aos medicamentos a todos os pacientes que preenchem os critérios estabelecidos pelo Ministério da Saúde (MINISTÉRIO DA SAÚDE 2004b). Essa iniciativa parece justificar a inexistência de diferença no acesso ao tratamento na população estudada.

Em outros países, ao contrário, a situação parece distinta. HADER e cols. (2001) acreditam que, talvez por motivos socioeconômicos, as mulheres norte-americanas apresentem menor chance de usar antiretrovirais. O mesmo foi observado por STRATHDEE e cols. (1998) entre pacientes UDI no Canadá, não obstante o acesso gratuito à terapia medicamentosa naquele país. Dessa forma, observa-se que o acesso ao tratamento pode apresentar iniqüidades de gênero que extrapolam as restrições econômicas. Freqüentemente, em alguns contextos sócioculturais, a revelação do diagnóstico de infecção por HIV, por si só, acarreta forte reação de estigma e discriminação, particularmente em relação à população feminina, restringindo portanto seu acesso integral ao tratamento (UNAIDS 2004d).

A UNAIDS (2004b) recentemente reconheceu os desafios existentes nesse aspecto. Em vários países, para se garantir o acesso eqüitativo para mulheres jovens e adultas serão necessárias mudanças de atitude de modo 
a remover barreiras estruturais ao tratamento, que incluem, entre outros, regulamentos e legislações discriminatórias.

Como se tem observado que o tratamento com HAART determina grande impacto no risco de morte e na incidência das doenças definidoras de aids (LEE e cols. 2001, JAIN e cols. 2003, MARINS e cols. 2003, MOCROFT e cols. 2003, PORTER e cols. 2003, SIGHEM e cols. 2003), pressupõe-se que qualquer grupo de pacientes que não tenha igual acesso à HAART apresente pior prognóstico da doença.

No presente estudo, à análise de sobrevida dos pacientes para o desfecho óbito relacionado à aids consideraram-se como falhas os óbitos tendo como causa básica aids, qualquer afecção oportunista definidora de aids (CDC 1992) ou afecção não definidora de aids reconhecidamente relacionada à infecção pelo HIV (ALBRECHT 1997). Nessa última categoria incluiu-se um paciente que faleceu em decorrência de câncer do reto. Sabese hoje que a infecção pelo papilomavírus humano (HPV) é uma doença sexualmente transmissível fortemente associada à infecção pelo HIV e que nessa co-infecção eleva-se o risco de desenvolvimento de lesões precursoras e de câncer anogenital em pacientes de ambos os sexos (FRISCH e cols. 2000).

Do ponto de vista metodológico, as análises de sobrevida na infecção por HIV/aids têm utilizado populações com características distintas quando se comparam os diferentes estudos. Em alguns casos, optou-se por avaliar apenas pacientes com diagnóstico de aids na estimativa do tempo de sobrevida até o óbito relacionado a essa doença (RAPITI e cols. 2000, LEE e cols. 2001, MENESIA e cols. 2001, FORDYCE e cols. 2002, MARINS e cols. 2003). Em outros estudos, entretanto, que envolveram grandes casuísticas, foram incluídos indivíduos soropositivos para a infecção pelo HIV, independentemente de preencherem ou não os critérios diagnósticos de aids. Dentre esses podem ser citados a coorte EuroSIDA, que analisou dados de cerca de 10.000 pacientes selecionados em 70 centros europeus (MOCROFT e cols. 2003), a coorte ATHENA com aproximadamente 4.000 
pacientes holandeses em uso de HAART (SIGHEM e cols. 2003), a coorte suiça (Swiss HIV Cohort Study) com quase 3.000 indivíduos (LEDERGERBER e cols. 1999) e a coorte da clínica de HIV da universidade norte-americana Johns Hopkins com cerca de 1.400 pessoas (CHAISSON e cols. 1995).

À semelhança desses estudos, na coorte acompanhada na Casa da Aids, optou-se por avaliar a sobrevida até o óbito relacionado à doença para o total de 310 mulheres e 762 homens que compuseram a coorte em seguimento no serviço, independentemente do estadio clínico apresentado no momento da inclusão no estudo.

Os resultados obtidos nessa análise revelaram pior prognóstico da doença na população feminina. O risco de uma paciente atendida na Casa da Aids entre janeiro de 1998 e março de 2003 morrer de aids foi $86 \%$ maior quando comparado ao de um paciente do sexo masculino.

Analogamente ao observado nessa população, SANTORO-LOPES e cols. (1998) encontraram, no Rio de Janeiro, risco de óbito por aids igual a 4,4 na comparação entre mulheres e homens.

RAPITI e cols. (2000), em estudo desenvolvido na Itália, verificaram que os pacientes com diagnóstico de aids entre 1996 e 1997 e com pior nível socioeconômico apresentaram menor sobrevida em relação àqueles com maior status. Essa diferença ficou mais evidenciada na análise estratificada por sexo. $\mathrm{Na}$ comparação entre o pior e o melhor status socioeconômico os homens apresentaram risco de óbito igual a 2,27 e as mulheres, 4,85 .

Por outro lado, tanto MENESIA e cols. (2001) como CAMPOS e cols. (2005), em estudos realizados, respectivamente, em Ribeirão Preto e no Rio de Janeiro, não verificaram diferenças na sobrevida entre homens e mulheres com aids. Distinção no risco de óbito entre os sexos também não foi observada em outros estudos realizados em países desenvolvidos 
(LEPRI e cols. 1994, DUNNE e cols. 1997, SIGHEM e cols. 2003, NICASTRI e cols. 2005).

Pode-se atribuir as diferenças nos achados dos diversos pesquisadores à época em que os estudos foram conduzidos (era préHAART versus pós-HAART), a características sócio-demográficas dos pacientes avaliados ou ainda a particularidades do contexto epidemiológico analisado.

Independentemente da variável sexo, neste estudo, outras variáveis mostraram-se preditoras para o óbito por aids após ajuste para o tipo de tratamento anti-retroviral recebido: idade ao diagnóstico de infecção por HIV, diagnóstico de afecção oportunista prévia à admissão ou durante o seguimento no serviço, ter apresentado menor número de células CD4+ periféricas inferior a $200 / \mathrm{mm}^{3}$ ou maior carga viral plasmática de HIV igual ou superior a 100.000 cópias $/ \mathrm{mL}$. Essas variáveis são sabidamente relacionadas ao prognóstico e ao risco de morte associado à doença, denotando maior atividade do vírus ou maior depressão do estado imunitário do paciente.

A partir dos elementos acima descritos, devem-se analisar eventuais fatores associados às diferenças observadas no prognóstico da população feminina com HIV/aids. Por que as mulheres, embora tenham apresentado, à matrícula no serviço, estadio clínico menos avançado que os homens e igual acesso ao tratamento, evoluíram mais freqüentemente para a morte?

Reconhecem-se entre os fatores determinantes à vulnerabilidade ao HIV na população feminina a dificuldade na busca e acesso às informações. Essas mulheres, em geral, são donas de casa, com parceiros fixos e possuem baixa escolaridade e sofrem com "o silêncio e o descaso tradicionalmente associado com a sexualidade e a saúde feminina" (PARKER e GALVÃO 1996). 
HALLMAN (2004) verificou que o baixo status socioeconômico repercutiu mais significativamente nas mulheres do que entre os homens no que diz respeito a práticas de sexo desprotegido. Esse comportamento se por um lado aumenta o risco de aquisição do HIV entre os indivíduos expostos, por outro pode também elevar o risco de re-infecção entre parceiros sexuais soropositivos, determinando maior carga viral plasmática (GROBLER e cols. 2004).

Muitos programas de prevenção primária e secundária relacionados à infecção pelo HIV não levam em conta as desigualdades entre os sexos. $\mathrm{Na}$ realidade, as mulheres enfrentam uma série de vulnerabilidades e fatores de risco relacionados à infecção e ao adoecimento que não afetam os homens, muitos dos quais estão implícitos nas relações sociais e nas realidades econômicas das sociedades (ONUSIDA 2004).

A independência econômica da mulher é importante também para reduzir sua exposição à violência por parte do parceiro e a outros fatores de risco relacionados ao HIV. As mulheres que sofrem violência doméstica apresentam menor poder de negociação nas relações sexuais, especialmente no que diz respeito ao uso de camisinhas (TÜRMEN 2003).

É importante também reconhecer a necessidade das pessoas de buscar posição social e auto-estima. Portanto, as desigualdades socioeconômicas em relação ao gênero devem ser diminuídas para se obter redução na vulnerabilidade feminina ao HIV.

De acordo com FITZPATRICK (2001), indivíduos com baixa autoestima podem apresentar depressão e outros transtornos psiquiátricos, resultando muitas vezes em falta de confiança e de determinação para adotar ou manter comportamentos apropriados de promoção e manutenção da saúde. $A$ isto se acresce a falta de autonomia das mulheres até mesmo na decisão de fazer ou não o teste anti-HIV; muitas precisam obter o consentimento prévio do parceiro (MAMAN e cols. 2002). O retardo no diagnóstico da infecção nesses casos pode-se relacionar com menor acesso 
ao tratamento e conseqüentemente a maior morbidade e mortalidade associada a aids. Entretanto, essa característica não parece justificar 0 maior risco de morte observado para as mulheres assistidas na Casa da Aids, visto que ingressaram no serviço em fases mais precoces da história natural da infecção.

Da mesma maneira, pode-se especular que o menor acesso à informação, por parte das mulheres vivendo com HIV/aids, pode comprometer também sua compreensão da necessidade de se manterem sob seguimento clínico, de modo a poderem se beneficiar das intervenções profiláticas e terapêuticas hoje disponíveis. A título de exemplo, SEGURADO e cols. (2002), na avaliação do cuidado clínico prestado a 1068 mulheres com HIV/aids na Casa da Aids e no Centro de Referência e Treinamento em DST/aids da Secretaria de Estado da Saúde de São Paulo, observaram que entre $40 \%$ e $50 \%$ das mulheres entrevistadas, apesar do pleno acesso aos testes laboratoriais, não compreendiam corretamente o significado das determinações de carga viral plasmática de HIV e de células CD4+, exames imprescindíveis para o seguimento laboratorial evolutivo das pacientes.

Outra questão pertinente refere-se à adesão à terapia medicamentosa. McDONALD e cols. (2001) observaram menor adesão ao tratamento anti-retroviral na população feminina, porém tal associação não é consensual entre diferentes pesquisadores. Assim, em estudo com 1972 pacientes de 60 serviços das cinco regiões brasileiras, NEMES e cols. (2004) encontraram prevalência de $75 \%$ na adesão à terapia. Não foi observada diferença com significância estatística entre os sexos, porém verificaram que a baixa escolaridade e idade inferior a 45 anos foram preditores da não adesão. Apesar de se dispor de acesso universal e gratuito ao medicamento anti-retrovirais, pode haver outras barreiras econômicas que comprometam a adesão ao tratamento. Da mesma forma, HADER e cols. (2001) não acreditam que a variável sexo seja preditora de adesão à HAART. 
No presente estudo, por conta de seu desenho como coorte retrospectiva, não foi possível avaliar o papel da adesão medicamentosa no prognóstico dos pacientes analisados. Considerando-se a importância dessa variável no desempenho do cuidado prestado a pessoas vivendo com HIV/aids nos dias atuais, recomenda-se a realização de estudos prospectivos planejados com a finalidade de contribuir para melhor esclarecimento dessa questão.

Deve-se ainda considerar que as mulheres possuem necessidades específicas no enfrentamento de uma doença com as características da aids. Além de lidarem com suas próprias demandas de cuidado, freqüentemente assumem um papel destacado como cuidadoras de seus parceiros e filhos, por vezes acometidos da doença (SOWELL e cols. 1999, SEGURADO e cols. 2002).

Além disso, avaliar se a qualidade de vida de pacientes com HIV/aids difere segundo sexo é relevante na comparação da evolução da infecção. SANTOS (2003), em estudo desenvolvido na Casa da Aids, verificou menores escores na qualidade de vida das mulheres para os domínios psicológico e meio ambiente. Analogamente, MRUS e cols. (2005) encontraram diferença estatisticamente significativa entre os sexos no domínio físico, incluindo funcionamento corporal, dor e energia/fadiga. Tais diferenças de gênero na expressão de queixas somáticas, psicológicas e em aspectos estruturais relativos ao meio ambiente podem contribuir também para comprometer a evolução da infecção na população feminina.

A interpretação dos resultados de estudos epidemiológicos requer a avaliação crítica da possibilidade de existência de viéses bem como do papel de variáveis de confusão, com avaliação da possível influência desses sobre os resultados obtidos (ROTHMAN e GREENLAND 1998).

Neste estudo deve-se considerar inicialmente as limitações inerentes ao método utilizado, baseado em observações oriundas de coorte retrospectiva. Observou-se, no momento da coleta de dados, falta de 
padronização nos registros realizados no serviço por ocasião das consultas médicas. Procurou-se superar essa limitação por meio da elaboração da ficha padronizada de coleta de dados e pela restrição no número de investigadores que se responsabilizaram por esta tarefa, cabendo a um mesmo profissional o preenchimento de $91 \%$ das fichas analisadas. No entanto, verificou-se mesmo assim inexistência de dados para algumas variáveis de interesse do estudo.

Segundo SANTOS SILVA (1999), a elevada freqüência de valores ignorados para algumas variáveis pode comprometer a interpretação dos resultados da análise de estudos de coorte retrospectiva. Nos dados coletados nesta pesquisa fatores de eventual importância prognóstica como, por exemplo, profilaxias de afecções oportunistas ou reatividade ao teste tuberculínico não puderam ser avaliados em virtude da incompletude de dados.

As perdas de seguimento constituem também fontes de viés de seleção nos estudos de coorte, com potencial de afetar os resultados observados. Neste estudo, todavia, houve baixo número de perdas durante o acompanhamento $(n=106(9,9 \%))$, o que torna menos importante a influência destas nos resultados obtidos.

Por outro lado, deve-se considerar que falhas no preenchimento dos registros de óbitos podem ter subestimado o número de desfechos consultados na avaliação do tempo de sobrevida até o óbito relacionado à aids.

Deve-se ainda destacar que o presente estudo baseou-se na avaliação de uma coorte prevalente de homens e mulheres vivendo com HIV/aids. Essa abordagem, se por um lado torna os estudos de sobrevida mais factíveis na prática, por outro, apresenta limitações metodológicas intrínsecas, uma vez que se desconhece o momento da infecção para cada um dos indivíduos selecionados. Observa-se dessa forma maior 
heterogeneidade no estadio evolutivo dos indivíduos da amostra estudada no momento de inclusão na coorte.

Ao contrário dessa abordagem, alguns estudos têm buscado acompanhar indivíduos para os quais se conhece ou se estima de modo confiável a data da soroconversão (LEPRI e cols. 1994, HOUWELING e cols. 1999, DETELS e cols. 1998, PORTER e cols. 2003). Porém, na prática clínica a identificação do momento de infecção por HIV, mesmo no seguimento de indivíduos expostos à aquisição desse retrovírus é bastante difícil, tendo em vista o fato de que a infecção aguda é habitualmente assintomática e a monitoração sorológica periódica é pouco factível.

Não obstante tais dificuldades, a execução de estudos a partir das vivências rotineiras em serviços de saúde deve ser estimulada, por permitir melhor conhecimento da realidade prática na assistência à saúde e poder servir para aprimoramento das ações ali conduzidas.

De um modo geral, o cuidado às pessoas com HIV/aids baseia-se em estratégias dirigidas à população acometida pela infecção. Entretanto, o benefício de tais intervenções pode variar significativamente em diferentes grupos como, por exemplo, entre homens e mulheres. A análise estratificada por sexo dos dados da epidemia permite identificar de forma mais clara o papel desempenhado pelas relações de gênero nos desfechos de interesse (incidência e mortalidade) e pode contribuir para uma ação mais eficaz sobre a doença.

Este estudo observou que as mulheres parecem ter-se beneficiado em menor intensidade do cuidado recebido em um serviço universitário de referência do Município de São Paulo. O reconhecimento dos fatores associados a maior vulnerabilidade no cuidado por parte da população feminina pode contribuir para o planejamento de novas iniciativas, visando aprimorar a assistência prestada, em tempos de HAART, às pessoas vivendo com HIV/aids de um modo geral e às mulheres, em particular. 


\section{CONCLUSÕES}




\section{CONCLUSÕES}

Em relação à análise comparativa do perfil clínico e epidemiológico de homens e mulheres com infecção por HIV/aids acompanhados na Casa da Aids no período de janeiro de 1998 a dezembro de 2002, o presente estudo permite destacar as seguintes conclusões:

$\checkmark$ as mulheres receberem diagnóstico de infecção por HIV em idades mais jovens e possuíam menor escolaridade à admissão ao serviço;

$\checkmark$ enquanto os homens foram submetidos ao teste sorológico anti-HIV principalmente em decorrência de sintomas sugestivos da infecção, as mulheres mais freqüentemente foram testadas ainda assintomáticas;

$\checkmark$ no momento da admissão ao serviço as mulheres mostravam-se em estadio clínico menos avançado, exibiam maior número de linfócitos CD4+ em sangue periférico, maior freqüência de carga viral indetectável ou menor viremia plasmática;

$\checkmark$ ao final do seguimento evolutivo no serviço, as mulheres não apresentaram diferença nos valores mensurados de células CD4+e de carga viral de HIV, em relação aos homens;

$\checkmark$ os homens foram mais freqüentemente admitidos no serviço sob tratamento anti-retroviral, porém à análise estratificada segundo estadio clínico não se verificou diferença entre os sexos no tipo de tratamento anti-retroviral recebido, seja no momento da matrícula na Casa da Aids, como ao final do seguimento no serviço; 
$\checkmark$ enquanto se verificou declínio na proporção de internações masculinas na era HAART, as mulheres, ao contrário, apresentaram aumento no número de admissões hospitalares;

$\checkmark$ não houve diferença significativa nos coeficientes de incidência de aids entre homens e mulheres;

$\checkmark$ não houve diferença significativa nos coeficientes de mortalidade por aids entre homens e mulheres;

o tempo mediano de progressão para aids foi de 10,3 anos e foram identificados como preditores desse desfecho, após ajuste pela variável sexo, a determinação mais elevada de carga viral de HIV superando 100.000 cópias $/ \mathrm{mL}$ durante o seguimento na Casa da Aids e o tipo de tratamento anti-retroviral recebido, observando-se menor probabilidade de progressão para aids entre os pacientes que receberam HAART por período igual ou superior a $50 \%$ do tempo de terapêutica;

após 15 anos do diagnóstico de infecção por HIV, a proporção de sobreviventes foi de $75,4 \%$. Após ajuste segundo tipo de tratamento anti-retroviral recebido ao final do seguimento, mostraram-se independentemente associados ao óbito por aids: o sexo feminino, a idade ao diagnóstico de infeç̧ão por HIV, a menor determinação de células CD4+ inferior a $200 / \mathrm{mm}^{3}$ e a maior carga viral de HIV superando 100.000 cópias $/ \mathrm{mL}$ durante o seguimento na Casa da Aids, ao lado da ocorrência de afecção oportunista prévia à admissão ou durante o seguimento no serviço. 


\section{REFERÊNCIAS}




\section{REFERÊNCIAS}

Albrecht $\mathrm{H}$. Redefining AIDS: towards a modification of the current AIDS case definition. Clin Infect Dis 1997; 24:64-74.

Alves MTSSB, Silva AAM, Nemes MIB, Brito LGO. Tendências da incidência e da mortalidade por Aids no Maranhão, 1985 a 1998. Rev Saúde Pública 2003; 37:177-82.

Anjos RMP. Sobrevida dos pacientes com aids na região de SorocabaSP 1985-1997. São Paulo; 2000. [Tese de Doutorado - Instituto Emílio Ribas].

Boletim Epidemiológico-Aids. Ministério da Saúde. Brasília (DF) 2001; 14(2).

Boletim Epidemiológico-Aids. Ministério da Saúde. Brasília (DF) 2004; 17(1).

Boletim Epidemiológico-Aids e DST. Ministério da Saúde. Brasília (DF) 2005; 1(1).

Boletim Epidemiológico de Aids do Município de São Paulo. Secretaria Municipal da Saúde. São Paulo (SP) 2004; 8(8).

Campos DP, Ribeiro SR, Grinsztejn B, Veloso VG, Valente JG, Bastos FI et al. Survival of AIDS patients using two case definitions, Rio de Janeiro, Brazil, 1986-2003. AIDS 2005; 19 Suppl 4:S22-26.

[CDC] Centers for Disease Control. 1993 revised classification system for HIV infection and expanded surveillance of definition for AIDS among adolescents and adults. MMWR Morb Mortal Wkly Rep 1992; 41(RR-17):119. 
[CDC] Centers for Disease Control and Prevention. The global HIV and AIDS epidemic, 2001. MMWR Morb Mortal Wkly Rep 2001; 50(21):434-9.

[CDC] Centers for Disease Control and Prevention. HIVIAIDS surveillance Report, 2003. Atlanta: CDC; 2004. v.15.

Chaisson RF, Keruly JC, Moore RD. Race, sex, drug use, and progression of human immunodeficiency virus disease. N Engl J Med 1995; 333:751-6.

Chequer C, Hearst N, Hudes ES, Castilho E, Ruhterford G, Loures L et al. Determinants of survival in adult Brazilian AIDS patients, 1982-89. The Brazilian State AIDS Program Co-ordinators. AIDS 1992; 6:483-7.

Collett D. Modelling survival data in medical research. London: Chapman \& Hall; 1994.

Cox DR. Regression models and life tables. J R Stat Soc 1972; 34:187-202.

Dean MM, Carrington M, Winkler C, Huttley G, Smith M, Allikmets R et al. Genetic restriction of HIV-1 infection and progression to AIDS by a deletion allele of the CKR5 structural gene. Science 1996; 273:1856-62.

Detels R, Muñoz A, McFarlane G, Kingsley LA, Margolick JB, Giorgi J et al. Effectiveness of potent antiretroviral therapy on time to AIDS and death in men with known HIV infection duration. JAMA 1998; 280:1497-503.

Doring M. Sobrevida dos pacientes com aids no Município de Passo Fundo-RS, período de 1988 a 1997. São Paulo; 1998. [Dissertação de Mestrado - Faculdade de Saúde Pública da USP].

Dunne MT, Ruskin HJ, Mulcahy FM. Survival with AIDS in Ireland. AIDS 1997; 11:1281-90. 
Egger M, Hirschel B, Francioli P, Sudre P, Wirz M, Flepp M et al. Impact of new antiretroviral combination therapies in HIV infected patients in Switzerland: prospective multicentre study. BMJ 1997; 315:1194-9.

Egger M, May M, Chêne G, Phillips AN, Lederbeger B, Dabis F et al. Prognosis of HIV-1 infected patients starting highly active antiretroviral therapy a collaborative analysis of prospective studies. Lancet 2002; 360:119-29.

Farias NSO. Mortalidade por Aids e condições socioeconômicas no município de São Paulo, 1994 a 1999. São Paulo; 2002. [Tese de Doutorado - Faculdade de Saúde Pública da USP].

Fitzpatrick R. Social status and mortality [editorial]. Ann Intern Med 2001; 134:1001-3.

Fletcher RH, Fletcher SW, Wagner EH, editors. Epidemiologia clínica. 2. ed. Porto Alegre: Artes Médicas; 1989.

Fonseca MG, Szwarcwald CL, Derrico M, Andrade CLT, Veras CT, Bastos FI. Aids e grau de escolaridade no Brasil: evolução temporal de 1986 a 1996. Cad Saúde Pública 2000; 16 Supl 1:77-87.

Fonseca MG, Travassos C, Bastos FI, Silva NV, Szwarcwald CL. Distribuição social da Aids no Brasil, segundo participação no mercado de trabalho, ocupação e status sócio-econômico dos casos de 1987 a 1998. Cad Saúde Pública 2003; 19:1351-63.

Fordyce EJ, Singh TP, Nash D, Gallagher B, Forlenza S. Survival rates in NYC in the era of combination ART. J Acquir Immune Defic Syndr 2002; 30:111-8. 
Frahm N, Adam S, Kiepiela P, Linde $\mathrm{CH}$, Hewitt HS, Lichterfeld $\mathrm{M}$ e cols. HLA-B63 presents HLA-B57/B58 - restrict cytotoxic -T-lymphocyte epitotes and is associated with low human immunodeficiency virus load. J Virol 2005; 79:10218-25.

Frisch M, Biggar RJ, Goedert JJ. Human papillomavirus-associated cancers in patients with human immunodeficiency virus infection and acquired immunodeficiency syndrome. J Natl Cancer Inst 2000; 92:1500-10.

Gotlieb SLD, Castilho EA, Buchalla CM. O impacto da aids na esperança de vida, Brasil, 1996. Bol Epidemiol Aids 2000; 13(2):33-8.

Greub G, Ledergeber B, Battegay M, Grob P, Perrin L, Furrer H et al. Clinical progression, survival and immune recovery during antiretroviral therapy in patients with HIV-1 and hepatitis C virus coinfection: the Swiss HIV cohort study. Lancet 2000; 356:1800-5.

Grobler J, Gray CM, Rademeyer C, Seoighe C, Ramjee G, Karim SA et al. Incidence of HIV-1 dual infection and its association with increased viral load set point in a cohort of HIV-1 subtype C-infected female sex workers. J Infect Dis 2004; 190:1355-9.

Guimarães MDC. Estudo temporal das doenças associadas à AIDS no Brasil, 1980-1999. Cad Saúde Pública 2000; 16 Supl 1:21-36.

Hader SL, Smith DK, Moore JS, Holmberg SD. HIV infection in women in the United States-status at the millennium. JAMA 2001; 285:1186-92.

Hallman K. Socioeconomic disadvantage and unsafe sexual behaviors among young women and men in South Africa. Policy Res Div Work Pap [serial on line] 2004; (190):1-52. Available from: http://www.popcouncil.org/pdfs/wp/190.pdf [2005 Aug 10]. 
Hera MG, Ferreros I, Amo J, Olalla PG, Hoyos SP, Muga R et al. Gender differences in progresión to AIDS and death from HIV seroconversion in a cohort of injecting drug users from 1986 to 2001. J Epidemiol Community Health 2004; 58:944-50.

Houweling H, Wiessing LG, Hamers FF, Termorshuizen F, Gill ON, Sprenger MJW. An age-period-cohort analysis of 50875 AIDS cases among injecting drug users in Europe. Int J Epidemiol 1999; 28:1141-8.

Jain MK, Skiest DJ, Cloud JW, Jain CL, Burns D, Berggren RE. Changes in mortality related to human immunodeficiency virus infection: comparative analysis of inpatient deaths in 1995 and in 1999-2000. Clin Infect Dis 2003; 36:1030-8.

Kalton G. Introduction to survey sampling. Beverly Hills: Sage Publications; 1983.

Kaplan EL, Meier P. Nonparametric estimation from incomplete observations. J Am Stat Assoc 1958; 53:457-81.

Kish L. Survey sampling. New York: John Willey \& Sons; 1965.

Kleinbaum DG. Survival analysis: a self learning text. New York: SpringerVerlag; 1996.

Laurenti R, Mello Jorge MHP de, Lebrão ML, Gotlieb SLD. Estatísticas de Saúde. 2. ed. São Paulo: E.P.U.; 2005.

Ledergerber B, Egger M, Opravil M, Telenti A, Hirschel B, Battegay M et al. Clinical progression and virological failure on highly active antiretroviral therapy in HIV-1 patients: a prosprective cohort study. Lancet 1999; 353:863-8. 
Lee ET. Statistical methods for survival data analysis. Belmond: Lifetime Learning Publications; 1980.

Lee LM, Karon JM, Selik R, Neal JJ, Fleming PL. Survival after AIDS diagnosis in adolescents and adults during the treatment era, United States, 1984-1997. JAMA 2001; 285:1308-15.

Lepri AC, Pezzotti P, Dorrucci M, Phillips AN, Rezza G, Italian Seroconversion Study. HIV disease progression in 854 women and men infected through injecting drug use and heterosexual sex and followed for up to nine years from seroconversion. BMJ 1994; 309:1537-42.

Levy JA. HIV and the pathogenesis of AIDS. 2. ed. Washington(DC): ASM Press; 1998.

Lowndes CM, Bastos FI, Giffin KM, dos Reis ACGV, d’Orsi E, Alary M. Differential trends in mortality from AIDS in men and women in Brazil (19841995). AIDS 2000; 14:1269-73.

Lundgren JD, Pedersen C, Clumeck N, Gatell JM, Johnson AM, Lederbeger $B$ et al. Survival differences in European patients with AIDS 1979-1989. The AIDS in Europe Study Group. BMJ 1994; 308:1068-73.

Maman S, Mbwambo JK, Hogan NM, Kilonzo GP, Campbell JC, Weiss E et al. HIV-positive women report more lifetime partner violence: findings from a voluntary counseling and testing clinic in Dar es Salaam, Tanzania. Am J Public Health 2002; 92:1331-7.

Mantel N. Evaluation of survival data and two new rank order statistics arising in its consideration. Cancer Chemother Rep 1966; 50:163-70. 
Marins JRP, Jamal LF, Chen SY, Barros MB, Hudes ES, Barbosa AA et al. Dramatic improvement in survival among adult Brazilian Aids patients. AIDS 2003; 17:1675-82.

Marubini E, Valsecchi MG. Analysing survival data from clinical trials and observational studies. Chichester: John Wiley \& Sons; 1995.

McDonald K, Bartos M, Rosenthal D. Australian women living with HIV/AIDS are more sceptical than men about antiretroviral treatment. AIDS Care 2001; 13:15-26.

Melnick SL, Sherer R, Louis TA, Hillman D, Rodriguez EM, Lackman C et al. Survival and disease progression according to gender of patients with HIV infection. JAMA 1994; 272:1915-21.

Mellors JW, Kingsley LA, Rinaldo CRJ, Todd JA, Hoo BS, Kokka RP et al. Quantification of HIV-1 RNA in plasma predicts outcome after seroconversion. Ann Intern Med 1995; 122:573-9.

Mellors JW, Muñoz A, Giorgi JV, Margolick JB, Tassoni CJ, Gupta P et al. Plasma viral load and CD4+ lymphocytes as prognostic markers of HIV-1 infection. Ann Intern Med 1997; 126: 946-54.

Menesia EO, Passos ADC, Monteiro ME, Dal-Fabbro AL, Laprega MR. Sobrevivência de pacientes com aids em uma cidade do sudeste brasileiro. Rev Panam Salud Pública 2001; 10:29-36.

Ministério da Saúde. Consenso gestante 2004 [on line]. 2004a. Disponível em: http://www.aids.gov.br/final/biblioteca/gestante_2004/ consensogestante2004. doc [2005 Set 15]. 
Ministério da Saúde. Recomendações para terapia anti-retroviral em adultos e adolescentes infectados pelo HIV 2004 [on line]. 2004b. Disponível em:http://www.aids.gov.br/data/documents/storedDocuments/ \%7BB8EF5DAF-23AE-4891-AD36-1903553A3174\%7D/\%7B94A5DEB6-6F59470A-A2DE-9DD49C7ECF75\%7D/consenso_adulto_adolescente.doc [2005 Dez 4].

Ministério da Saúde. Resposta_2005 [on line]. 2005. Disponível em: http://www.aids.gov.br/final/biblioteca/resposta/resposta_2005.pdf [2005 Set 15].

Mocroft A, Youle M, Morcinek J, Sabin CA, Gazzard B, Johnson MA et al. Survival after diagnosis of AIDS: a prospective observational study of 2625 patients. BMJ 1997; 314:409-13.

Mocroft A, Gill MJ. Davidson W, Phillips AN. Are there gender differences in starting protease inhibitors HAART, and disease progression despite equal access to care? J Acquir Immune Defic Syndr 2000; 24:475-82.

Mocroft A, Ledergerber B, Katlama C, Kirk O, Reiss P, d'Armino Monforte A et al. Decline in the AIDS and death rates in the EuroSIDA study: an observational study. Lancet 2003; 362:22-9.

Monga HK, Rodrigues-Barradas MC, Breaux K, Khattak K, Troisi CL, Velez $M$ et al. Hepatitis $C$ virus infection-related morbidity and mortality among patients with human immunodeficiency virus infection. Clin Infect Dis 2001; 33:240-7.

Moore AL, Sabin CA, Johnson MA, Phillips NA. Gender and clinical outcomes after starting highly active antiretroviral treatment: a cohort study. $\mathbf{J}$ Acquir Immune Defic Syndr 2002; 29:197-202. 
Mrus IM, Williams PG, Tsevat J, Cohn SE, Wu AW. Gender differences in health-related quality of life in patients with HIV/AIDS. Qual Life Res 2005; 44:479-91.

[MS-CN-DST/AIDS]. Ministério da Saúde. Coordenação Nacional DST/AIDS. Saúde divulga novos números da aids no Brasil - 26/5/2004. [on line]. 2004. Disponível em:

http://www.aids.gov.br/data/Pages/LUMISE77B47C8ITEMID8B 563C82477845D2AD098492EDDC9CD1PTBRIE.htm [2004 Mai 26].

Nascimento AMG, Barbosa CS, Medrado B. Mulheres em Camaragibe: representação social sobre a vulnerabilidade feminina em tempos de AIDS. Rev Bras Saúde Matern Infant 2005; 5:77-86.

Nemes MIB, Carvalho HB, Souza MFM. Antiretroviral therapy adherence in Brazil. AIDS 2004; 18 Supl 3:S15-20.

Nicastri E, Angeletti C, Palmisano L, Sarmati L, Chiesi A, Geraci A et al. Gender differences in clinical progression of HIV-1-infected individuals during long-term highly active antiretroviral therapy. AIDS 2005; 19:577-83.

Nobre V, Braga E, Rayes A, Serufo JC, Godoy P, Nunes N et al. Opportunistic infections in patients with aids admitted to an university hospital of the southeast of Brazil. Rev Inst Med Trop Sao Paulo 2003; 45:69-74.

Nuesch R, Geigy N, Schaedler E, Battegay M. Effect of highly active antiretroviral therapy on hospitalization characteristics of HIV-infected patients. Eur J Clin Microbiol Infect Dis 2002; 21:684-7.

ONUSIDA. Situación de la epidemia de SIDA: 2004. Ginebra: Organización Mundial de la Salud; 2004. 
[PAHO] Pan American Health Organization. Women and HIVIAIDS: prevention and care strategies. Washington (DC); 2000.

Palella FJJr, Delaney KM, Moorman AC, Lovelless MO, Fuhrer J, Satten GA et al. Declining morbidity and mortality among patients with advanced human immunodeficiency virus infection. N Engl J Med 1998; 338:853-60.

Parker R, Galvão J. Quebrando o silêncio: mulheres e AIDS no Brasil. Rio de Janeiro: Relume-Dumará/ABIA/IMS/UERJ; 1996. Introdução; p.7-15.

Pascom ARP, Fonseca MGP, Dhalia CBC. Epidemia de aids no Brasil. In: Ministério da Saúde CN-DST/AIDS. Resposta_2005 [on line]. 2005. p.12-5. Disponível em: http://www.aids.gov.br/final/biblioteca/resposta/resposta_2005.pdf [2005 Set 15].

Perez-Hoyos S, del Amo J, Muga R, del Romero J, Garcia O, Guerrero R et al. Effectiveness of highly active antiretroviral therapy in Spanish cohorts of HIV seroconverters: differences by transmission category. AIDS 2003; 17:353-9.

Peto R, Pike MC, Armitage P, Breslow NE, Cox DR, Howard SV et al. Design and analysis of randomized clinical trials requiring prolonged observation of each patient. II. Analysis and examples. Br J Cancer 1977; 35:1-39.

Porter K, Babiker A, Bhaskaran K, Darbyshire J, Perzzotti P, Walker AS. Determinants of survival following HIV-1 seroconversion after the introduction of HAART. Lancet 2003; 362:1267-74.

Porter K, Zaba B. The empirical evidence for the impact of HIV on adult mortality in the developing world: data from serological studies. AIDS 2004; 18 Suppl 2:S9-17. 
Price P, James I, Fernandez S, French M. Alleles of the gene encoding IL-1 [alpha] may predict control of plasma viraemia in HIV-1 patients on highly active antiretroviral therapy. AIDS 2004; 18:1495-501.

Prins M, Meyer L, Hessol NA. Sex and the course of HIV infection in the preand highly active antriretroviral therapy eras. AIDS 2005; 19:357-70.

Quinn RC, Overbaugh J. HIVIAIDS in women: an expanding epidemic. Science 2005; 308:1582-3.

Rapiti E, Porta D, Forastiere F, Fusco D, Perucci CA. Socioeconomic status and survival of persons with AIDS after the introduction of highly active antiretroviral therapy. Epidemiology 2000; 11:496-501.

Rothman KJ, Greenland S. Modern epidemiology. 2. ed. Philadelphia: Lippincott-Raven Publishers; 1998.

Saah AJ, Hoover DR, He Y, Kingsley LA, Phair JP. Factors influencing survival after AIDS: report from the Multicenter AIDS Cohort Study (MACS). J Acquir Immune Defic Syndr 1994; 7:287-95.

Santoro-Lopes G, Harrison LH, Moulton LH, Lima LAA, de Pinho AMF, Hofer $\mathrm{C}$ et al. Gender and survival after AIDS in Rio de Janeiro, Brazil. J Acquir Immune Defic 1998; 19:403-7.

Santos ECM. Qualidade de vida de portadores do vírus da imunodeficiência humana. São Paulo; 2003. [Dissertação de MestradoFaculdade de Saúde Pública da USP].

Santos NJSS. A AIDS entre as mulheres no Estado de São Paulo. In: Parker R, Galvão J. Quebrando o silêncio: mulheres e AIDS no Brasil. Rio de Janeiro: Relume-Dumará/ABIA/IMS/UERJ; 1996; p.33-59. 
Santos Silva I dos. Cancer epidemiology: principles and methods. Lyon: IARC; 1999.

Segurado AC, Miranda SD, Latorre MRDO, Brazilian Enhancing Care Initiative Team. Evaluation of the care of women living with HIVIAIDS in Sao Paulo State, Brazil . AIDS Patient Care STDs 2003; 17:85-93.

Schechter MT, Hogg RS, Aylward B, Craib KJ, Le TN, Montaner JS. Higher socioeconomic status is associated with slower progression of HIV infection independent of access to health care. J Clin Epidemiol 1994; 47: 59-67.

Shott S. Statistics for health professionals. Philadelphia: WB Saunders Company; 1990.

Siegel S. Estatística não-paramétrica para as ciências do comportamento. São Paulo: McGraw-Hill; 1975.

Sighem Al van, Wiel MA van de, Ghani AC, Jambroes M, Reiss P, Gyssens IC et al. Mortality and progression to AIDS after starting highly active antiretroviral therapy. AIDS 2003; 17:2227-36.

Sowell RL, Moneyham L, Aranda-Naranjo B. The care of women with AIDS. Special needs and considerations. Nurs Clin North Am 1999; 34:179-99.

Strathdee AS, Palepu A, Cornelisse PGA, Yip B, O’Shaughnessy MV, Montaner JSG et al. Barriers to use of free antiretroviral therapy in injection drug users. JAMA 1998; 280:547-9.

Szwarcwald CL, Bastos FI, Esteves MAP, Andrade CLT. A disseminação da epidemia da Aids no Brasil, no período de 1987-1996: uma análise espacial. Cad Saúde Pública 2000; 16 Supl1:7-19. 
Tancredi MV. Tendência da epidemia de aids no Município de São Paulo, 1985 a 2000. São Paulo; 2003. [Dissertação de Mestrado-Faculdade de Saúde Pública da USP].

Triola MF. Introdução à estatística. 7. ed. Rio de Janeiro: Livros Técnicos e Científicos Editora, 1999.

Tsantes A, Nikolopoulos G, Masgala A, Paraskeva D. Assessing the secular trends in the transmission of HIV in Greece. Sex Transm Infect 2005; 81:230-2.

Türmen T. Gender and HIV/AIDS. Int J Gynaecol Obstet 2003; 82:411-8.

UNAIDS. Report on the global HIV/aids epidemic. Geneva: UNAIDS/WHO; 2002.

UNAIDS. Gender and HIVIAIDS. Geneva: UNAIDS/WHO; 2003.

UNAIDS. Report on the global AIDS epidemic. Geneva: UNAIDS/WHO; 2004a.

UNAIDS. Facts sheets on HIVIAIDS care and treatment. Geneva: UNAIDS/WHO; 2004b.

UNAIDS. Number of women living with HIV increases in each region of the world [on line]. 2004c. Available from: http://www.unaids.org/html/ pub/media/ press_releases02/PR_EpiLaunch_23Nov04_en_pdf/PR_E [2005 Jan 5].

UNAIDS. Ensuring equitable access to antiretroviral treatment for women. Geneva: UNAIDS/WHO; 2004d.

UNAIDS. AIDS epidemic update. Geneva: UNAIDS/WHO; 2005. 
[UNFPA] United Nations Population Fund. Tendências da população mundial [on line]. 2005. Available from:http://www.unfpa.org.br/ESTRUT/SERV/ arquivos/tendencias_da_populaçao_mundial.htm [2005 Sep 1].

United Nations. The millennium development goals report. New York: United Nations Department of Public Information; 2005.

Vella S, Giuliano M, Floridia M, Chiesi A, Tomino C, Seeber A et al. Effect of sex, age and transmission category on the progression to AIDS and survival of zidovudine-treated symptomatic patients. AIDS 1995; 9:51-6.

Vermelho LL, Silva LP, Costa AJL. Epidemiologia da transmissão vertical do HIV no Brasil [on line]. 1999. Disponível em: http://www.aids.gov.br/udtv/ boletim_jun_ago99/trans_vertical.htm [2002 Jul 21]. 
ANEXO 1 


\section{HOSPITAL DAS CLÍNICAS \\ DA FACULDADE DE MEDICINA DA UNIVERSIDADE DE SÃo PAULO \\ CAIXA POSTAL, 8091 - SÃO PAULO - BRASIL \\ DIRETORIA CLÍNICA}

\section{Comissão de Ética para Análise de Projetos de Pesquisa}

\section{APROVAÇÃO}

A Comissão de Ética para Análise de Projetos de Pesquisa - CAPPesq da Diretoria Clínica do Hospital das Clínicas e da Faculdade de Medicina da Universidade de São Paulo, em sessão de 09.10.02, APROVOU o Protocolo de Pesquisa $n^{\circ}$ 699/02, intitulado: "Fatores prognósticos da infecção por HIV/aids entre homens e mulheres atendidos em Centro de Referência da Cidade de São Paulo.", apresentado pelo Departamento de DOENÇAS INFECCIOSAS E PARASITÁRIAS.

Pesquisador(a) Responsável: PROF. DR. ALUÍsIO AUGUSTO COTRIM SEGURADO

Pesquisador(a) Executante: PATRÍCIA EMÍLIA BRAGA

CAPPesq, 09 de Outubro de 2002.

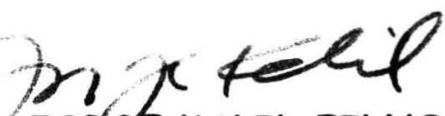

PROF. DR. JORGE KALIL FILHO

Presidente da Comissão de Ética para Análise de Projetos de Pesquisa

OBSERVAÇÃO: Cabe ao pesquisador elaborar e apresentar à CAPPesq, os relatórios parciais e final sobre a pesquisa (Resolução do Conselho Nacional de Saúde $n^{\circ} 196$, de 10.10.1996, inciso IX.2, letra "c"). 
ANEXO 2 


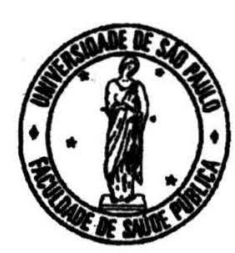

\section{Universidade de São Paulo}

\section{Faculdade de Saúde Pública}

COMTEE DE ÉTICA-COEP

Av. Dr. Arnaldo, 715 - CEP 01246-904 - São Paulo - Brasil

Telefones: (55-11) 3066- 7734 - fone/fax (55-11) 3064 -7314 - e-mail: mdgracas@usp.br

\section{Of.COEP/261/02}

10 de outubro de 2002

Pelo presente, informo que o Comitê de Ética em Pesquisa da Faculdade de Saúde Pública da Universidade de São Paulo-COEP, analisou e aprovou, em sua $8^{\mathrm{a}} .02$, realizada em 08.10 .02 , de acordo com os requisitos da Resolução CNS/196/96, o Protocolo de Pesquisa n. ${ }^{\circ}$ 860, intitulado: "FATORES PROGNÓSTICOS DA INFECÇÃO POR HIV/AIDS ENTRE HOMENS E MULHERES ATENDIDOS EM CENTRO DE REFERÊNCIA DA CIDADE DE SÃO PAULO", apresentado pela pesquisadora Patrícia Emília Braga e recomenda que o Termo de Compromisso seja anexado no respectivo projeto.

Atenciosamente,

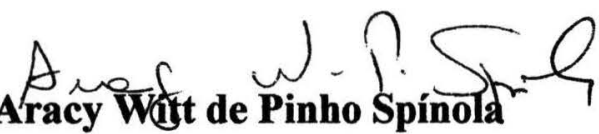

Professora Titular

Vice-Coordenadora do Comitê de Ética em Pesquisa da FSP-COEP 
ANEXO 3 


\section{TERMO DE COMPROMISSO}

Nós abaixo-assinadas, investigadoras responsáveis pelo projeto "Fatores prognósticos da infecção por HIV/aids entre homens e mulheres atendidos em Centro de Referência da Cidade de São Paulo" comprometemonos a preservar o anonimato dos sujeitos da pesquisa, bem como garantir o sigilo e a confidencialidade no manuseio das informações relativas aos pacientes estudados.

Certificamos, outro sim, que os dados coletados serão utilizados exclusivamente com o propósito previsto nos objetivos da pesquisa.

São Paulo, 15 de outubro de 2002.
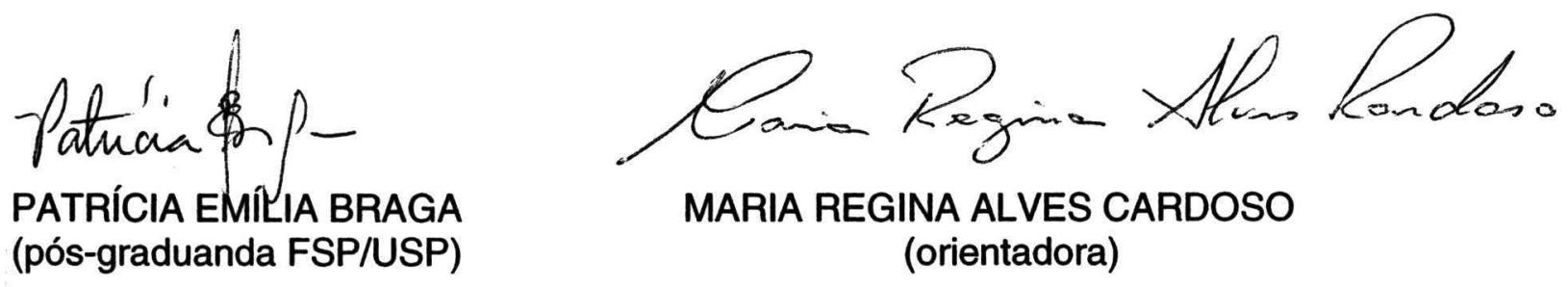

(pós-graduanda FSP/USP)

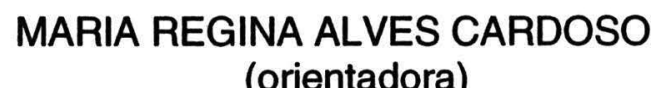

(orientadora) 
ANEXO 4 


\section{GUIA DE ELEGIBILIDADE}

Identificação: $\{10\}$

\begin{tabular}{|lll}
\hline No registro HC do(a) paciente: $\{$ REGHC $\}$ & \\
\hline Iniciais do nome do(a) paciente: $\{$ NOME $\}$ & \\
\hline Sexo: $\{$ SEXO $\}$ & 1. Masculino & 2. Feminino
\end{tabular}

Data de nascimento: \{DATNASC $\}$

$\mathrm{O}(\mathrm{A})$ paciente foi atendido(a) na Casa da Aids alguma vez entre $1 / 1 / 1998$ e 31/12/2002?
( ) 0. NÃO $\Longrightarrow$ NÃO PREENCHA O QUESTIONÁRIO
( ) 1. SIM $\Longrightarrow$ PROSSIGA COM O QUESTIONÁRIO

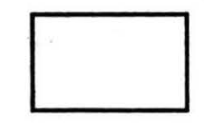

$\mathrm{O}(\mathrm{A})$ paciente foi acompanhado(a) na Casa da Aids por 30 dias ou mais?
( ) 0. NÃO $\Longrightarrow$ NÃO PREENCHA O QUESTIONÁRIO
( ) 1. SIM $\Rightarrow$ PROSSIGA COM O QUESTIONÁRIO

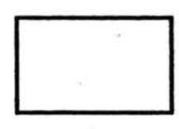

\begin{tabular}{|c|c|c|c|}
\hline & PREENCHIMENTO & CODIFICAÇÃO & DIGITAÇÃO \\
\hline NOME & & & \\
\hline DATA & -1 & & \\
\hline \{DTPREE & & & 1 \\
\hline
\end{tabular}




\section{INFORMAÇÕES SOBRE O(A) PACIENTE}

ESCOLARIDADE à admissão na CASA DAAIDS: \{ESCOLA\}

\begin{tabular}{|l|l|l|l|l|l|}
\hline analfabeto & 0 & ginásio completo & 4 & superior completo & 8 \\
\hline 1ario incompleto & 1 & colegial incompleto & 5 & ignorado & 9 \\
\hline 1ario completo & 2 & colegial completo & 6 & & \\
\cline { 1 - 3 } ginásio incompleto & 3 & superior incompleto & 7 & & \\
\cline { 1 - 3 } & &
\end{tabular}

OCUPAÇÃO à admissão na CAȘA DAAIDS: \{ocuP\}

ESTADO CIVIL: \{ESTCIV\}

\begin{tabular}{|l|l|l|}
\hline Solteiro(a) & 1 & \\
\hline Casado(a)/Amasiado(a) & 2 & \\
\cline { 1 - 2 } Viúvo(a) & 3 & \\
\hline Divorciado(a)/Desquitado(a) & 4 & \\
\cline { 1 - 2 } DATA DE MATRíCULA CASA DAAIDS:\{DTMATR\} & & DIA MES ANO \\
\cline { 1 - 2 }
\end{tabular}

CATEGORIA DE EXPOSIÇÃO AO HIV (segundo modelo hierarquizado): \{CATEXP\}

\begin{tabular}{|l|c|}
\hline Ignorado & 0 \\
\hline Uso de drogas injetáveis & 1 \\
\hline Bissexual & 2 \\
\hline Homossexual & 3 \\
\hline Heterossexual & 4 \\
\hline Transfusão sangüínea & 5 \\
\hline
\end{tabular}

DATA DO $1^{\circ}$ TESTE HIV POSITIVO:\{DTPOSIT\}

MOTIVO PELO QUAL REALIZOU TESTE HIV: \{MOTNO\}

\begin{tabular}{|l|c|}
\hline Informação não disponível & 0 \\
\hline Sintomas sugestivos de infeç̧ão por HIV/aids & 1 \\
\hline Triagem sorológica em banco de sangue & 2 \\
\hline Triagem sorológica de doadores de órgãos & 3 \\
\hline Triagem sorológica de doadores de esperma & 4 \\
\hline Triagem sorológica de doadores de leite & 5 \\
\hline Triagem no pré-natal & 6 \\
\hline Assintomático com parceiro(a) soropositivo & 7 \\
\hline $\begin{array}{l}\text { Outros \{MoTivout\} } \\
\text { Citar: }\end{array}$ & 8 \\
\hline
\end{tabular}




\section{DIAGNÓSTICOS ATÉ O MOMENTO DA ADMISSÃO NA CASA DA AIDS}

\begin{tabular}{|l|c|}
\hline ESTADIO CLÍNICO HIV: $\{\mathrm{HIV}\}$ & 1 \\
\hline Assintomático & 2 \\
\hline Sintomático não aids & 3 \\
\hline Aids &
\end{tabular}

Só responder o quadro abaixo, se a resposta anterior for igual a 3 (AIDS)

\begin{tabular}{|c|c|c|c|}
\hline $\begin{array}{l}\text { AFECÇÕES OPORTUNISTAS: } \\
\text { (segundo CID-10 adaptado para HIV/aids) }\end{array}$ & NÃO & SIM & $\begin{array}{l}\text { DATA } \\
\text { (MES/ANO) }\end{array}$ \\
\hline a) Apresentou alguma afecção oportunista? $\{$ afec1 1$\}$ & 0 & 1 & \\
\hline $\begin{array}{l}\text { b) Candidiase esofágica, brônquica, traqueal ou } \\
\text { pulmonar \{CAND1\} }\end{array}$ & 0 & 1 & \{DTCAND1\} \\
\hline c) Câncer cervical invasivo \{CACER 1$\}$ & 0 & 1 & $\frac{1}{\text { \{DTCACER } 1\}}$ \\
\hline d) Criptococose extrapulmonar \{CRIPTO1\} & 0 & 1 & $\frac{1}{\{\text { DTCRIPT1\} }}$ \\
\hline $\begin{array}{l}\text { e) Criptosporidíase intestinal com diarréia por } \\
\text { prazo superior a } 1 \text { mês }\{\text { CRIPINT } 1\}\end{array}$ & 0 & 1 & $\left.\frac{I}{\{D T C R I P I} 1\right\}$ \\
\hline f) Demência associada ao HIV \{DEMEN1\} & 0 & 1 & $\frac{1}{\{\text { DTDEMEN1\} }}$ \\
\hline $\begin{array}{l}\text { g) Doença pelo citomegalovírus exceto do } \\
\text { fígado, baço e linfonodos\{cıтomeg1\} }\end{array}$ & 0 & 1 & \{ \\
\hline h) Estrongiloidiase extra-intestinal \{ESTRONG1\} & 0 & 1 & {$[\overline{\text { DTESTRO1\} }}$} \\
\hline i) Histoplasmose extrapulmonar $\{$ HISTO 1$\}$ & 0 & 1 & \{DTHISTO1\} \\
\hline $\begin{array}{l}\text { j) Infecção pelo vírus do herpes simples, causando } \\
\text { úlcera mucocutânea (por prazo superior a } 1 \text { mês), } \\
\text { bronquite, pneumonite ou esofagite \{HERPES1\} }\end{array}$ & 0 & 1 & 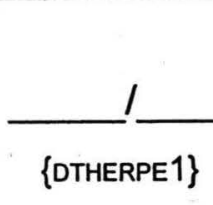 \\
\hline $\begin{array}{l}\text { k) Isosporiase com diarréia por prazo superior a } \\
1 \text { mês }\{\text { IsosPoR } 1\}\end{array}$ & 0 & 1 & $\frac{I}{\{\text { DTISOSP1\} }}$ \\
\hline I) Leucoencefalopatia multifocal progressiva \{LEMP1\} & 0 & 1 & IDTLEMP1\} \\
\hline
\end{tabular}




\begin{tabular}{|c|c|c|c|}
\hline m) Linfoma cerebral $1^{\text {ario }}\{$ LINFSNC 1$\}$ & 0 & 1 & $\frac{1}{\text { DTTLINNC1\} }}$ \\
\hline $\begin{array}{l}\text { n) Linfoma não-Hodgkin de células B ou de linfócitos } \\
\text { B de fenótipo imunológico desconhecido \{LINFNH1\} }\end{array}$ & 0 & 1 & -1 \\
\hline $\begin{array}{l}\text { o) Micobacteriose disseminada por Mycobacterium } \\
\text { avium-intracellulare ou Mycobacterium kansaii \{MAc1\} }\end{array}$ & 0 & 1 & IDTMAC1\} \\
\hline p) Nocardiose \{NOCARD 1$\}$ & 0 & 1 & $\frac{1}{\text { [DTNOCAR1\} }}$ \\
\hline 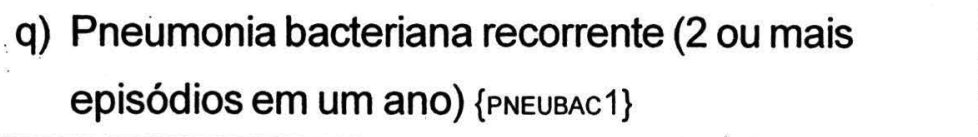 & 0 & 1 & $\frac{1}{\text { \{DTPNEUB2\} }}$ \\
\hline r) Pneumonia por Pneumocystis carinii \{PCP1\} & 0 & 1 & $\frac{1}{\{\mathrm{DTPCP} 2\}}$ \\
\hline s) Sarcoma de Kaposi \{sk1\} & 0 & 1 & $\frac{1}{\{\text { DTSK2\} }}$ \\
\hline t) Toxoplasmose do SNC $\{$ Toxo 1$\}$ & 0 & 1 & $\frac{1}{\{0 \pi T 0 \times 02\}}$ \\
\hline u) Tuberculose pulmonar \{твPчLм1\} & 0 & 1 & $\frac{1}{\{\text { DTTBPUL2\} }}$ \\
\hline v) Tuberculose disseminado $\{$ TBDIs 1$\}$ & 0 & 1 & 1 \\
\hline w) Sepse recorrente por Salmonella não typhi \{SEPSE1\} & 0 & 1 & 1 \\
\hline x) Sindrome consumptiva do HIV \{sLM1\} & 0 & 1 & 1 \\
\hline
\end{tabular}

\begin{tabular}{|c|c|c|c|c|}
\hline OUTRAS COMORBIDADES: & NÃO & SIM & \multicolumn{2}{|c|}{ DATA (MEES/ANO) } \\
\hline a) Apresentou comorbidades? \{сомоRв1\} & 0 & 1 & & \\
\hline b) Hipertensão \{HIPERT1\} & 0 & 1 & \{DTHPER1\} & 1 \\
\hline c) Diabetes $\{$ DIABET 1$\}$ & 0 & 1 & \{DTDABEE1\} & 1 \\
\hline d) Cardiopatia \{CARDIO1\} & 0 & 1 & \{DTCARDI1\} & 1 \\
\hline e) Hipercolesterolemia \{HIcoLes 1$\}$ & 0 & 1 & \{DTHICOL1\} & 1 \\
\hline f) Hipertrigliceridemia $\{$ HITRIGL 1$\}$ & 0 & 1 & $\{$ DTRRIGL1\} & I. \\
\hline $\begin{array}{ll}\text { g) }\{\text { outros\} Qual? } & \{\text { foucomo1\} } \\
& \text { \{uccomo2 }\}\end{array}$ & 0 & 1 & $\begin{array}{l}\text { \{DTOUTсом1\} } \\
\text { \{DTOUTсOM2\} }\end{array}$ & - \\
\hline
\end{tabular}


Identificação: $\{10\}$

3. PARÂMETROS LABORATORIAIS NA ADMISSÃO OU

$1^{\circ}$ EXAME REALIZADO NO ACOMPANHAMENTO NA CASA DA AIDS

\begin{tabular}{|c|c|c|}
\hline EXAMES & RESULTADO & DATA DO EXAME \\
\hline $\mathrm{CD} 4+/ \mathrm{mm}^{3}$ (número de células) & $\{c 041\}$ & IDTCD41\} \\
\hline CARGA VIRAL HIV ( $n^{\circ}$ de cópias/ml) & 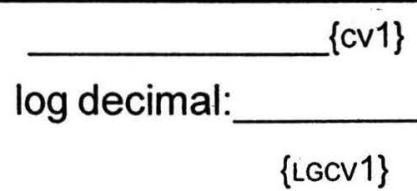 & - \\
\hline
\end{tabular}

\begin{tabular}{|c|c|c|c|}
\hline & 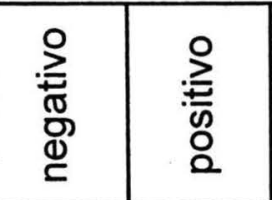 & 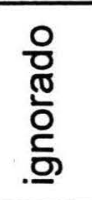 & $\begin{array}{c}\text { DATA } \\
\text { (DIA/MES/ANO) }\end{array}$ \\
\hline $\begin{array}{l}\text { Hepatite B: } \\
\text { anti-HBc \{HEPBANTC }\}\end{array}$ & 0 & 9 & \{ 1 I \\
\hline $\mathrm{AgHBS}\{$ HEPBAG $\}$ & 0 & 9 & $\frac{1}{\{\mathrm{DTHEPB} 2\}}$ \\
\hline Anti-HBs \{HEPBANTS\} & 0 & 9 & $\frac{1}{\{\mathrm{DTHEPB} 3\}}$ \\
\hline $\begin{array}{l}\text { Hepatite C: } \\
\text { Anti-HCV \{HEPCANT\} } \\
\text { Método: }\end{array}$ & 1 & 9 & \{DTHEPC 1\} \\
\hline PCR HCV $\{$ HEPCPCR $\}$ & 0 & 9 & $\frac{1}{\{D T H E P C 2\}}$ \\
\hline $\begin{array}{l}\text { HTLV: } \\
\quad \text { Elisa \{HTLVELIS\} }\end{array}$ & 0 & 9 & $\frac{1}{\{D T H T L V 1\}}$ \\
\hline \multirow{6}{*}{ Western Blot $\left\{H_{T L L W B}\right\}$} & HTLV-I+ & 1 & \multirow{6}{*}{$\frac{1}{\{\mathrm{DTHTLV} 2\}}$} \\
\hline & HTLV-II + & 2 & \\
\hline & HTLV-I/II + & 3 & \\
\hline & negativo & 4 & \\
\hline & Indeterminado & 5 & \\
\hline & ignorado & 9 & \\
\hline
\end{tabular}




\begin{tabular}{|c|c|c|c|c|}
\hline & 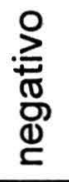 & 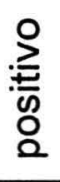 & 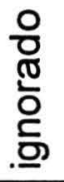 & $\begin{array}{c}\text { DATA } \\
\text { (DIAMES/ANO) }\end{array}$ \\
\hline \multirow{3}{*}{$\begin{array}{l}\text { SíFILIS: } \\
\text { Sorologia treponêmica \{SIFTREP\} } \\
\text { MÉTODo: } \longrightarrow \text { \{METSTR\} }\end{array}$} & \multirow{3}{*}{0} & \multirow{3}{*}{1} & \multirow{3}{*}{9} & \\
\hline & & & & 1 \\
\hline & & & & \{DTSIFTR $\}$ \\
\hline Sorologia não treponêmica \{SIFNTREP\} & \multirow[t]{2}{*}{0} & \multirow[t]{2}{*}{1} & \multirow[t]{2}{*}{9} & 1 \\
\hline Ḿ́todo: $\quad$ _METSINTR\} & & & & \{DTSIFNTR\} \\
\hline CHAGAS: $\{$ CHAGAS $\}$ & \multirow[t]{2}{*}{0} & \multirow[t]{2}{*}{1} & \multirow[t]{2}{*}{9} & 1 \\
\hline MÉTODO: $\longrightarrow\{$ METCHAG\} & & & & $\{$ DTCHAG \\
\hline
\end{tabular}

\begin{tabular}{|l|c|c|}
\hline & RESULTADO & DATA DO EXAME \\
\hline PPD & $\{\mathrm{PPD}\}$ & $\mathrm{mm}$ \\
\hline
\end{tabular}

\section{TRATAMENTO ANTI-RETROVIRAL ATÉ ADMISSÃO NA CASA DA AIDS}

\begin{tabular}{|c|c|c|c|c|}
\hline TRATAMENTO ANTI-RETROVIRAL & NÃO & SIM & INÍCl & S/ANO) \\
\hline a) Faz tratamento anti-retroviral?\{TRAT\} & 0 & 1 & & \\
\hline b) Monoterapia com ITRN \{MONOADM\} & 0 & 1 & \{DTMONOAD\} & 1 \\
\hline $\begin{array}{l}\text { c) } 2 \text { Inibidores da Transcriptase } \\
\text { Reversa Nucleosi-dicos (ITRN) \{ITRNADM\} }\end{array}$ & 0 & 1 & \{DTTRRAA $\}$ & 1 \\
\hline d) 2 ITRN + 1 ITRNN \{ITRNNADM\} & 0 & 1 & \{DTITRNN1\} & 1 \\
\hline e) 2 ITRN + 1 IP \{IPADM $\}$ & 0 & 1 & \{DTIPADM $\}$ & 1 \\
\hline $\begin{array}{l}\text { f) \{outRo1\} } \\
\text { Qual? }\end{array}$ & 0 & 1 & \{DTOUTADM\} & - \\
\hline $\begin{array}{l}\text { g) Profilaxia da Transmissão } \\
\text { Materno Infantil \{TM\}\} } \\
\text { Qual? }\end{array}$ & 0 & 1 & \{DTTMADM\} & I \\
\hline
\end{tabular}


5. DURANTE O SEGUIMENTO NA CASA DA AIDS até 30/03/2003

\begin{tabular}{|c|c|c|}
\hline EXAMES EVOLUTIVOS & RESULTADO & $\begin{array}{c}\text { DATA EXAME } \\
\text { (dia/mês/ano) }\end{array}$ \\
\hline MENOR número de células CD4+/mm³ & $\{$ CDOMENOR\} & $\frac{1}{\{D T C D 4 M E N\}}$ \\
\hline MAIOR número de células CD4+/mm ${ }^{3}$ & $\{$ CD4MAIOR & $\frac{1}{\text { \{DTCD4MA1\} }}$ \\
\hline ÚLTIMO teste de células CD4+/mm ${ }^{3}$ & $\{C D 4 U L T\}$ & $\frac{1}{\{\mathrm{DTCD} 4 \mathrm{ULT}\}}$ \\
\hline $\begin{array}{l}\text { MENOR CARGA VIRAL HIV } \\
\left.\text { ( } n^{\circ} \text { de cópias } / m \mathrm{~m}\right)\end{array}$ & 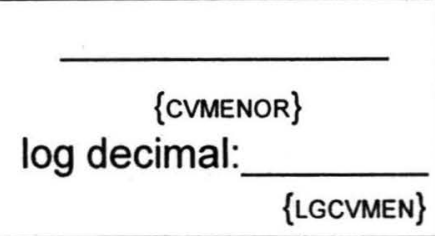 & $\frac{1}{\{D T C V M E N\}}$ \\
\hline $\begin{array}{l}\text { MAIOR CARGA VIRAL HIV } \\
\left.\text { ( } n^{\circ} \text { de cópias } / \mathrm{ml}\right)\end{array}$ & $\overline{\text { log decimal: }} \frac{}{\{\text { LGCVMAI\} }}$ & $\frac{1}{\{\text { DTCVMAl\} }}$ \\
\hline $\begin{array}{l}\text { ÚLTIMO TESTE DE CARGA VIRAL HIV } \\
\text { ( } \mathrm{n}^{\circ} \text { de cópias/ml) }\end{array}$ & $\frac{\text { \{DTCVULT }\}}{\text { log decimal: }} \frac{}{\{\text { LGCVULT }\}}$ & $-\frac{1}{\{\mathrm{CVuLT}\}}$ \\
\hline
\end{tabular}

\begin{tabular}{|c|c|c|c|c|}
\hline ALTERAÇÕES NO TRATAMENTO & NÃO & SIM & \multicolumn{2}{|c|}{ INICIO (MESS/ANO) } \\
\hline $\begin{array}{l}\text { a) Mantém tratamento anti-retroviral inicial? } \\
\text { \{SEMALT\} }\end{array}$ & 0 & 1 & & \\
\hline $\begin{array}{l}\text { b) Profilaxia da Transmissão Materno Infantil } \\
\text { \{TMI1\} Qual? }\end{array}$ & 0 & 1 & \{DTTMALT\} & 1 \\
\hline c) Monoterapia com ITRN \{MONOALT\} & 0 & 1 & $\{$ DTMONOAL $\}$ & 1 \\
\hline $\begin{array}{l}\text { d) } 2 \text { Inibidores da Transcriptase Reversa } \\
\text { Nucleosi-dicos (ITRN) } \quad \text { [ITRNALT\} }\end{array}$ & 0 & 1 & \{DITRNAL $\}$ & 1 \\
\hline e) 2 ITRN + 1 ITRNN \{ITRNNALT\} & 0 & 1 & \{DTITRNN2\} & 1 \\
\hline f) 2 ITRN + 1 IIP & 0 & 1 & $\{$ DTPALIT & 1 \\
\hline $\begin{array}{lr}\text { g) }\{\text { OUTRO2\} Qual? } & \{\text { OUALT1\} } \\
& \text { \{OUALT } 2\} \\
& \text { \{OUALT\} }\end{array}$ & 0 & 1 & $\begin{array}{l}\text { \{DTOUALT1 } \\
\text { \{DTOUALT2 } \\
\text { \{DTOUALT3 }\end{array}$ & 1 \\
\hline
\end{tabular}




\begin{tabular}{|c|c|c|c|c|}
\hline $\begin{array}{l}\text { QUIMIOPROFILAXIA } \\
\text { PRIMÁRIA }\end{array}$ & : & $\sum_{\bar{S}}$ & $\begin{array}{l}\text { DATA INICIO } \\
\text { (MÊS/ANO) }\end{array}$ & $\begin{array}{l}\text { DATA TÉRMINO } \\
\text { (MÊs/ANO) }\end{array}$ \\
\hline $\mathbf{P C P}\{P C P Q P 1\}$ & 0 & 1 & $\{$ DTINPCP 1$\}$ & $\{$ DTTEPCP 1$\}$ \\
\hline TOXO $\{$ TOXOQP 1$\}$ & 0 & 1 & $\{$ DTINTOX 1$\}$ & \{DTTETOX 1$\}$ \\
\hline CMV $\{$ CMVQP1 $\}$ & 0 & 1 & $\{$ DTINCMV1\} & $\{$ DTTECMV 1$\}$ \\
\hline TB $\{$ TBQP 1$\}$ & 0 & 1 & $\{$ DTINTB 1$\}$ & \{DTTETB1\} \\
\hline HERPES $\{$ HERPESQP 1$\}$ & 0 & 1 & $\{$ DTINHER 1$\}$ & \{DTTEHER 1$\}$ \\
\hline $\begin{array}{l}\text { QUIMIOPROFILAXIA } \\
\text { SECUNDÁRIA }\end{array}$ & 售 & $\sum$ & $\begin{array}{l}\text { DATA INÍCIO } \\
\text { (MÊS/ANO) }\end{array}$ & $\begin{array}{c}\text { DATA TÉRMINO } \\
\text { (MÊS/ANO) }\end{array}$ \\
\hline PCP $\{$ PCPQP 2$\}$ & 0 & 1 & $\{$ DTINPCP2 $\}$ & $\{$ DTTEPCP 2$\}$ \\
\hline TOXO \{TOXOQP 2$\}$ & 0 & 1 & $\{$ DTINTOX 2$\}$ & $\{$ DTTETOX 2$\}$ \\
\hline CMV \{CMVQP2\} & 0 & 1 & $\{$ DTINCMV2\} & \{DTTECMV2\}. \\
\hline TB $\{\mathrm{TBQP} 2\}$ & 0 & 1 & $\{$ DTINTB2 $\}$ & $\{$ DTTETB2 $\}$ \\
\hline HERPES \{HERPESQP2\} & 0 & 1 & \{DTINHER2 $\}$ & $\{$ DTTEHER 2$\}$ \\
\hline
\end{tabular}

\begin{tabular}{|c|c|c|c|c|}
\hline VACINAS & 운 & $\sum$ & $\begin{array}{c}\text { DATA } \\
\text { (MÊS/ANO) }\end{array}$ & $\begin{array}{l}\text { NÚMERO } \\
\text { DE DOSES }\end{array}$ \\
\hline HEPATITE B $\{$ VACHEPB $\}$ & 0 & 1 & $\frac{1}{\{\text { DTVAHEPB }\}}$ & $\{$ NVACHEPB $\}$ \\
\hline DUPLA ADULTO \{VACDUPAD $\}$ & 0 & 1 & $\frac{1}{\text { DDTVADUPA }}$ & \{NVACDUPA $\}$ \\
\hline PNEUMOCÓCICA \{VACPNEU\} & 0 & 1 & 1 & $\{$ NVACPNEU\} \\
\hline GRIPE $\{$ VACGRIP $\}$ & 0 & 1 & $\frac{1}{\{\text { DTVAGRIP\} }}$ & $\{$ NVACGRIP\} \\
\hline $\begin{array}{l}\text { \{Outra3\} } \\
\text { Qual? }\end{array}$ & 0 & 1 & 1 & \{NVACOUT\} \\
\hline
\end{tabular}


Identificação: $\{10\}$

AFECÇÕES OPORTUNISTAS:

(segundo CID-10 adaptado para HIV/aids)

\begin{tabular}{l|l|l|l} 
NÃO & SIM & & DATA
\end{tabular}

(segundo CID-10 adaptado para HIVIais)

a) Apresentou alguma afecção oportunista? \{AFEC2\}

b) Candidiase esofágica, brônquica, traqueal ou pulmonar \{CAND2\}

c) Câncer cervical invasivo \{CACER2\}

d) Criptococose extrapulmonar \{CRIPTO2\}

e) Criptosporidiase intestinal com diarréia por prazo superior a 1 mês \{CRIIINT2\}

f) Demência associada ao HIV \{DEmen2\}

g) Doença pelo citomegalovírus exceto do fígado, baço e linfonodos\{CтTомEg2\}

h) Estrongiloidiase extra-intestinal \{ESTRONG2\}

i) Histoplasmose extrapulmonar \{HISTO2\}

j) Infecção pelo vírus do herpes simples, causando úlcera mucocutânea (por prazo superior a 1 mês), bronquite, pneumonite ou esofagite \{HERPES 2 \}

k) Isosporiase com diarréia por prazo superior a 1 mês \{ISOSPOR 2$\}$

I) Leucoencefalopatia multifocal progressiva \{LEMP2\}

m) Linfoma cerebral $1^{\text {ario }}$ \{LINFSNC2\}

n) Linfoma não-Hodgkin de células $B$ ou de linfócitos B de fenótipo imunológico desconhecido \{LINFNH2\}

o) Micobacteriose disseminada por Mycobacterium avium-intracellulare ou Mycobacterium kansaii \{Mac2\}

p) Nocardiose \{NOCARD2\} 


\begin{tabular}{|c|c|c|c|c|c|c|}
\hline \multicolumn{3}{|c|}{ 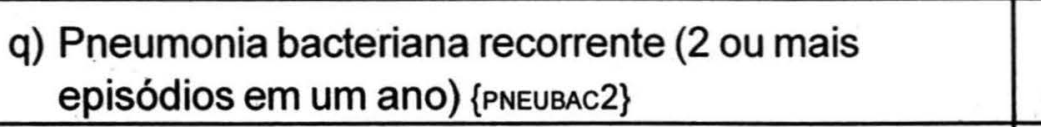 } & 0 & 1 & & $\frac{1}{\text { \{DTPNEUB2\} }}$ \\
\hline \multicolumn{3}{|l|}{ r) Pneumonia por Pneumocystis carinii \{PCP2\} } & 0 & 1 & & $\stackrel{1}{\{\text { DTPCP2\} }}$ \\
\hline \multicolumn{3}{|l|}{ s) Sarcoma de Kaposi \{sk2\} } & 0 & 1 & & $\frac{1}{\text { \{DTSK2\} }}$ \\
\hline \multicolumn{3}{|l|}{ t) Toxoplasmose do SNC $\{$ Toxo2\} } & 0 & 1 & & IDтाохо2\} \\
\hline \multicolumn{3}{|l|}{ u) Tuberculose pulmonar \{tвpuım2\} } & 0 & 1 & & $\frac{1}{\{0 \text { ITBPUL2\} }}$ \\
\hline \multicolumn{3}{|l|}{ v) Tuberculose disseminado \{твоIs 2$\}$} & 0 & 1 & & $\frac{1}{\text { \{оттBDIS2\} }}$ \\
\hline \multicolumn{3}{|c|}{ w) Sepse recorrente por Salmonella não typhi \{SEPSE2\} } & 0 & 1 & & $\frac{1}{\text { \{DTSEPSE2\} }}$ \\
\hline \multicolumn{3}{|l|}{ x) Síndrome consumptiva do HIV\{sLIM2\} } & 0 & 1 & & $\frac{1}{\{0 T S L I M 2\}}$ \\
\hline OUTRAS COMORBIDADES: & NÃO & SIM & & \multicolumn{3}{|c|}{ DATA (MES/ANO) } \\
\hline Apresentou comorbidades? \{сомоRВ2\} & 0 & 1 & & & & 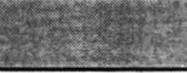 \\
\hline Hipertensão \{HIPERT2\} & 0 & 1 & & \multicolumn{3}{|c|}{ \{DTHIPER2\} } \\
\hline Diabetes \{DIABET 2$\}$ & 0 & 1 & & \multicolumn{3}{|c|}{ DTDIABE 2} \\
\hline Cardiopatia \{CARDIO2\} & 0 & 1 & & \multicolumn{3}{|c|}{ DTCARDI2\} } \\
\hline Hipercolesterolemia \{HICOLEs2\} & 0 & 1 & & $\multicolumn{3}{|c|}{\text { DTHICOL } 2}_{-}$ \\
\hline Hipertrigliceridemia $\{$ HIITRIGL2\} & 0 & 1 & & \multicolumn{3}{|c|}{ \{DTTRIGL2\} } \\
\hline $\begin{array}{l}\text { \{оuсомо } 3\} \\
\text { ооссомо } 4\}\end{array}$ & 0 & 1 & & \multicolumn{2}{|c|}{ \{Dтоисом4\} } & 1 \\
\hline
\end{tabular}

\section{GESTAÇÕES durante o seguimento na CASA DAAIDS: \{GESTA\}}

\begin{tabular}{|c|c|c|c|c|}
\hline Não se aplica (para ho & ens) & & & 1 \\
\hline Ausente (para mulhere & & & & 2 \\
\hline Presente & & & & \\
\hline DATADIAGNÓSTICO & $1^{\mathrm{a}}: 1$ & 1 & $3^{\mathrm{a}}: \quad 1 \quad 1$ & 3 \\
\hline & \{DTGEST1\} & \{DTGEST2\} & $\{$ DTGEST3\} & \\
\hline
\end{tabular}




\section{DESFECHOS}

Paciente foi internado(a) antes ou durante o perído de seguimento na CASA DA AIDS? \{INTERN\}
0. NÃO
1. SIM

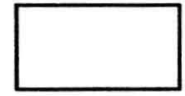

\begin{tabular}{|c|c|c|c|}
\hline INTERNAÇÕES & $\begin{array}{c}\text { DATA ENTRADA } \\
\text { (DIA/MES/ANO) }\end{array}$ & $\begin{array}{c}\text { DATA SAÍDA } \\
\text { (DIA/MÊS/ANO) }\end{array}$ & MOTIVO \\
\hline \multirow[t]{2}{*}{$1^{a}$} & 11 & 11 & \\
\hline & $\{$ INTEN1\} & $\{$ INTSA 1$\}$ & \{MOTINT1\} \\
\hline \multirow[t]{2}{*}{$2^{a}$} & 1 & 11 & \\
\hline & $\{$ INTEN2\} & $\{$ INTSA2 $\}$ & \{MOTINT2\} \\
\hline \multirow[t]{2}{*}{$3^{a}$} & 1 & 1 & \\
\hline & $\{$ INTEN3\} & $\{$ INTSA 3$\}$ & \{MOTINT3\} \\
\hline \multirow[t]{2}{*}{$4^{a}$} & 1 & 1 & \\
\hline & $\{$ INTEN4 $\}$ & $\{$ INTSA 4$\}$ & \{MOTINT4\} \\
\hline \multirow[t]{2}{*}{$5^{a}$} & 1 & 1 & \\
\hline & $\{$ INTEN5 $\}$ & $\{$ INTSA5 $\}$ & $\{$ MOTINT5\} \\
\hline
\end{tabular}

Data da última consulta na CASA DA AIDS até $30 / 3 / 2003$ :

\{DTULCONS\}

Situação do paciente ao final do periodo de seguimento: $\{F I M\}$

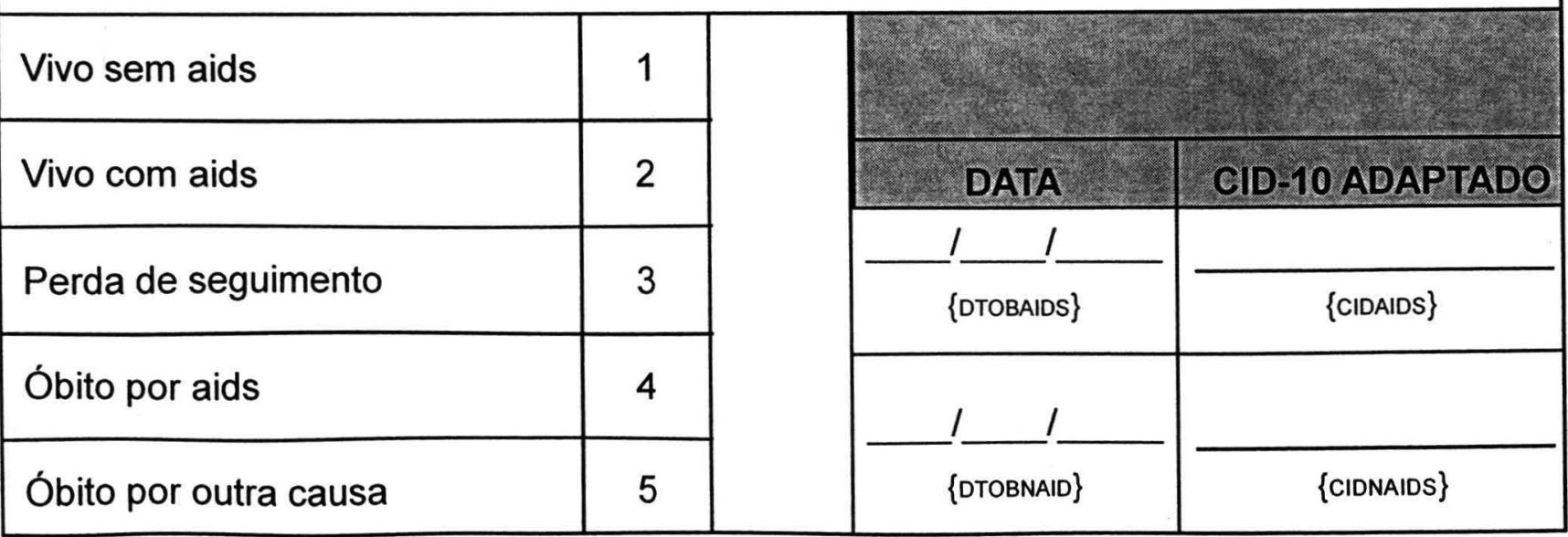


ANEXO 5 


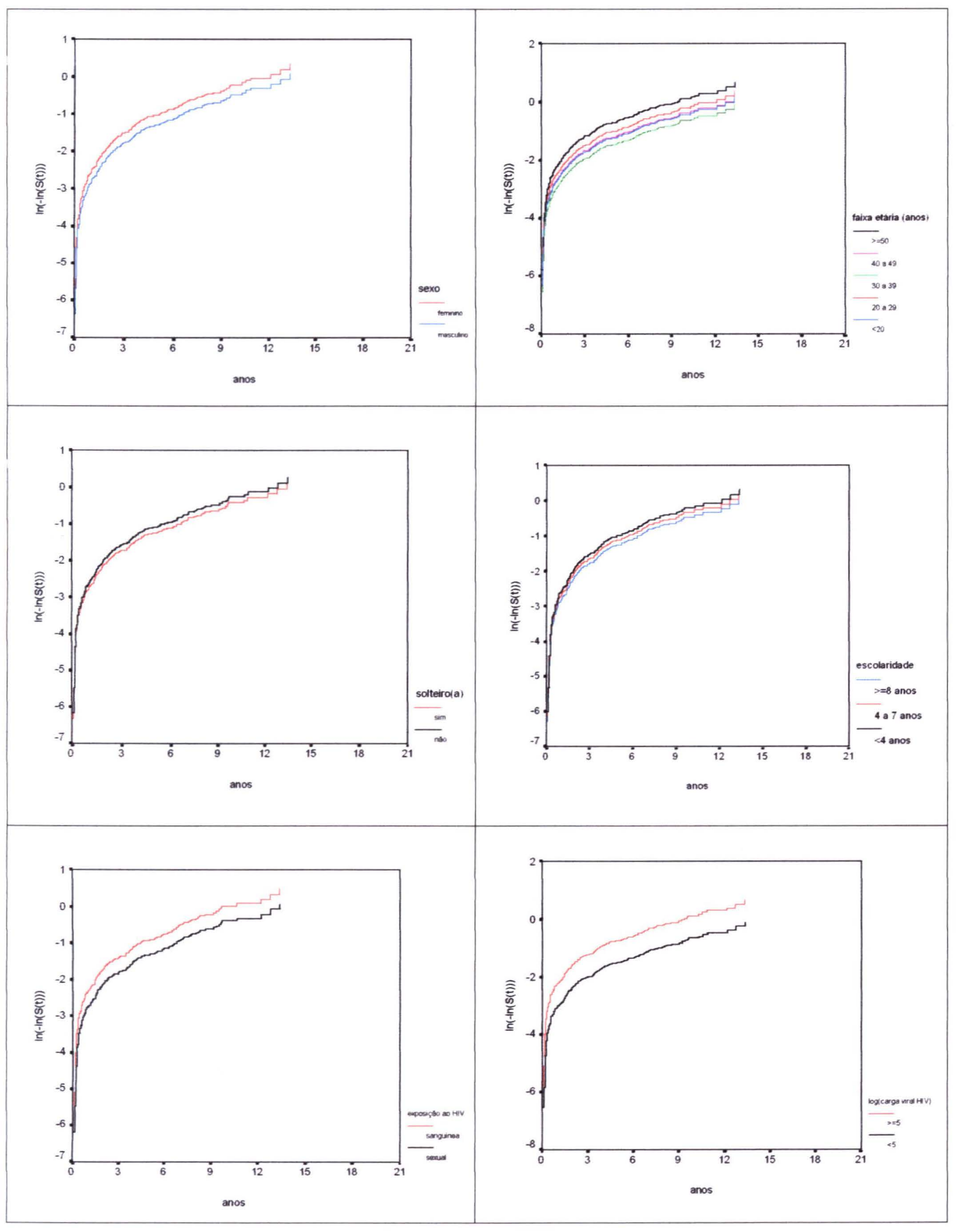




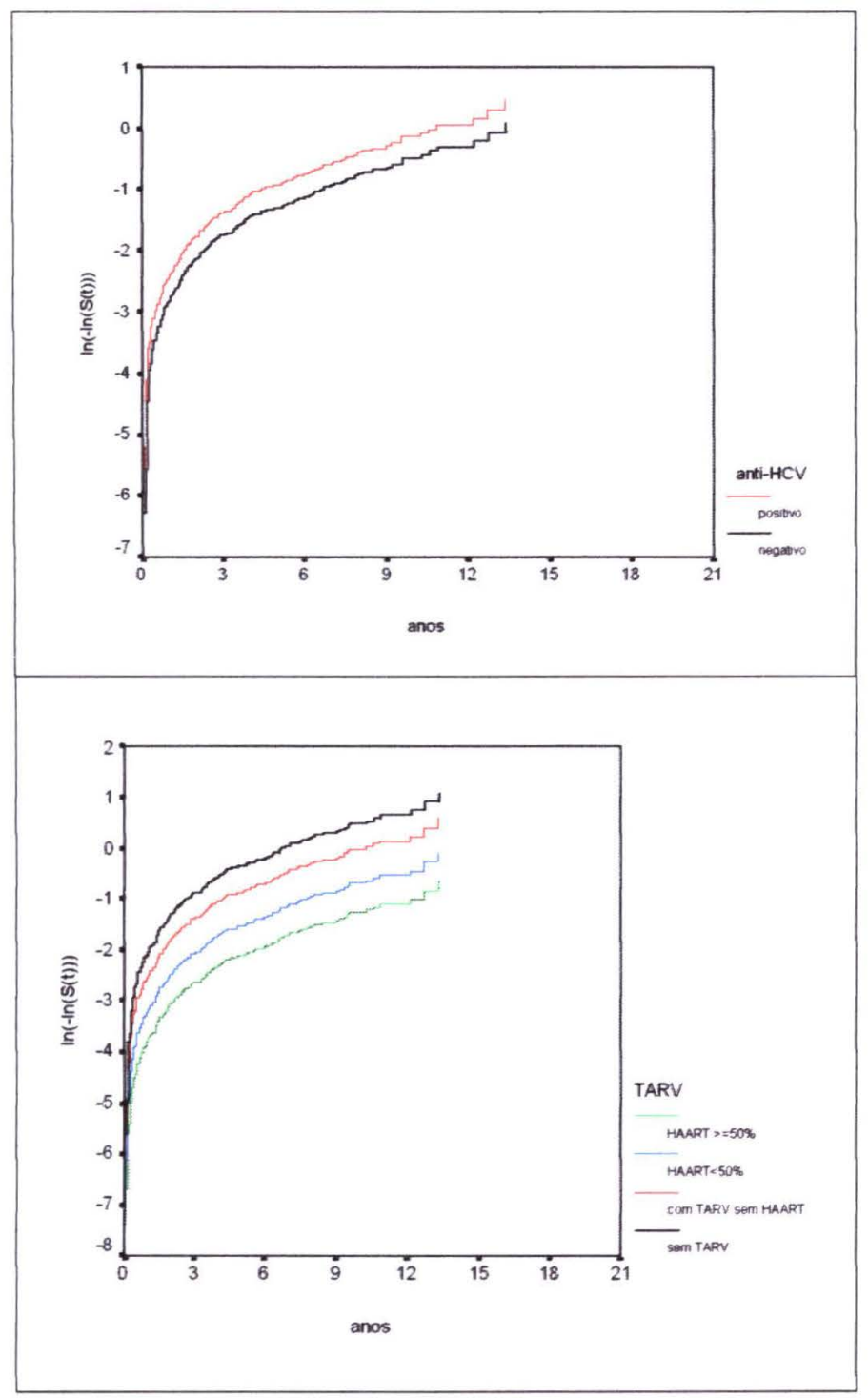


ANEXO 6 


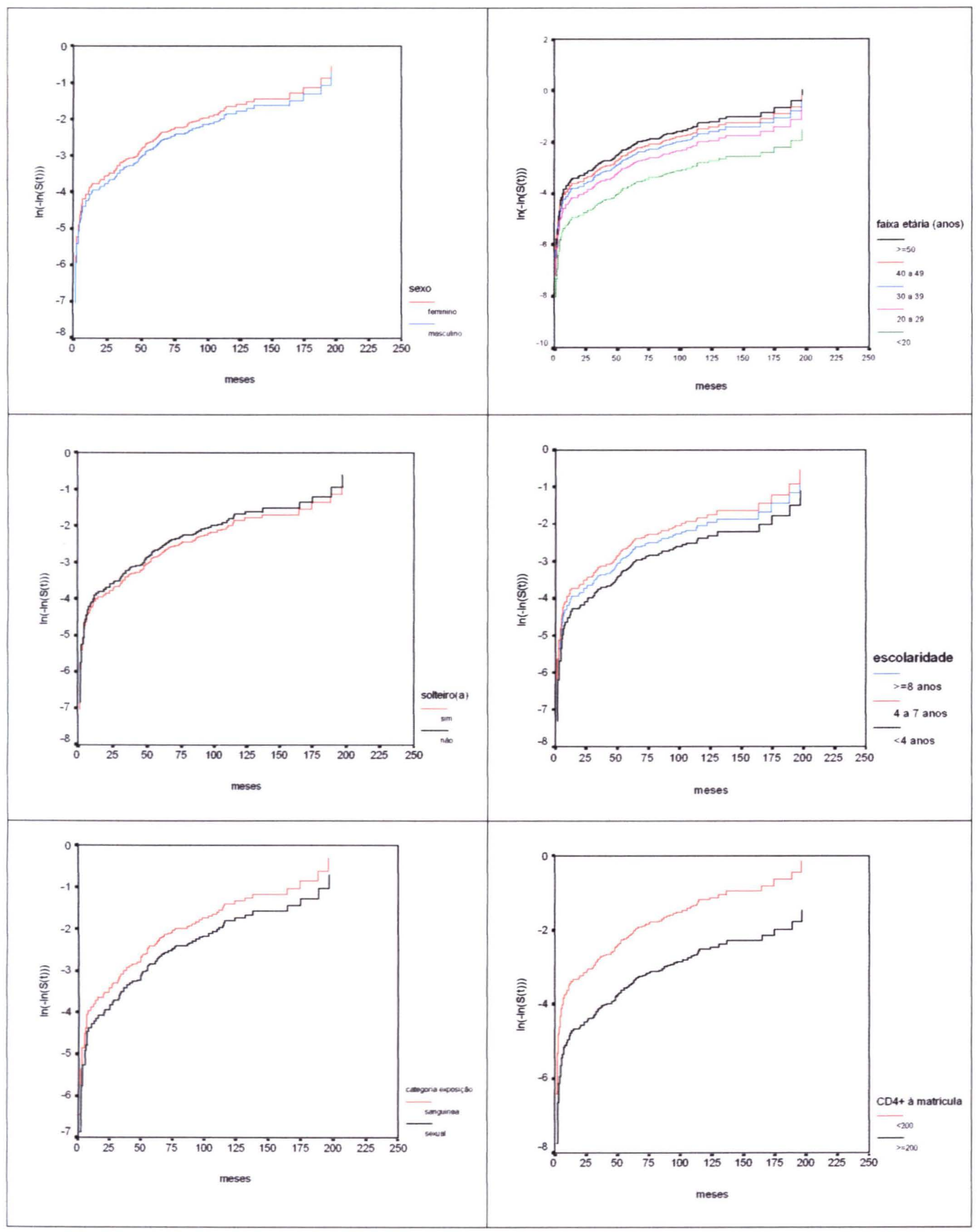




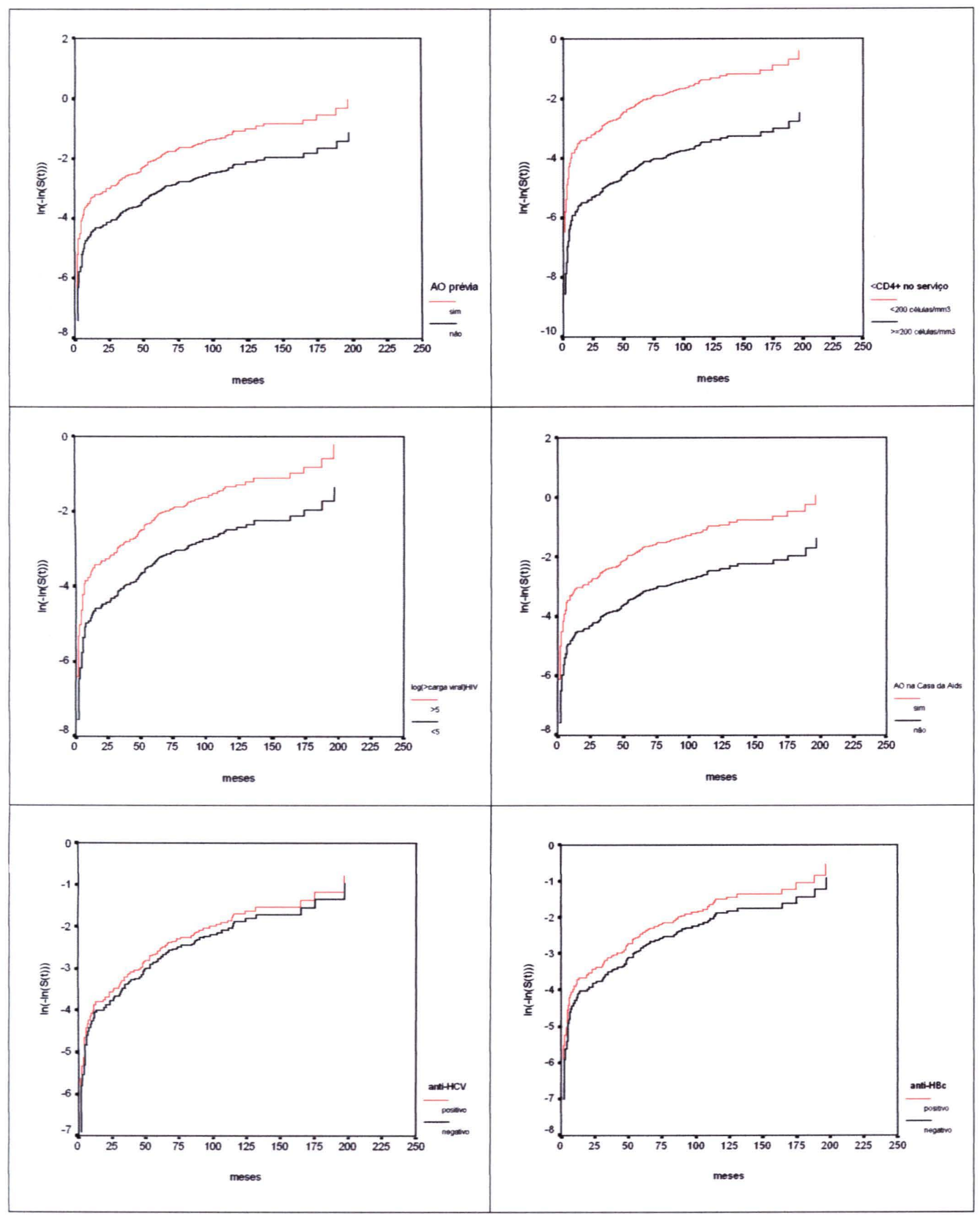




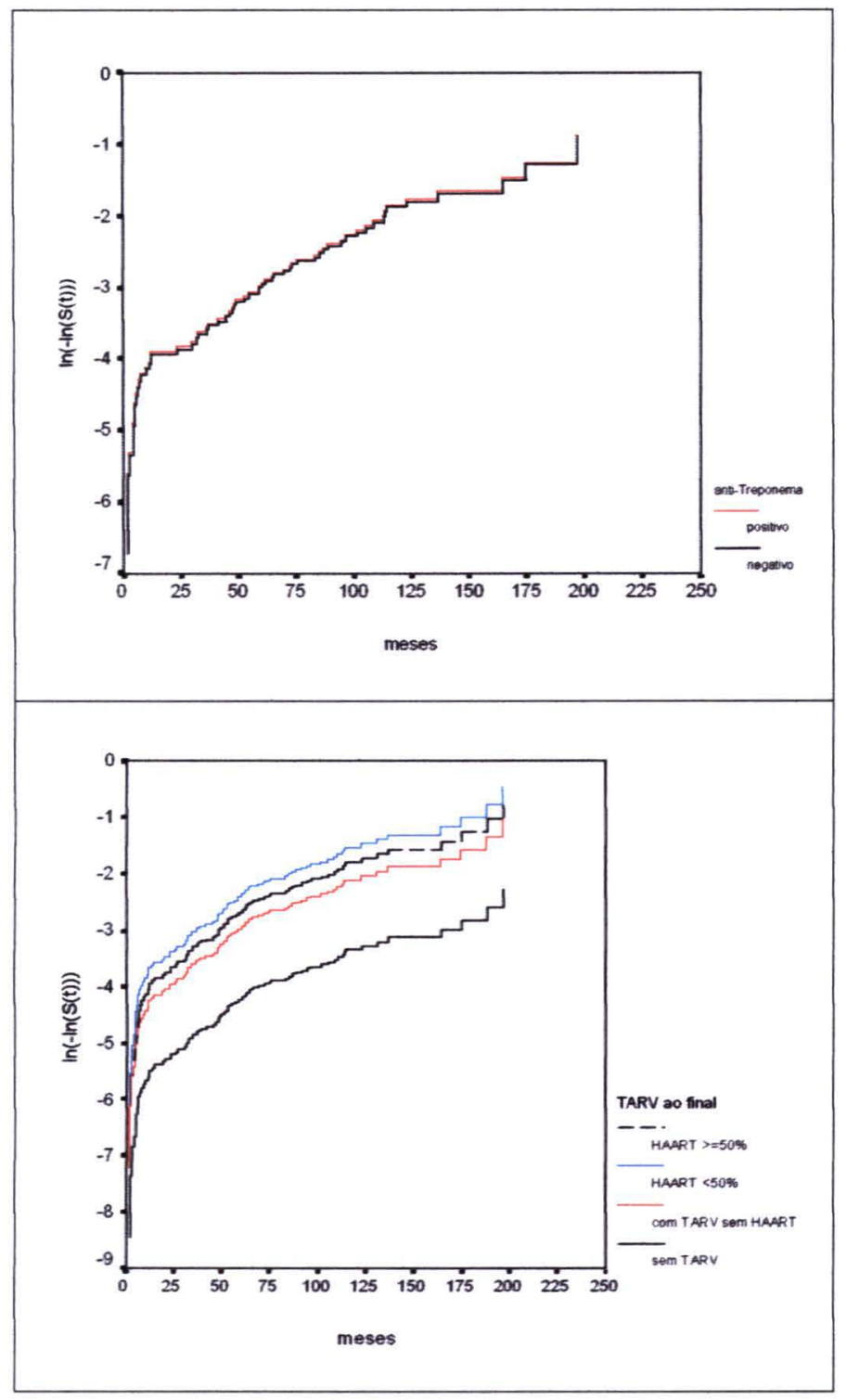

